\title{
Identifying and modifying behavioral determinants in response to the HIV epidemic in Indonesia
}

Citation for published version (APA):

Hinduan, Z. R. (2014). Identifying and modifying behavioral determinants in response to the HIV epidemic in Indonesia. [Doctoral Thesis, Maastricht University]. Datawyse / Universitaire Pers Maastricht. https://doi.org/10.26481/dis.20140603zh

Document status and date:

Published: 01/01/2014

DOI:

10.26481/dis.20140603zh

Document Version:

Publisher's PDF, also known as Version of record

\section{Please check the document version of this publication:}

- A submitted manuscript is the version of the article upon submission and before peer-review. There can be important differences between the submitted version and the official published version of record. People interested in the research are advised to contact the author for the final version of the publication, or visit the DOI to the publisher's website.

- The final author version and the galley proof are versions of the publication after peer review.

- The final published version features the final layout of the paper including the volume, issue and page numbers.

Link to publication

\footnotetext{
General rights rights.

- You may freely distribute the URL identifying the publication in the public portal. please follow below link for the End User Agreement:

www.umlib.nl/taverne-license

Take down policy

If you believe that this document breaches copyright please contact us at:

repository@maastrichtuniversity.nl

providing details and we will investigate your claim.
}

Copyright and moral rights for the publications made accessible in the public portal are retained by the authors and/or other copyright owners and it is a condition of accessing publications that users recognise and abide by the legal requirements associated with these

- Users may download and print one copy of any publication from the public portal for the purpose of private study or research.

- You may not further distribute the material or use it for any profit-making activity or commercial gain

If the publication is distributed under the terms of Article $25 \mathrm{fa}$ of the Dutch Copyright Act, indicated by the "Taverne" license above, 
๑) Zahrotur R. Hinduan,

Maastricht 2014

Cover design and Lay-out: Muhammad Roniyadi

Print: Datawyse / Universitaire Pers Maastricht

ISBN: 9789461593375

Universitaire Pers Maastricht 


\section{Identifying and modifying}

\section{behavioral determinants}

in response to the HIV epidemic in Indonesia

\section{DISSERTATION}

to obtain the degree of Doctor at

Maastricht University,

on the authority of the Rector Magnificus, Prof. dr. L. L. G. Soete

in accordance with the decision of the Board of Deans.

to be defended in public

on Tuesday, 3 June, 2014, at 14.00 hours

by

Zahrotur Rusyda Hinduan

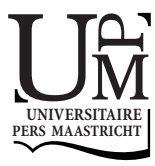




\section{Supervisors:}

Prof. dr. H. J. Hospers

Prof. dr. G. J. Kok

\section{Assessment committee:}

Prof. dr. R. A. C. Ruiter (chairman)

Prof. dr. N. K. de Vries

Dr. J. N. Leerlooijer, Wageningen University, Wageningen

Dr. L. E. Rijsdijk, Windesheim Honours College, Zwolle

Prof. dr. H.W. van den Borne

The present study was in part made possible by a grant from the Netherlands Fellowship Programme (grant CF7423/2011). 
"Where the land is stepped, there the sky is upheld" — Indonesian proverb 



\section{Contents}

$\begin{array}{lll}\text { CHAPTER } 1 \text { General introduction } & 9\end{array}$

CHAPTER 2 Characteristics of subjects counseled and tested for HIV in an Indonesian hospital: Factors associated with HIV-status and CD4 cell-count

CHAPTER 3 HIV-related knowledge and attitudes among Indonesian prison officers

CHAPTER 4 Factors associated with teachers' intention to teach HIV/AIDS-realated topics: An application of the Theory of Planned Behavior

CHAPTER 5 Development of a school-based drug education 65 program in Indonesia

CHAPTER 6 Effectiveness of substance use prevention program 85 for students in Indonesia: A pre- and post-test impact evaluation 



\section{CHAPTER 1}

\section{General Introduction}





\section{General Introduction}

\section{HIV/AIDS in Indonesia}

During the period of 2006 to 2008, the Human Immunodeficiency Virus (HIV) epidemic in Indonesia was still on the rise (Indonesian National AIDS Commission (INAC), 2011; World Health Organization (WHO), 2011). The cumulative number of HIV cases greatly increased from 8,054 in 2006 to 24,464 in 2008 (Figure 1). There were 7,195, 6,048 and 10,362 new HIV cases in 2006, 2007 and 2008, respectively (INAC, 2011). It was estimated that in 2014, the number of people living with HIV would be 541,700 (Ministry of Health $(\mathrm{MoH}), 2008)$. Although different behavior collectively enhanced the risk of contracting HIV, the use of intravenous drugs, such as heroin appeared to be the main behavior that increased the risk of transmission in Indonesia during that period of time. It was estimated that $54.5 \%$ of reported HIV cases were related to drugs injection (INAC, 2011; United Nations Development Programme (UNDP), 2007; WHO, 2011).

\section{Figure 1 : Number of HIV Cases in Indonesia (2006 - 2008)}

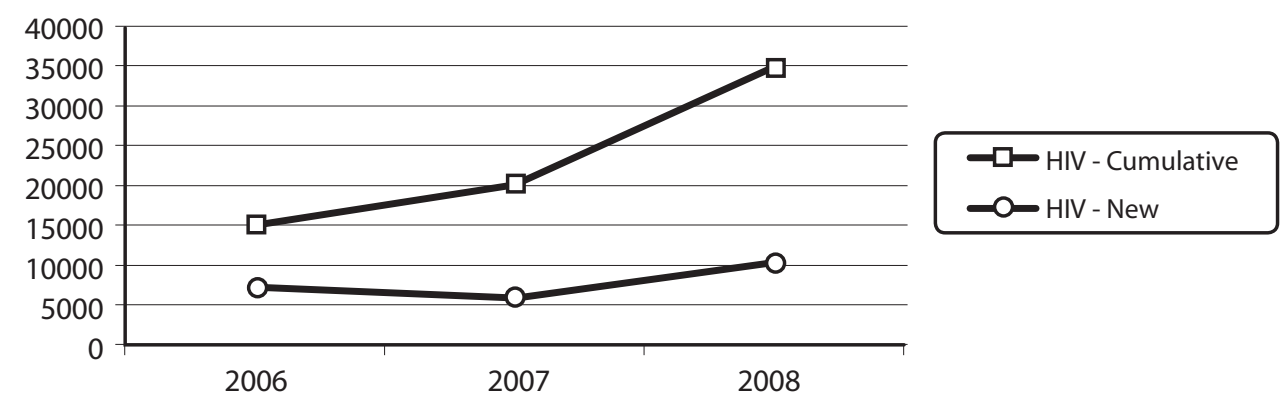

Bandung is one of the large cities in Indonesia, with a population size of approximately 40 million people. It is also one of the cities that had the most severe intravenous drug use epidemic. The rates of sharing injecting equipment among the users were high. Although the coverage of needle sharing programs in this city increased to $66 \%$ in 2007 , about $43 \%$ 
of intravenous drug users (IDUs) were estimated to be already HIV positive in that year (Integrated Biological-Behavioral Surveillance (IBBS), 2007; WHO, 2011). The fact that most IDUs were sexually active men brought another complication, since almost 50\% of male IDUs had multiple sex partners, including commercial sex partners. With condom use being unpopular in this population (Afriandi et al., 2009; IBBS, 2007; Morineau et al., 2012), there was a possibility that HIV-positive IDUs might spread HIV to the general population.

\section{The Responses}

Several prevention strategies were implemented by the Indonesian government in response to the disease, including increasing the national coverage of HIV testing among the high risk population (INAC, 2011). By getting tested for HIV, individuals can discover their health status and for those with an HIV-positive result, treatment, such as an antiretroviral therapy (ART), can be started. However, it was very difficult to engage people with testing, especially IDUs. Several studies from various areas in Indonesia (i.e. Jogjakarta and Bali) in 2006 had suggested that the fear of a positive result was the main factor that hindered them from being tested. Stigma and discrimination from society, especially from health care workers (HCWs), were other barriers to getting tested, as perceived by IDUs (Mahendradhata et al., 2008; Sasaki, Andryansyah, Moazzam, \& Kazahiro, 2011; Sawitri, Sumantera, Wirawan, Ford, \& Lehman, 2007). It was approximated that among 220 million people in the total population of Indonesia, less than 100,000 people were tested in 2007 and people usually presented relatively late for HIV testing (WHO, 2011). This could have led to late treatment and/or a higher possibility of transmitting the virus to others. As a result, the scaling-up of HIV testing, especially among the high risk groups, was essential to control the spread of HIV.

Another prevention strategy used by the government was to increase the awareness of HIV/AIDS among young adolescents. This was seen as highly relevant since young people between the ages of 20 and 29 contributed 55\% of all AIDS cases (INAC, 2011). Also, the majority of young people in this country had low comprehensive knowledge of HIV/AIDS (Statistics Indonesia, 2008). Although young adolescents were not considered as one of the most at risk groups for HIV, several studies had shown that the initiation of risky behaviors (injected drug use and unsafe sexual intercourse) typically started in the 13-16 age range (IBBS, 2007; MoH-WHO, 2003). As a result, drug education (DE) and education about sexual reproductive health $(\mathrm{SRH})$ were needed to increase awareness in young adolescents of the disease and its transmission modes. 


\section{Impacts on public services.}

The implementation of these two strategies: testing and education, affected several public services in this country such as health services, correctional institutions, and education sectors. The health service providers, such as hospitals were the main players in the scalingup of HIV testing among the most at risk groups and the general population. The scaling-up demanded a large number of skilled HCWs (WHO, 2011; WHO, 2008). Unfortunately, a study in several cities in Indonesia (including Bandung) showed that, in 2007, the health providers were not the main source of information about HIV/AIDS. People relied largely on television or non-government organizations (NGOs) to provide the information. This situation might have been due to the lack of HIV-related knowledge, particularly regarding HIV testing, among the HCWs as well as their negative attitude toward patients with HIV/ AIDS and the stigmatization that may have occurred as a result (Statistics Indonesia, 2008).

Correctional facilities also played an important role in scaling-up HIV testing, since prisons and detention centers were considered as high risk environments for HIV transmission. It was believed that in those facilities the inmates shared sharp tools for tattooing, body piercing, and inserting genital accessories; engaged in unsafe homosexual intercourse with other inmates; and shared used injection equipment and needles for illicit substance use (Ministry of Justice and Human Rights, 2010; Dolan, Kite, Black, Aceijas, \& Stimson, 2007; WHO, 2007). As a result, HIV prevention programs were urgently needed. In this setting, health care and support for the inmates was provided by prison officers. Studies in Western countries revealed a negative attitude among the officers toward handling inmates with HIV (Derlega, Winstead, \& Brockington, 2008; Dillon \& Allwright, 2005; Dursin, 2004). This treatment also happened in Indonesia and led to social isolation of inmates with HIV, while it also hindered other inmates from finding out their HIV status.

Finally, as receiving basic education is mandatory for all children in this country, the education sector was identified as a key player in providing prevention education for the majority of young people in Indonesia. Prevention education would be implemented in schools. The policy that was published in 1997 had selected teachers as the main agents in preventing the spread of HIV/AIDS, especially in increasing the knowledge related to DE and SRH (Ministry of Education, 1997). Unfortunately, several studies revealed that many teachers neglected teaching these sensitive issues (United Nations Educational, Scientific, and Cultural Organization (UNESCO), 2010). They were unwilling and/or unable to facilitate the two educational programs due to a lack of knowledge and skills. They were also unable to deal with the shame and guilt, especially in teaching the SRH. This made them uncomfortable with teaching these subjects. As a result, most of the programs were conducted sporadically and the schools relied on police officers or representatives from NGOs to facilitate these programs. These delivery agents might not be as suitable 
for facilitating the program, as a study revealed that, compared with a guest speaker, a trained regular teacher might produce stronger effects on the students' behavioral change (Albarracin, Durantini, \& Earl, 2006; Gottfredson \& Wilson, 2003).

It was apparent that the implementers of the programs in the three different settings of health care facilities, prisons, and schools, might not yet be ready to implement HIV prevention programs in their workplaces. Thus, there was a vast need for capacity building among those who would be implementing these HIV prevention programs. It was simply not feasible for the Indonesian government to handle all the HIV-related issues in Indonesia. To support the government in controlling the disease, a comprehensive program was established in 2007. The program, referred to as the IMPACT Program, aimed to improve the control of the HIV/ AIDS epidemic in Bandung, one of the cities with the highest number of IDUs and people living with HIV/AIDS (IBBS, 2007; WHO, 2011; Wisaksana et al., 2012). Since the disease is not a pure biomedical problem, this evidence-based program combined the biomedical and social-behavioral approaches in controlling the disease.

At the beginning of the project, scientific literature and evidence concerning HIV issues in Indonesia, especially those produced by program implementers, were very scarce since the issues had not been formally studied yet. Thus, the IMPACT Program conducted several preliminary need assessments to provide baseline information as a foundation for developing tailor-made intervention programs in this area. The chapters of this dissertation report several results from the IMPACT program, especially those that are related to the behavioral aspects of HIV prevention. The studies presented in this dissertation aim to increase our knowledge about: (1) the socio-cognitive determinants of various HIV prevention-related behaviors; and (2) the development and evaluation of a comprehensive behavioral intervention using the Intervention Mapping (IM) framework.

\section{Behavioral Changes and HIV Prevention Program}

As mentioned above, HIV/AIDS is not only a pure biomedical problem; thus a successful HIV prevention program needs a multidisciplinary approach. It is believed that a combination of biomedical strategies; social justice and human rights strategies; and behavioral modifications are needed in developing an effective HIV prevention program (Coates, Richter, \& Caceres, 2008). The behavioral strategies were very important in changing the risk behaviors among the most at risk populations. Previous studies from other countries have shown that behavioral changes successfully modify several risky behaviors of the most at risk groups, leading to the reduction in HIV transmission and other sexual transmitted diseases (Koblin, 2004; Winkelstein et al., 1988). In addition to the sustained behavioral modification among the targeted population, Indonesia also urgently needed behavioral change among health implementers to ensure the effectiveness of the development and the 
implementation of HIV prevention programs. For example, changes in the negative attitude among HCWs or prison officers were required as well as a decrease in the stigma toward people living with HIV/AIDS. In sum, behavioral changes were needed among the targeted population as well as the program implementers.

There are several behavioral theories that are frequently used in developing HIV prevention programs in order to (1) determine the groups most at risk and in need of intervention; (2) define specific determinants of the targeted behaviors; and (3) change the determinants (Bartholomew, Parcel, Kok, Gottlieb, \& Fernandez, 2011). In this section, we would like to describe one of the behavioral change theories, which is the Theory of Planned Behavior (TPB). The TPB was applied in several studies to identify possible determinants of targeted behaviors and also to select the intervention target groups. We would also describe the Intervention Mapping (IM) approach. The protocol guided the development of our intervention program for students.

\section{Theory of Planned Behavior.}

The Theory of Planned Behavior (TPB) (Ajzen, 1985) is an extension of the Theory of Reasoned Action (advanced in the mid-1960s by Fishbein). The theory is based on an assumption that individuals make reasoned behavioral decisions based on their plans or intentions (Ajzen, 1985). Conceptually, intention is defined as readiness to perform a behavior (Fishbein \& Ajzen, 2010). It is the most proximal determinant of a behavior. The expression of intention is, for example, the following statement ' $I$ will quit smoking within six months'. The individual's intention is a function of three determinants: attitude towards the behavior, perceived subjective norms $(\mathrm{SN})$, and perceived behavioral control (PBC).

Attitude towards the behavior refers to one's positive or negative evaluation of performing a given behavior (Ajzen, 1988; Ajzen, 2005; Fishbein \& Ajzen, 2010). For example, 'Quitting smoking makes me feel more energetic'. SN reflects one's perception of expectations from significant others to adopt a given behavior (Ajzen, 1991; Fishbein \& Ajzen, 2010), such as 'Most of my friends have quit smoking, they would expect me to do so as well'. The last component, PBC, is related to people's belief that they possess the specialized skills, resources and opportunities needed to perform a given behavior (Ajzen, 1991; Ajzen, 2002, Fishbein \& Ajzen, 2010), such as 'I have the necessary skills to say no to smoking'. This construct is quite identical to the concept of self-efficacy from Bandura. Several authors suggest the importance of control factors, as part of PBC, that can inhibit the performance of behavior; also known as perceived barriers (Ajzen, 1991; Ajzen, 2002, Fishbein \& Ajzen, 2010). The control factors can be internal factors (i.e. lack of refusal skills) and external factors (i.e. no clean needles). 
The TPB serves as the etiological theory in our studies. A combination of those three determinants will guide individuals' intentions and behaviors. The weight of the determinants will vary from behavior to behavior and between populations (Fishbein \& Ajzen, 2010). For example, $\mathrm{PBC}$ is the most salient determinant in predicting condom use among female sex workers in China and among male and female drug users in the US, but attitude and $\mathrm{SN}$ are the most salient factors in predicting the same behavior among Norwegian adolescents (Corby, Enguidanos, \& Kay, 1996; Gu et al., 2009; Myklestad \& Rise, 2008).

The theory has shown to be effective in explaining intentions to perform volitional behaviors in various contexts and especially in the context of health (including smoking cessation and condom use). A meta-analysis of 87 TPB studies applied to several health behaviors reported that TPB accounted for $41 \%$ of the variance in behavioral intentions and $44 \%-62 \%$ of the variance in behavior for a broad range of behaviors (Godin \& Kok, 1996). Another meta-analysis indicated that about $30 \%$ of the variance in behavior can be explained by the combined effect of intention and perceived behavioral control, the two cornerstones of the TPB (Ajzen, 2011; Armitage \& Conner, 2001). Although the theory does not provide any systematic method for changing people's behavior, several authors suggest that interventions using this theory to find the right beliefs to target, will succeed in increasing people's awareness of the negative outcomes associated with continuing the risk behaviors and the positive outcomes of the healthy behavior (attitude). They could also succeed increasing people's skills and self-efficacy in responding to social pressure (SN and PBC) (Bartholomew et al., 2011; Fishbein \& Ajzen, 2010). These interventions will lead to planned change in their intentions, and to perform of a targeted behavior.

\section{Intervention Mapping.}

Intervention Mapping (IM) is a comprehensive framework for planning, developing, implementing and evaluating a comprehensive health promotion program based on theories and evidence (Bartholomew et al., 2011). IM acknowledges the importance of the social environment of a target group. The behavior of the target group is influenced by their environments, which can include their families, their social networks, their organizations, their communities and their societies. The health implementers are also part of one of the environments that influence the behavioral change of the target group. 


\section{Table 1 : The Six Systematic Steps of the Intervention Mapping Framework}

\begin{tabular}{|c|c|}
\hline $\begin{array}{l}\text { Step 1: } \\
\text { Need } \\
\text { Assessment }\end{array}$ & $\begin{array}{l}\text { The first step of IM is a need assessment among the target group and their } \\
\text { social environment using the PRECEDE model (Bartholomewet al., 2011; } \\
\text { Green \& Kreuter, 2005). The main goal is to assess factors that affect quality of } \\
\text { life, especially the health-related factor. }\end{array}$ \\
\hline $\begin{array}{l}\text { Step 2: } \\
\text { Matrices }\end{array}$ & $\begin{array}{l}\text { The second step of IM is to specify performance objectives (POs) and change } \\
\text { objectives (COs). To be effective, the program has to focus on and change } \\
\text { specific behaviors of the target group (POs). This change has to be at the } \\
\text { individual level as well as at the environmental level. The purpose of this } \\
\text { step is to indicate changes in determinants (COs) that will be affected by the } \\
\text { intervention (Bartholomew et al., 2011). }\end{array}$ \\
\hline $\begin{array}{l}\text { Step 3: } \\
\text { Theory based } \\
\text { Intervention } \\
\text { Methods } \\
\text { and Practical } \\
\text { Applications }\end{array}$ & $\begin{array}{l}\text { After having identified the most important COs, the next IM step is to select } \\
\text { theoretical methods that can influence the determinants represented by } \\
\text { those objectives. In principle, a theoretical method might be fit to achieve } \\
\text { multiple COs or one CO can be achieved by several methods (Bartholomew } \\
\text { et al., 2011). It is essential to apply the theoretical parameters of use of } \\
\text { each learning method to ensure its effectiveness in changing the intended } \\
\text { determinants. The final task of this third IM step is to translate the theoretical } \\
\text { methods into practical educational strategies and tools so that the program } \\
\text { will be suitable and user-friendly in the targeted context. }\end{array}$ \\
\hline $\begin{array}{l}\text { Step 4: } \\
\text { Intervention } \\
\text { Program }\end{array}$ & $\begin{array}{l}\text { At the end of this step, it is expected that the program components and } \\
\text { materials will be developed, produced and pre-tested on the intended } \\
\text { participants. In developing the program, a participatory approach is essential. } \\
\text { This approach ensures that all stakeholders actively participate in decision } \\
\text { making so that their sense of ownership of the program is enhanced and the } \\
\text { content of the program fits socio-culturally in the implementation context } \\
\text { (MacDonald et al., 2011). }\end{array}$ \\
\hline $\begin{array}{l}\text { Step 5: } \\
\text { Adoption and } \\
\text { Implementation }\end{array}$ & $\begin{array}{l}\text { The main goal of this phase is to ensure complete implementation with fidelity } \\
\text { towards the intended methods, as well as sustainability of the program. As } \\
\text { a result, appropriate adoption, implementation and maintenance of the } \\
\text { program are planned carefully. The tasks of this step are to identify potential } \\
\text { adopters and implementers; re-evaluate the planning group; state program } \\
\text { use outcomes and specify implementation POs, determinants, a matrix } \\
\text { of change objectives and methods for adoption, implementation and } \\
\text { sustainability. The final task is to design an intervention for program use, } \\
\text { implementation and sustainability (Bartholomew et al., 2011). }\end{array}$ \\
\hline $\begin{array}{l}\text { Step 6: } \\
\text { Evaluation Plan }\end{array}$ & $\begin{array}{l}\text { The final step of the IM Framework involves an evaluation of the process and } \\
\text { the impact of the intervention program. The process evaluation is conducted } \\
\text { to ensure that the program will be implemented as planned and also to } \\
\text { improve the program. An impact evaluation is conducted to ensure that the } \\
\text { program affects the determinants (Bartholomew et al., 2011). }\end{array}$ \\
\hline
\end{tabular}




\section{Dissertation Outline}

This dissertation consists of two parts. The first part reports the findings of the need assessments in various settings (a referral hospital, a narcotic prison and several public schools) that will serve as the basis for developing a comprehensive intervention program in each setting (Chapter $2-4$ ). The second part describes the development and the evaluation of a substance use prevention program in public schools (Chapter $5-6$ ).

Our first study was among patients in the referral hospital in Bandung. One of the responses to the HIV epidemics in Indonesia was the scaling-up of HIV testing. Based on the $2007 \mathrm{WHO}$ guidelines, there is a vast need to promote provider initiated testing and counseling (PITC) as a way of conducting HIV testing among patients who came to health care facilities in Indonesia. To perform this procedure, the HCWs need to proactively identify several health symptoms among their patients. Unfortunately, their knowledge concerning common HIV-related health symptoms in Indonesia is still limited. Chapter 2 reports our first study, which identifies specific health symptoms and socio-cognitive determinants that can predict HIV-seropositivity and level of immunosuppression of patients in the hospital. Results from this study can be used by HCWs to identify patients who are likely to be HIV-infected, so that the HIV testing can be initiated.

Our second study was among prison officers. The aim of this study is to explore the determinants of HIV/AIDS-related risk behaviors in the correctional facilities. The officers, as the main program implementers, need to have correct knowledge and positive attitude about inmates with HIV/AIDS. Chapter 3 reports several misconceptions regarding the disease and the relationship between these misconceptions and the negative attitudes of officers towards the inmates. The results from this study can be used to develop an intervention program to diminish the HIV-related stigma among the prison officers.

The third study was among teachers. The teachers in public schools in Indonesia play an active role in increasing the HIV/AIDS awareness of young adolescents through drug education and sexual reproductive health programs. Chapter 4 reports factors that predict teachers' intention to teach the two programs in junior high schools. Furthermore, several perceived personal and environmental barriers in teaching the two subjects were also discussed. The results from this study can be used to develop an evidence-based intervention program for teachers in facilitating the programs among their students.

Chapter 5 describes a development of a comprehensive intervention program, which aims to prevent the early initiation of substance use and to reduce smoking behavior among junior high school students based on the IM protocol. The methods and results from each step of 
IM conducted in this setting will be discussed. The TPB serves as the main etiological theory whereas several other behavioral theories are also applied in determining the methods of changing personal determinants of the targeted behaviors. ${ }^{1}$

The evaluation of the prevention program is discussed in Chapter 6. In this study we will focus on the results of the immediate impact evaluation of the program among the students. The results of this study can be used to revise the program to ensure its effectiveness in achieving its initial goals. Furthermore, they can be used to develop other systematic intervention programs by other health planners in a context that is relatively similar (e.g. collectivist culture, one teacher needs to handle many students in each class and limited access to technologies). In addition, the results of the preliminary assessment in predicting the students' intentions to perform a substance-free behavior will be reported.

Finally, results from chapters $2-6$ will be discussed in Chapter 7 . The general discussion will be directed to future research studies and practical implications for developing and implementing effective intervention programs among the most at risk groups and the health implementers in this academic context.

1. The development of the SRH education will be discussed in another publication. 



\section{CHAPTER 2}

\section{Characteristics of}

Subjects Counseled and Tested for HIV in an Indonesian Hospital:

Factors associated with HIV status and

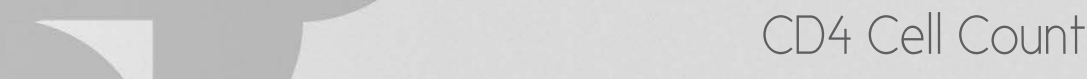

Based on: Hinduan, Z. R., Kesumah, N., Iskandar, Z., van Crevel, R., Alisjahbana, B., \& Hospers, H. J. (2009). Characteristics of subjects counseled and tested for HIV in an Indonesian hospital: Factors associated with HIV-status and CD4 cell-count. Acta Medica Indonesiana, 41 (Suppl. 1), 12-17. 



\section{Characteristics of Subjects Counseled and Tested for $H \mathrm{~V}$ in an Indonesian Hospital: Factors associated with HIV status and CD4 Cell Count}

\section{Abstract}

To identify the predictors of HIV seropositivity and the level of immunosuppression, a crosssectional study was conducted to examine HIV testing practice, HIV knowledge, perceived risk of being HIV positive, and health status among out patients enrolled in voluntary counseling and testing (VCT) and inpatients who underwent provider-initiated testing (PITC) in the largest teaching hospital in West Java, Indonesia. From 202 respondents, 47\% were HIV positive, and the median CD4 of those with HIVwas193/mm 3 for the VCT group $(\mathrm{n}=124)$ and $11 / \mathrm{mm}^{3}$ for the PITC group $(\mathrm{n}=78)$. HIV/AIDS related knowledge among those entering VCT was significantly higher than those entering PITC, but the perceived risk of being HIV-infected was lower. Logistic regression analysis predicting HIV status revealed a significant main effect for oral thrush and chronic diarrhea as well as for Hepatitis $C$ status $(p<.01)$. For those who are HIV positive, weight loss was strongly predictive of a low CD4 cell count $(p<.01)$. In this setting, the HIV seroprevalence is high and many HIV-infected subjects are symptomatic. Increasing HIV knowledge may lead to earlier HIV detection. Health care workers play an important role in referral for VCT and PITC, and several symptoms, alone or in combination, can help identify those who have the highest risk for HIV.

Keywords: VCT, PITC, HIV testing, level of knowledge, physical symptoms

\section{Introduction}

Indonesia has one of the fastest growing HIV epidemic in Asia, but relatively few people are counseled and tested for HIV (Afriandi et al., 2009; Joint United Nations Programme on HIV/AIDS (UNAIDS), 2008). Counseling and testing of people at risk of HIV infection is an essential component of HIV prevention and care. During counseling, people can be informed about the risks of HIV and be motivated to reduce the risk of becoming infected (if they are still HIV negative) or transmitting HIV virus to others (if they are already positive). 
In addition, for those who are HIV positive, the need for HIV treatment or other measures (e.g. PCP prophylaxis) can be evaluated. At the public health level, timely counseling and testing may help to control the HIV epidemic (Granich, Gilks, Dye, Cock, \&Williams, 2008). Traditionally, counseling and testing are conducted according to the principles of 'voluntary counseling and testing' (VCT). In this client-initiated approach, individuals actively seek HIV testing and counseling services because they wish to learn their status. The HIV test will only be done after counseling and in agreement with the client. The result of the test is discussed during a post-test counseling session. VCT has proven to be effective in increasing knowledge of HIV transmission, promoting behavior change (such as safer sexual intercourse), and improving the utilization of care and support services (Coates, Kamenga, Sweat, \& De Zoysa, 2004; Kamb et al. 1998); Marks, Crepaz, Senterfitt, \& Janssen, 2005). VCT aims to be an entry point to the HIV/AIDS-related services and, ideally, it is conducted when people have not had signs or symptoms of HIV infection. Unfortunately, the utilization of VCT among people at risk of HIV infection in Indonesia is still low. It is estimated that as many as $70 \%$ of those who are at high risk for HIV infection have not been tested and do not know their HIV status (UNAIDS, 2008). Furthermore, those who do get tested are often already seriously ill. For these people, primary prevention and sometimes, even HIV treatment, come too late.

To increase the uptake of HIV testing, there is an alternative approach to VCT, which is referred as provider-initiated testing and counseling (PITC). In PITC, health care workers (HCWs) recommend HIV testing to patients, with the primary goal of providing medical services which depend on knowledge of the patients' HIV status. Through PITC, patients who present to health facilities with signs, symptoms, or medical conditions suggesting HIV/AIDS may be recommended to take an HIV test. As with VCT, HIV testing in PITC is voluntary and requires informed consent, counseling, and confidentiality.

There is relatively little experience with PITC in Indonesia and so far there has been no systematic evaluation and comparison of the characteristics of subjects entering VCT or PITC. Such evaluation might help to increase referral to VCT and prioritization of patients for PITC. In this study, knowledge about HIV, perceived risk of being HIV positive, health status, HIV status, and stage of disease were examined among subjects entering VCT and PITC in a teaching hospital in Indonesia. Based on this characterization, predictors of HIV seropositivity and level of immunosuppression were identified. 


\section{Method}

\section{Participant Characteristics}

The study was conducted in Hasan Sadikin Hospital, the referral hospital for HIV in West Java (population 40 million). This hospital is one of the hospitals initially selected by the Indonesian Ministry of Health to provide VCT and HIV treatment. VCT mostly takes place in the HIV out patient clinic of this hospital. Patients were excluded from the study if they were: (a) unwilling to participate, (b) less than 18 years of age, and (c) unable to participate meaningfully (e.g., unconsciousness due to their physical condition).

\section{Study Procedures}

All procedures were approved by the Ethical Commission on Health Research of the participating institution. Data collection began in November 2007 and was completed in April 2008. Out patients attending VCT sessions in the HIV/AIDS clinic and patients undergoing PITC as part of routine clinical practice were recruited for this study. People registering for VCT were informed by the staff of the outpatient clinic that there was a research project taking place to improve VCT services and asked to answer a few questions before attending the counseling session. They were told that they would receive free blood tests as compensation for the extra time that participation required. For those who agreed, a research assistant (RA) would provide a consent form and assist them in filling out the questionnaire. Next, they attended the (routine) counseling session with the clinic's counselors. After counseling, informed consent was obtained and blood was drawn for an HIV test. Results were discussed in a second post-test counseling session. For in patients undergoing PITC, RAs visited the hospital wards. The patients were informed about the research, and those who agreed to participate were helped in filling out the consent form and questionnaire. All questionnaires were collected prior to HIV testing and counseling.

\section{Measures}

Data collected included socio demographic information, clients' perceived risk of contracting HIV/AIDS and knowledge about HIV. The perceived risk of being HIV positive was assessed by a single question with a response format of no risk/low risk/moderate risk/ high risk. Knowledge was assessed through 11 items covering general areas of HIV/AIDS knowledge, with a true/false response format. The reliability of the knowledge items was high (Cronbach's $a=.97)$. The mean number of correct responses was computed to create the HIV/AIDS knowledge score ranging from 0 (all items incorrect) to 10 (all items correct). Health status was evaluated by questionnaire and blood examination. The presence or absence of eight symptoms typically associated with HIV/AIDS or sexually transmitted infections during the past six months were recorded. Blood examination consisted 
of serological testing for HIV, hepatitis B virus, hepatitis C virus, syphilis (VDRL) and measurement of the CD4 cell count (for HIV positive patients) per ml blood using flow cytometry. External quality control of HIV testing (conducted by the National Serology Reference Laboratory, Melbourne, Australia) has shown 100\% accuracy in Hasan Sadikin Hospital (Indarti, van Crevel, \& Tjandrawati, 2009).

Naturally, all questions were written in Indonesian. However, for the purpose of this article the questions were translated into English by a professional translator. Next, another professional translator translated the English questions back to Indonesian, which were checked by the research team to ensure there was no loss of meaning or inadequate translations.

\section{Statistical Analysis}

Data are presented as percentage or median (range). Statistical differences between groups were examined using Chi square (for categorical values) or parametric tests (for continuous variables). Two-sided $p$ values $<.05$ were considered significant. Univariate and multivariate logistic regression were done using HIV status and low CD4 cell count as dependent variables. Risk estimates were expressed as odds ratios (OR) with 95\% confidence intervals $(\mathrm{Cl})$. For multivariate analysis related to HIV status, factors significantly associated in univariate analysis, as well as gender and type of testing (VCT/PITC), were included. Due to the number of subjects with available data, only the four strongest factors in univariate analysis were included in the multivariate analysis related to CD4 cell count.

\section{Results}

\section{Baseline Characteristics and Health Status of Subjects Entering VCT and PITC}

A total number of 202 subjects were included in the study, 124 entering VCT (61.4\%) and 78 enrolled in PITC (38.6\%). Subjects enrolled in PITC were more often males, had a lower educational level, lower knowledge related to HIV/AIDS, and a higher perceived risk of being HIV infected (Table1). Many subjects reported HIV/AIDS-related symptoms, especially those enrolled in PITC (Table2). In this group, weight loss, chronic diarrhea, chronic fever, persistent cough, and oral thrush were more common than among subjects entering VCT. On the other hand, those tested through VCT were more likely to report genital warts. There were no differences between VCT and PITC in the proportions reporting skin problems or urethral discharge. 
Table 1 : Baseline Characteristics of Subjects Entering VCT and PITC

\begin{tabular}{|c|c|c|c|}
\hline & $\begin{array}{c}\text { VCT } \\
\mathrm{N}=124\end{array}$ & $\begin{array}{c}\text { PITC } \\
N=78\end{array}$ & p value \\
\hline \multicolumn{4}{|l|}{ Socio-demographics } \\
\hline Median age, years (Range) & $28(19-67)$ & $28.5(18-73)$ & ns \\
\hline Male gender, $\%$ & $68(54.8 \%)$ & $45(57.7 \%)$ & * \\
\hline Married, \% & $77(62.1 \%)$ & $45(57.7 \%)$ & ns \\
\hline Completed senior high school, $\%$ & $47(37.9 \%)$ & $10(13.0 \%)$ & ** \\
\hline \multicolumn{4}{|l|}{ HIV-testing practice } \\
\hline Never HIV-tested before, \% & $94(75.8 \%)$ & $67(87.0 \%)$ & ns \\
\hline \multicolumn{4}{|l|}{ Source of HIV/AIDS information } \\
\hline Health Professional, \% & $74(59.7 \%)$ & 75 (96.2\%) & ** \\
\hline Friends and relatives, $\%$ & $25(20.2 \%)$ & 0 & ** \\
\hline HIV/AIDS related NGOs, \% & $12(9.7 \%)$ & 0 & ** \\
\hline Other (TV, radio, school, workplace,etc.),\% & $13(10.4 \%)$ & $3(3.8 \%)$ & * \\
\hline Total knowledge score, means & 7.25 & 5.06 & ** \\
\hline \multicolumn{4}{|l|}{ Risk perception } \\
\hline Perceived no risk, $\%$ & $75 \%$ & $88.5 \%$ & * \\
\hline
\end{tabular}

Note. ${ }^{*} p<.05 .{ }^{* *} p<.01$.

The HIV-prevalence among subjects counseled and tested was very high but no difference was found between VCT and PITC (45.9\% and 50.6\%, respectively). This was also true for hepatitis C infection (Table2). CD4 cell counts of patients diagnosed with HIV through PITC were significantly lower than the CD4 cell counts of HIV-infected patients diagnosed through VCT. More than two-thirds $(68.7 \%$ ) of patients infected with HIV had a CD4 cell count below 200/ $\mathrm{mm}^{3}$, which is an indication for HIV treatment, and more than half (56.7\%) had a CD4 cell count less than $50 \mathrm{~mm}^{3} / \mathrm{ml}^{\text {. }}$ 
Table 2 : Health Conditions according to VCT / PITC

\begin{tabular}{|c|c|c|c|}
\hline & \\
\hline & $\begin{array}{c}\text { VCT } \\
\mathrm{N}=124\end{array}$ & $\begin{array}{c}\text { PITC } \\
N=78\end{array}$ & p value \\
\hline \multicolumn{4}{|l|}{ Health Symptoms } \\
\hline Weight Loss & $39(31.5 \%)$ & $63(80.8 \%)$ & $* *$ \\
\hline Chronic Diarrhea & $19(15.3 \%)$ & $31(39.7 \%)$ & ** \\
\hline Chronic Fever & $13(10.5 \%)$ & $47(60.3 \%)$ & $* *$ \\
\hline Persistent Cough & $21(16.9 \%)$ & $24(30.8 \%)$ & * \\
\hline Skin Problem & $24(19.4 \%)$ & $11(14.1 \%)$ & ns \\
\hline Oral Thrush & $29(23.4 \%)$ & $29(37.2 \%)$ & * \\
\hline Urethral Discharge & $7(5.6 \%)$ & $2(2.6 \%)$ & ns \\
\hline Genital Warts & $15(12.1 \%)$ & $2(2.6 \%)$ & * \\
\hline \multicolumn{4}{|l|}{ Blood Examination } \\
\hline HIV Positive & $56(45.9 \%)$ & $39(50.6 \%)$ & ns \\
\hline Hepatitis B Positive & $6(5.0 \%)$ & $4(5.2 \%)$ & ns \\
\hline Hepatitis C Positive & $37(30.67 \%)$ & $25(32.5 \%)$ & ns \\
\hline Syphilis Positive & $1(.8 \%)$ & $0 \%$ & ns \\
\hline CD4 cells / mm3, median (range) § & $193(2-621)$ & $12(1-229)$ & ** \\
\hline CD4 cells $<200 / \mathrm{mm} 3, \% \S$ & 36.2 & 65 & $* *$ \\
\hline
\end{tabular}

Note. $* p<.05 . * * p<.01$.

$\S$ For those with HIV

\section{Factors associated with HIV status}

HIV infection was strongly associated with physical symptoms and HCV infection. HIV infected individuals reported more weight loss during the last six months and more chronic diarrhea, skin problems, and oral thrush (Table3). There was no significant difference between HIV positive and HIV negative patients in the prevalence of chronic fever, cough, urethral discharge or genital ulcers. Infection with HCV was significantly more common among HIV-infected patients than HIV negative individuals (49.5 vs 21.2\%; $\mathrm{p}<.01$ ). Logistic regression showed that chronic diarrhea, oral thrush, and HCV infection were independently and strongly associated with HIV infection (Table3). In univariate analysis, male gender was associated with HIV infection. Male gender was also strongly associated with HCV infection and health symptoms. After correction for these confounding factors, female (and not male) gender proved to be associated with being HIV infected. 
Table 3 : Summary of Logistics Regression for Variables Predicting HIV Status $(N=202)$

\begin{tabular}{l|c|c}
\hline \multicolumn{1}{c|}{ Predictors } & Beta & Sig \\
\hline Type Of HIV Testing & -.73 & Ns \\
\hline Gender & .84 & $*$ \\
\hline Risk Perception & -.13 & Ns \\
\hline Total Knowledge & -.78 & Ns \\
\hline Weight Loss & -.67 & Ns \\
\hline Chronic Diarrhea & -1.45 & $* *$ \\
\hline Oral Thrush & -1.58 & $* *$ \\
\hline HCV positive & 1.27 & $* *$ \\
\hline
\end{tabular}

Note. Type of HIV test was coded $1=$ VCT and $2=$ PITC; Gender was coded $1=$ Female and $2=$ Male (including transgender); Perceived risk was coded $0=$ not present and $1=$ present; Health symptoms (weight loss, chronic diarrhea and oral thrush) were coded $1=$ yes and $2=$ no, HCV and HIV status were coded $1=$ negative and $2=$ positive

Dependent variable: HIV status

${ }^{*} p<.05 .{ }^{* *} p<.01$.

The presence of certain health symptoms and HCV infection proved highly predictive of HIV infection. Forty three out of 55 patients with oral thrush (78\%) were HIV infected, and the same was true for $74.5 \%$ of patients with chronic diarrhea and $75.8 \%$ of patients with $\mathrm{HCV}$ infection. When HCV infection and health symptoms were combined, these factors had an even higher predictive value. All 18 patients (100\%) presenting with HCV infection and chronic diarrhea, and all 21 patients (100\%) presenting with chronic diarrhea and oral thrush were HIV positive. Similarly, 26 of 30 patients $(86.7 \%)$ presenting with both HCV infection and oral thrush were HIV-infected.

\section{Factors associated with CD4 Cell Count}

Table 4 : Summary of Multiple Regression for Variables Predicting CD4 Count Cell $(\mathrm{N}=95)$

\begin{tabular}{l|c|c}
\multicolumn{1}{c|}{ Predictors } & Beta & Sig \\
\hline Type Of HIV Testing & -.24 & $*$ \\
\hline Gender & .10 & $\mathrm{Ns}$ \\
\hline Risk Perception & .11 & $\mathrm{Ns}$ \\
\hline Total Knowledge & .04 & $\mathrm{Ns}$ \\
\hline Weight Loss & .28 & $*$ \\
\hline Chronic Diarrhea & .09 & $\mathrm{Ns}$ \\
\hline Oral Thrush & .27 & $*$ \\
\hline HCV positive & -.25 & $*$ \\
\hline
\end{tabular}

Note. Type of HIV test was coded $1=$ VCT and $2=$ PITC; Gender was coded $1=$ Female and $2=$ Male (including transgender); Perceived risk was coded $0=$ not present and $1=$ present; Health symptoms (weight loss, chronic diarrhea and oral thrush) were coded $1=$ yes and $2=$ no, HCV and HIV status were coded $1=$ negative and $2=$ positive

Dependent Variable: CD4 count cell

$* p<.05 . * * p<.01$. 
Physical symptoms were also strongly related with the CD4 cell count, as a marker of immunosuppression level or stage of disease (Table4). CD4 cell counts were available for 67 HIV-infected patients, and those with a CD4 cell count below 50/mm ${ }^{3}$ reported significantly more weight loss, diarrhea, fever, and oral thrush. As described above, PITC was associated with low CD4 cell counts, as was male gender in univariate analysis. HCV infection and persistent cough were more common among those with low CD4 counts but this was not statistically significant. From the four strongest predictors of a low CD4 cell count in univariate analysis, only weight loss and PITC remained independently associated with a low CD4 cell count, while oral thrush showed a tendency to be related to low CD4 count (Table $4 ; \mathrm{p}=$.06). The apparent relation between male gender and CD4 cell count was actually due to confounding by health symptoms and HCV infection.

\section{Discussion}

We characterized subjects undergoing HIV counseling and testing, either through VCT or PITC, in an Indonesian hospital. Several conclusions can be drawn from our results. First, subjects in PITC have a lower knowledge about HIV/AIDS-related issues, more HIV/ AIDS-related health symptoms, and a higher perceived risk of being HIV infected than subjects enteringVCT. Second, the HIV prevalence among subjects counseled and tested was high and many subjects appeared seriously ill with very low CD4 cell counts reflecting advanced HIV/AIDS. Third, chronic diarrhea, oral thrush, and HCV status were highly predictive of HIV infection while weight loss emerged as a strong predictor of a low CD4 cell count.

Subjects who presented themselves for HIV counseling and testing (VCT) were different from those enrolled in PITC. Patients enrolled in PITC had more limited knowledge related to HIV/AIDS. This finding is in line with a previous study from Uganda (Kipp, Alibhai, Saunders, Konde-lule, \& Ruhunda, 2009). Patients who knew less about HIV-AIDS may not have attributed their symptoms to possible HIV infection, which may have contributed to the fact that they did not seek HIV testing earlier.

Furthermore, PITC patients had a lower educational back ground than VCT patients. Lower education has been identified in several studies as related to a lower health status and worse health related behavior (Cox, Miller, \& Mull, 1987; Kipp et al., 2009; Loeb, O'Neill, \& Gueldner, 2001; Wallwer, Crow, Sands, \& Becker, 1988). Several studies have suggested that lower education is associated with a lower motivation to participate in health programs (Cox, Miller, \& Mull, 1987; Loeb et al. 2001; Wallwer, Crow, Sands, \& Becker, 1988). This might also apply to patients enrolled in PITC and thereby contribute to the fact that they did not undergo HIV testing earlier. 
PITC patients had higher perceived risk of being HIV infected than subjects entering VCT. There are several possible explanations for this finding. First, people who have a higher number of sexual partners and inject more drugs may think they have a higher chance of being HIV infected, as suggested in previous research (Booth, Zhang, \& Kwiatkovski, 1999). At least for injecting drugs, our data does not support this possibility, as HCV infection (as a proxy parameter for intravenous drug use) was not higher in PITC than in VCT. Second, physical symptoms themselves may lead to increased anxiety and a higher perceived risk of being infected. Finally, the procedure itself may be related to perceived risk of being infected. Patients enrolled in PITC are approached by a health careworker to receive an HIV test instead of seeking the HIV testing themselves. They may be taken by surprise or even frightened. From our study, no definite explanation can be found.

The HIV seroprevalence among patients who are tested for HIV in this hospital is relatively high and, of those tested positive, many presented with severe immunosuppression. This finding reflects the situation in Indonesia, where up take of HIV testing is low (UNAIDS, 2008). Some significant factors that have prevented people in Bandung from receiving a test earlier include a lack of confidentiality of test results; financial barriers, and a low perception of the benefits (Suherman, in preparation). Similar conclusions were also found in studies conducted in Bali (Ford, Wirawan, Sumantera, Sawitri, \& Stahre, 2004; Sawitri, Sumantera, Wirawan, Ford, \& Lehman, 2006). Although not purposively intended, results from our own study may suggest that lack of knowledge and low risk perception can be reasons for patients' late testing in this health setting.

The fact that people are not tested, or tested late, has important implications in terms of HIV transmission. For all those tested positive, primary prevention comes too late. In addition, given their very low CD4 cell count and advanced stage of disease, the majority of HIV infected subjects in this study will already have been infected for many years, during which they may have transmitted the virus to others. Late testing also has implications for treatment as HIV treatment is usually more complicated and less successful for those who are diagnosed with advanced HIV/AIDS (Wisaksana et al., 2009).

Another important finding from our study is the fact that certain health symptoms, especially chronic diarrhea, weight loss, oral thrush and skin problems, were strongly associated with HIV infection. This is due to the fact that most HIV-infected individuals had advanced HIV/ AIDS, as also reflected by the low CD4 cell count, especially among those enrolled in PITC. These symptoms, alone or in combination, can be used as simple clues for health care workers to identify people at risk of HIV infection. Such clues may thus help in prioritizing patients for PITC; thereby increasing up take of HIV testing and HIV treatment. Many earlier studies have focused on behavioral correlates of HIV infection, but both patients and health care workers often find it difficult to discuss drug use or sexual behavior. This is usually not 
the case for physical symptoms and, as such, these clues are easier to use when trying to identify patients as at risk of infection. Of course, this does not help to identify asymptomatic HIV-infected individuals. To reach that group, targeted screening, for instance of prisoners or marital partners of HIV patients, may help (Nelwan et al. 2009; Wisaksana et al. 2009). In contrast to settings where HIV is primarily driven by sexual transmission, symptoms suggesting sexually transmitted diseases were rare and not associated with HIV infection.

HCV infection was strongly associated with HIV infection. This finding confirms that drug injection in this setting is the main risk factor for HIV transmission in Indonesia (except for Papua) (Afriandi et al., 2009), and the data are in line with the HCV prevalence in a large cohort of HIV-infected patients in Bandung which showed that $83 \%$ of male and $29.7 \%$ of female patients were HCV infected (Wisaksana et al., 2009). Male gender appeared to be a risk factor for HIV infection, but this was actually due to confounding by HCV infection and physical signs, which were both much more common among males.

Not surprisingly, physical symptoms were more common among those with low CD4 cell counts. In addition, patients diagnosed through PITC had lower CD4 cell counts, which seem logical as health care workers will most easily recognize those with the most severe signs and symptoms.

This study suffers from the limitations of a cross-sectional study with a relatively small number of subjects in a single institution. Still, we can conclude that health professionals in hospitals or in other health settings should proactively educate patients and initiate HIV testing. HIV prevalence was high and HIV-infected patients mostly presented late. Future research, including subjects at risk who have not been tested yet, should help to identify barriers to (early) HIV testing. A number of physical symptoms (especially chronic diarrhea and oral thrush) and HCV infection were highly predictive of HIV infection and these 'clues' can be used by health care workers to identify people for PITC. Future research should be extended to community and other settings, and should accommodate questions regarding patients' history of risk behaviors and barriers to HIV testing. 


\section{CHAPTER 3}

\section{HIV-related Knowledge}

and Attitudes among Indonesian Prison Officers

Based on: Hinduan, Z. R., Suherman, H., Pinxten, W. J. L., Alisjahbana, B, \& Hospers, H. J. (2013). HIV-related knowledge and attitudes among Indonesian prison officers. International Journal of Prisoner Health, 9, 92-102. 



\title{
HIV-related Knowledge and Attitudes among Indonesian Prison Officers
}

\begin{abstract}
Prison officers have a vital role in running a secure and healthy living environment for the inmates. The purpose of this article is to examine the relationship between HIV/AIDSrelated knowledge and attitude towards inmates living with HIV among the officers in an Indonesian narcotics prison. Ninety-three prison officers from a narcotics prison in Bandung, Indonesia voluntarily participated in this cross sectional study by completing a self-reported questionnaire. A prior focus group discussion was also held among selected participants. Statistical data analyses indicated that all domains of HIV/AIDS-related knowledge, i.e. knowledge of HIV transmission, general HIV/AIDS knowledge, and knowledge of HIV prevention had substantial positive correlations with the prison officers' attitude towards inmates living with HIV. These results show that the more knowledgeable the officers are, the less likely they are to respond in an unfavorable manner to inmates living with HIV and vice versa. Despite the limited number of participants involved in this study, the knowledge gaps that are identified should be the starting point for the development of educational interventions for prison officers. Sufficient educational programs and the most updated materials need to be made available within the prison. Commitment from prison authorities as well as a proper policy is also needed.
\end{abstract}

Keywords: attitude, HIV/AIDS, inmates, knowledge, prison officers

\section{Introduction}

Prison is a potential high risk environment for the spread of the human immunodeficiency virus (HIV) and Hepatitis $\mathrm{C}(\mathrm{HCV})$, especially in low and middle income countries, such as Indonesia (Joint United Nations Programme on HIV/AIDS (UNAIDS)/ World Health Organization (WHO), 2009). The prevalence of people living with HIV and HCV in Indonesian prisons has been found to be considerably higher than among the general population (Djauzi, 2009; Dolan, Kite, Black, Aceijas, \& Stimson, 2007; Ministry of Justice and Human Rights, 2010; Nelwan et al., 2010). 
In Indonesia, there is a specific type of prison called a narcotics prison. This type of prison houses inmates who are arrested for drug-related crimes, including producing, dealing, possessing, or using illicit drugs (Ministry of Justice and Human Rights, 2010). The narcotics prison specializes in accommodating convicted male inmates. Female inmates, including those who are arrested for drug-related crimes, are incarcerated in specialist female prisons. The narcotics prisons, which are located in big cities in Indonesia, are rapidly becoming full, with the number of inmates exceeding the capacity of the prisons. These conditions promote the transmission of diseases among the inmates, including HIV (Djauzi, 2009).

The results from an HIV sero-surveillance survey showed that the HIV prevalence rates in Indonesian prisons range from $0 \%$ in general prisons to $32 \%$ in narcotics prisons (Ministry of Health $(\mathrm{MoH}), 2010)$. The high HIV prevalence in narcotics prisons is not surprising since all inmates in this kind of prison are convicted for drug-related offences and drug injection is one of the main HIV transmission routes in Indonesia(Dolan et al., 2007; Nelwan et al., 2010; Solomon et al., 2009; UNAIDS/WHO, 2009; United Nations Office of Drugs and Crime (UNODC), 2006). Almost ninety percent of inmates reported illicit substance use prior to their detention (Narcotics Board of Indonesia, 2004).

In addition, several studies suggest that HIV infections may occur in prisons since the prison environment may facilitate behaviors that pose a risk for HIV transmission among inmates. Inmates who use intravenous substances while imprisoned are likely to share used injection equipment and needles in the absence of the clean ones. The inmates also share sharps in the prisons for tattooing, body piercing, and inserting genital accessories (Mesquita et al., 2007; Ministry of Justice and Human Rights, 2010; WHO, 2007). In addition, despite the lack of precise data regarding the prevalence rate of male-to-male sexual practice in Indonesian prisons, there are reports confirming homosexual intercourse among male inmates in Indonesia, usually without the use of condoms (Ministry of Justice and Human Rights, 2010).

Furthermore, HIV prevention programs in prisons in Indonesia are scarce, and harm-reduction interventions, such as condom distribution or needle exchange programs are still controversial (Mesquita et al., 2007; UNAIDS, 2005). Most Indonesian prisons are overcrowded, have a limited health budget for inmates and ill-equipped health facilities. Health funding for each inmate is approximately 1 US dollar per year (UNAIDS, 2005). Approximately $40 \%$ of Indonesian prisoners had no health care workers and no "in-house" basic health care services to provide health assistance (Djauzi, 2009; Dursin, 2004; WHO, 2007).

Within the prisons, prison officers potentially have a vital role in maintaining a secure and healthy living environment for the inmates. Besides performing daily security checks and search procedures, a prison officer has other responsibilities, such as providing appropriate care and support for inmates, contributing to drug rehabilitation programs and making sure that inmates have access to professional help when needed. Ideally, prison officers should 
be able to establish and maintain a positive working relationship with inmates, balancing authority with care and understanding.

A study in Scottish Prisons shows that the prison officers had a higher level of risk perception of contracting HIV compared to the inmates (McKee, Markova, \& Power, 1995). Moreover, they expressed concern about working with inmates living with HIV (Dillon and Allwright, 2005; Mahaffrey and Markus, 1995; Mclntyre, Marquart, \& Brewer, 1995). As a result, those officers may have unfavorable attitudes towards inmates living with HIV. This is also apparent in the Indonesian context. Several Indonesian chief prison wardens have expressed their ignorance toward an HIV epidemic among inmates. For example, they refuse to take responsibility when inmates get infected with HIV in their prisons (Dursin, 2004). According to them, the health problems among inmates are not as important as other problems, such as security issues or financial problems within their prisons. As a result, they believe that they do not have to take care of inmates living with HIV.

Moreover, in the preliminary focus group discussions (FGDs) with prison officers working in a narcotics prison in Bandung, West Java, Indonesia, which was conducted in preparation for the present study, the following illustrative quotes were noted:

"Inmates living with HIV should be located in an isolation block"

"Many inmates refuse to be (HIV) tested because they are afraid of being isolated"

"We want to be healthy so we are afraid to be close to inmates living with HIV".

These quotes illustrate the uncomfortable feelings that some officers expressed about inmates living with HIV. These unfavorable attitudes may be associated with feelings of discomfort related to interaction with inmates living with HIV and may lead to social and physical isolation of the inmates (Dillon and Allwright, 2005; Power et al., 1991). Moreover, HIV-related social isolation may lead inmates to take higher risks as they may not have participated in any HIV prevention programs such as HIV testing (Babalola, 2007; Parker and Aggleton, 2003; UNAIDS, 2004) or they may delay HIV treatment (Derlega, Winstead, \& Brockington, 2008). Finally, HIV infected prisoners may also transmit the virus to other inmates or prison personnel, and - after release - may expose spouses or other sexual partners due to a lack of understanding about risk behavior.

Previous studies exploring the occupational health concerns of prison officers have highlighted their limited HIV/AIDS-related knowledge (McIntryre et al., 1995; Rotily et al., 2001). In the preliminary FGDs, most prison officers mentioned that they have limited knowledge related to HIV. It is difficult for them to take necessary and effective precautions at work since not all staff receive proper HIV/AIDS-related training. They also reported misconceptions about transmission routes (i.e. "Saliva can spread the virus"), symptoms of HIV (i.e. "Inmates living with HIV cannot do their daily activities"), and also HIV prevention 
(i.e. "To prevent the HIV transmission, I need to use a stick to poke an inmate with HIV"). This lack of knowledge probably contributes to negative attitudes towards inmates living with HIV.

This article reports the results of a study that examines the relationship between HIV/AIDSrelated knowledge and attitudes toward inmates living with HIV among a sample of prison officers in a narcotics prison in Bandung, Indonesia.

\section{Methods}

\section{Participant Characteristics}

Data were collected in a narcotics prison in Bandung. Normally, the capacity of this prison is 450 inmates. However, by the end of 2011, the total number of inmates in this prison was 1,406 . Approximately 1,350 inmates have used drugs at some time with approximately $20 \%$ convicted for using intravenous substances. Between August 2007 and January 2009, it was reported that almost $40 \%$ of the new prisoners with a history of using injected drugs were already living with HIV (Nelwan et al., 2010). The prison officers comprised of prison guards, administrative staff and Officers of the Department of Social Rehabilitation Program. In total, there were 128 officers. All of them had the responsibility to establish a healthy working relationship with the inmates.

\section{Study Procedures}

All prison officers were invited to participate in this cross-sectional study. Participation in this study was voluntary and anonymous with no incentive for participation. The questionnaire used did not contain questions that would reveal the respondents' identity and the respondents were assured that only the researchers had access to the raw data. The preliminary FGDs among several officers had been conducted before the quantitative data collection for all officers. The Standing Committee on Ethics in Health Research of the Faculty of Medicine, Padjadjaran University - Hasan Sadikin Hospital Bandung approved this study (reference no. 113/FKUP-RSHS/KEPK/Kep./EC/2007).

Data collection was conducted over the course of two days in the prison in 2007. Each participant came to the prison meeting room and received the questionnaire in an envelope. The respondents first received general instructions from the researchers on how to complete the questionnaire and were then asked to individually complete it. After completion, they were asked to return the questionnaire to the envelope, seal it, and hand it in. Ninetythree respondents completed the questionnaire, yielding a participation rate of $72.65 \%$. Almost half of the respondents were prison guards $(47.31 \%)$, followed by administrative staff $(27.96 \%)$ and Officers of the Department of Social Rehabilitation Program (24.73\%). 


\section{Measures}

The questionnaire comprised the following components:

1. Demographic information (i.e., gender, age, and educational background). Comparable studies among prison officers in several western countries showed the variation in results due to the effects of these demographic variables on the officers' level of knowledge and attitudes towards inmates living with HIV (Derlega et al., 2008;Dillon and Allwright, 2005), hence the these demographics were included as control variables.

2. HIVIAIDS Knowledge. The knowledge scale was developed based on the results of the preliminary FDGs among the prison officers. The scale consisted of 49 items that addressed three areas of HIV/AIDS knowledge: (a) general knowledge concerning HIV/AIDS (e.g., "There are no medications available to cure HIV"), (b) knowledge concerning HIV transmission (e.g., "The virus can be transmitted by sneezing") and (c) knowledge of HIV prevention (e.g., "HIV infection can be prevented by immunization"). The response format was true/false. The number of correct responses for the total scale and for each subscale was computed. Higher scores indicate more knowledge. The reliability coefficients of the three subscales were high $(a=.72$ for general knowledge subscale, $a=.89$ for HIV transmission subscale and $a=.74$ for HIV prevention subscale).

3. Attitude towards inmates living with HIV. This scale was also developed based on the results of the preliminary FGDs and focused on attitudes toward inmates living with HIV, which was measured through 21 items. A sample item was: "Inmates living with HIV must be ashamed about their disease". Responses were given on a 4-point Likert-type scale, ranging from $1=$ strongly disagree to $4=$ strongly agree. Higher scores on this scale indicate a more favorable attitude towards inmates living with HIV. The reliability coefficient of the scale was .78. It means the reliability of the scale was high.

Naturally, all questions were posed in the Indonesian language. However, for the purpose of the present paper the questions were translated into English by a professional translator.

\section{Statistical Analysis}

Spearman correlation coefficients were computed to examine bivariate relationships for ordinal variables. Then, to examine the effect of each knowledge component on the attitude, stepwise regression analyses were also computed. Further analyses were conducted to determine whether the knowledge scores were from the same population, using T-tests. All statistical analyses were carried out with the SPSS Program for Windows (Version 17.0). 


\section{Results}

\section{Descriptive Statistics}

Respondents' mean age was 41.42 years old (SD = 7.09) (range 23 - 54). Slightly more than half of the respondents $(68.82 \%)$ were male. Half of them had either a senior high school degree $(50.54 \%)$ or a higher education degree (bachelor and master degrees) $(49.46 \%)$.

Table 1 : Descriptive Statistics and Correlations among Major Variables $(N=93)$

\begin{tabular}{l|c|c|c|c}
\hline \multicolumn{1}{c|}{ Variables } & $\begin{array}{c}\text { Percentage } \\
\text { (\%) }\end{array}$ & $\begin{array}{c}\text { Maximum } \\
\text { Score }\end{array}$ & Mean & SD \\
\hline 1. Male officers & 68.82 & & & \\
\hline 2. Educational level & & & & \\
\hline - Senior high school & 50.54 & & & \\
- Higher education & 49.46 & & 41.42 & 7.09 \\
\hline 3. Age & & 78 & 62.08 & 6.81 \\
\hline 4. Attitude toward inmates with HIV & & 14 & 9.75 & 2.82 \\
\hline 5. General knowledge & & 21 & 15.00 & 4.69 \\
\hline 6. Transmission-related knowledge & & 12 & 8.59 & 2.71 \\
\hline 7. Prevention-related knowledge & & & & \\
\hline
\end{tabular}

Table 1 presents the means (M) and standard deviations (SD) of the study variables. In general, the officers had a relatively favorable attitude towards inmates living with HIV. The mean score (average) was $62.08(\mathrm{SD}=6.81)$ (Range $13-78)$. There were no significant attitude differences among male and female prison officers. Further analysis showed that the officers with a higher educational degree had a significantly more positive attitude than those with a lower educational degree $(\mathrm{t}(91)=3.56, \mathrm{p}<.01)$.

The average knowledge score was 32.53 ( $S D=8.91)$, suggesting that, overall, participants were relatively knowledgeable about HIV/AIDS. Prison officers with a higher educational level were more knowledgeable $(M=36.56, S D=7.40)$ than those with a lower educational level $(M=29.06, S D=8.69)$, and this difference was statistically significant, $(\mathrm{t}(91)=4.44$, $\mathrm{p}<.01)$. Similarly, female prison officers $(M=35.48, S D=7.73)$ were significantly more knowledgeable than male officers $(M=31.20, S D=9.16 ; t(91)=2.11, p<.05)$. There were no significant attitude and knowledge differences between older and younger officers. 


\section{Correlations among Study Variables}

Table 2 : Correlations among Study Variables $(N=93)$

\begin{tabular}{|c|c|c|c|c|c|c|c|}
\hline Variables & G & A & EL & ATT & GK & TK & PK \\
\hline Gender (G) & - & & & & & & \\
\hline Age $(A)$ & $-.24^{*}$ & - & & & & & \\
\hline Educational Level (EL) & .06 & $-.30^{* *}$ & - & & & & \\
\hline $\begin{array}{l}\text { Attitude toward inmates with } \\
\text { HIV (ATT) }\end{array}$ & .17 & $-.24^{*}$ & $.38^{* *}$ & - & & & \\
\hline General knowledge (GK) & $.25^{*}$ & $-.21^{*}$ & $.38^{* *}$ & $.46^{* *}$ & - & & \\
\hline $\begin{array}{l}\text { HIV Transmission-related } \\
\text { knowledge (TK) }\end{array}$ & .15 & $-.31^{* *}$ & $.45^{* *}$ & $.60^{* *}$ & $.58^{* *}$ & - & \\
\hline $\begin{array}{l}\text { HIV Prevention-related } \\
\text { knowledge (PK) }\end{array}$ & $.25^{*}$ & $-.34^{* *}$ & $.30^{* *}$ & $.45^{* *}$ & $.54^{* *}$ & $.63^{* *}$ & - \\
\hline
\end{tabular}

Note. ${ }^{*} p<.05 * * p<.01$.

It can be seen that the attitude toward inmates measure had a strong relationship with all subscales of HIV/AIDS related knowledge (HIV transmission-related knowledge, $r=.60$, general knowledge, $r=.46$ and HIV prevention-related knowledge, $r=.43$ ).

Moreover, a moderate correlation was found between attitude and educational level $(r=$ .38). Furthermore, each knowledge subscale also had moderate correlations with educational level. Gender was associated with two subscales of knowledge, i.e. general knowledge and HIV prevention-related knowledge. Finally, age correlated negatively with attitude and knowledge, indicating more negative attitudes and lower knowledge levels among older respondents. 


\section{Direct Effects of Knowledge Components on Officers' Attitude toward Inmates Living with HIV}

\section{Table 3 : Summary of Stepwise Regression Analyses for Variables Predicting Attitude towards HIV-Positive Inmates $(N=93)$}

\begin{tabular}{|c|c|c|c|c|c|}
\hline $\begin{array}{c}\text { Variables } \\
\text { Entered }\end{array}$ & $\beta$ & $\begin{array}{l}\text { Variables } \\
\text { Entered }\end{array}$ & $\beta$ & $\begin{array}{l}\text { Variables } \\
\text { Entered }\end{array}$ & $\beta$ \\
\hline \multicolumn{2}{|l|}{ Step 1} & \multicolumn{2}{|l|}{ Step 1} & \multicolumn{2}{|l|}{ Step 1} \\
\hline $\begin{array}{l}\text { General } \\
\text { Knowledge }\end{array}$ & $.44^{* *}$ & $\begin{array}{l}\text { HIV transmission } \\
\text { Knowledge }\end{array}$ & $.55^{* *}$ & $\begin{array}{l}\text { HIV prevention } \\
\text { Knowledge }\end{array}$ & $.45^{* *}$ \\
\hline \multicolumn{2}{|l|}{ Step 2} & \multicolumn{2}{|l|}{ Step 2} & \multicolumn{2}{|l|}{ Step 2} \\
\hline $\begin{array}{l}\text { General } \\
\text { Knowledge }\end{array}$ & $.31^{* *}$ & $\begin{array}{l}\text { HIV transmission } \\
\text { Knowledge }\end{array}$ & $.46^{* *}$ & $\begin{array}{l}\text { HIV prevention } \\
\text { Knowledge }\end{array}$ & $.34^{* *}$ \\
\hline Gender & .06 & Gender & .06 & Gender & .05 \\
\hline Age & -.10 & Age & -.04 & Age & -.06 \\
\hline Education & $.23^{*}$ & Education & .16 & Education & $.25^{*}$ \\
\hline \multicolumn{2}{|l|}{$\mathrm{R}^{2}=.27$} & \multicolumn{2}{|l|}{$\mathrm{R}^{2}=.34$} & \multicolumn{2}{|l|}{$R^{2}=.27$} \\
\hline
\end{tabular}

Note. ${ }^{*} p<.05 * * p<.01$.

After measuring the correlation between the research variables, three stepwise regression analyses were conducted to examine the effect of each knowledge component on the attitude. In all regressions, the three components of knowledge were entered in Step 1. The control variables - gender, age, and education - were entered in Step 2.

Table 3 presents the standardized $\beta$ values. The three components of HIV related knowledge were significantly attributed to officers' attitudes towards inmates living with HIV, while controlling for gender, age, and education.

\section{Knowledge Differences between Prison Officers}

Table 4 shows a comparison made between prison officers who had an attitude score above the median and officers with an attitude score below the median. In respect of the general knowledge subscale, the large majority of prison officers appeared to be aware of the use of blood tests to identify HIV status $(96 \%)$ as well as the nature $(94 \%)$ and the cause $(87 \%)$ of HIV. On the other hand, a substantial proportion incorrectly answered questions about the implication of Methadone Maintenance Therapy (MMT) on reducing HIV transmission in the prisons $(42 \%)$ and medical efforts in curing opportunistic infections and in reducing HIV transmissions (43\%). In addition, knowledge about Voluntary Counseling and Testing 
(VCT), MMT, and a cure for HIV significantly differentiated staff with a more positive attitude from those with a more negative attitude.

Table 4 : Mean Scores for Respondents with Positive and Negative Attitude toward Inmates with HIV/AIDS ( $=93)$

\begin{tabular}{|c|c|c|c|c|}
\hline \multirow[b]{2}{*}{ General Knowledge } & \multicolumn{2}{|c|}{ Attitude } & \multirow[b]{2}{*}{ Sig } & \multirow{2}{*}{$\begin{array}{l}\text { Total } \\
\text { Correct } \\
(\%)\end{array}$} \\
\hline & $\begin{array}{c}\text { Negative } \\
\text { (<median) }\end{array}$ & $\begin{array}{c}\text { Positive } \\
\text { (> median) }\end{array}$ & & \\
\hline $\begin{array}{l}\text { To know her/his HIV status, a person can get } \\
\text { a blood test }\end{array}$ & .94 & .98 & .39 & .96 \\
\hline $\begin{array}{l}\text { HIV/AIDS is a disease which will destroy the } \\
\text { body's natural immunity against infection }\end{array}$ & .92 & .95 & .52 & .94 \\
\hline HIV/AIDS is caused by black magic & .80 & .95 & $.03^{*}$ & .87 \\
\hline $\begin{array}{l}\text { By taking VCT, an inmate can know her/his } \\
\text { HIV status }\end{array}$ & .66 & 1.00 & $.00^{* *}$ & .82 \\
\hline $\begin{array}{l}\text { There is something a person can do to avoid } \\
\text { getting HIV/AIDS or the virus that causes HIV/ } \\
\text { AIDS }\end{array}$ & .70 & .79 & .32 & .74 \\
\hline $\begin{array}{l}\text { Anal sex is more dangerous than vaginal sex } \\
\text { for the transmission of HIV }\end{array}$ & .76 & .72 & .67 & .74 \\
\hline There is no cure for the disease & .62 & .88 & $.00^{* *}$ & .74 \\
\hline $\begin{array}{l}\text { You can tell from looking at a person if s/he } \\
\text { has the HIV/AIDS virus }\end{array}$ & .60 & .79 & $.04^{* *}$ & .69 \\
\hline $\begin{array}{l}\text { There are counseling sessions before and } \\
\text { after the HIV test }\end{array}$ & .48 & .81 & $.00^{* *}$ & .63 \\
\hline HIV/AIDS is like having the common cold & .54 & .74 & $.04^{* *}$ & .63 \\
\hline $\begin{array}{l}\text { The appearance of inmates with HIV is similar } \\
\text { to healthy inmates }\end{array}$ & .60 & .63 & .79 & .61 \\
\hline $\begin{array}{l}\text { Chronic Diarrhea is one of the HIV/AIDS } \\
\text { symptoms }\end{array}$ & .56 & .49 & .50 & .53 \\
\hline $\begin{array}{l}\text { There are medicines that can cure the co- } \\
\text { infections of HIV/AIDS }\end{array}$ & .40 & .47 & .53 & .43 \\
\hline $\begin{array}{l}\text { Methadone Maintenance Therapy (MMT) } \\
\text { Program does not have any implication on } \\
\text { reducing the number of HIV transmissions in } \\
\text { prisons }\end{array}$ & .26 & .60 & $.00^{* *}$ & .42 \\
\hline
\end{tabular}

Note. ${ }^{*} p<.05 * * p<.01$ 
As can be seen from Table 5, the majority of officers could give correct answers to questions related to needle sharing, sexual intercourse, and blood transfusion (98\%, 97\% and 96\%, respectively). However, the majority of them found it difficult to give correct answers to questions concerning oral-related HIV transmission, such as sharing a tooth brush, saliva, and kissing. Only $20 \%, 37 \%$ and $37 \%$ of the officers gave correct answers to those questions, respectively. This suggests that not many officers know that HIV cannot be transmitted through those oral routes.

Table 5 : Mean Scores for HIV Transmission Knowledge of Respondents with Positive and Negative Attitudes toward Inmates with HIV/AIDS ( $=93)$

\begin{tabular}{|c|c|c|c|c|}
\hline \multirow[b]{2}{*}{ HIV transmission knowledge } & \multicolumn{2}{|c|}{ Attitude } & \multirow[b]{2}{*}{ Sig } & \multirow{2}{*}{$\begin{array}{c}\text { Total } \\
\text { Correct } \\
(\%)\end{array}$} \\
\hline & $\begin{array}{c}\text { Negative } \\
\text { (< median) }\end{array}$ & $\begin{array}{c}\text { Positive } \\
\text { (> median) }\end{array}$ & & \\
\hline Sharing a needle & .96 & 1.00 & .16 & .98 \\
\hline Sexual intercourse & .94 & 1.00 & .11 & .97 \\
\hline Blood transfusion & .92 & 1.00 & .06 & .96 \\
\hline Talking to inmates with HIV/AIDS & .82 & 1.00 & $.01^{* *}$ & .90 \\
\hline Handshaking & .78 & 1.00 & $.00^{* *}$ & .88 \\
\hline Sharing a razor & .86 & .91 & .06 & .88 \\
\hline Tattooing & .82 & .95 & $.04^{*}$ & .88 \\
\hline Sitting on the same toilet seats & .80 & .91 & .15 & .85 \\
\hline Sharing plates & .74 & .91 & .23 & .82 \\
\hline Breast feeding & .76 & .88 & .13 & .82 \\
\hline Touching the prison bars of HIV inmates & .72 & .93 & $.01^{* *}$ & .81 \\
\hline Sneezing & .54 & .88 & $.00^{* *}$ & .70 \\
\hline $\begin{array}{l}\text { Carrying the remains of inmates with HIV/ } \\
\text { AIDS }\end{array}$ & .58 & .79 & $.03^{*}$ & .68 \\
\hline Sweat & .52 & .77 & $.02^{* *}$ & .63 \\
\hline Sharing a cigarette & .40 & .86 & $.00^{* *}$ & .61 \\
\hline Feces & .44 & .77 & $.00^{* *}$ & .59 \\
\hline Mosquito biting & .44 & .74 & $.00^{* *}$ & .58 \\
\hline Vomit & .30 & .79 & $.00^{* *}$ & .53 \\
\hline Kissing & .22 & .53 & $.00^{* *}$ & .37 \\
\hline Saliva & .22 & .53 & $.00^{* *}$ & .37 \\
\hline Sharing a toothbrush & .10 & .30 & $.02 *$ & .20 \\
\hline
\end{tabular}

Note. ${ }^{*} p<.05 * * p<.01$ 
Moreover, when comparing the officers with a less favorable attitude with those with a more positive attitude, several significant differences were found with respect to knowledge related to specific HIV transmission routes, such as oral routes (sharing a cigarette and a toothbrush, vomiting, kissing, saliva), air routes (sneezing and talking), and skin routes (handshaking, touching the prison bars, mosquito bites). There were no significant differences between the two groups with respect to knowledge regarding the common routes of HIV transmission, i.e. sharing needles, sexual intercourse, blood transfusion, and breast feeding.

From the knowledge of HIV prevention subscale (Table 6), it is apparent that there were significant knowledge differences between those officers who had a more positive attitude towards inmates living with HIV compared to those with a more negative attitude, especially the knowledge that relates to the effect of mosquito fogging (spraying insecticide to control mosquitoes) in preventing HIV transmission among the inmates.

Table 6 : Mean Scores for HIV Prevention Knowledge of Respondents with Positive and Negative Attitudes toward Inmates with HIV/AIDS ( $N=93)$

\begin{tabular}{|c|c|c|c|c|}
\hline \multirow[b]{2}{*}{ HIV prevention knowledge } & \multicolumn{2}{|c|}{ Attitude } & \multirow[b]{2}{*}{ P value } & \multirow{2}{*}{$\begin{array}{c}\text { Total } \\
\text { Correct } \\
\text { (\%) }\end{array}$} \\
\hline & $\begin{array}{l}\text { Negative } \\
\text { (< }<\text { median) }\end{array}$ & $\begin{array}{c}\text { Positive } \\
\text { (> median) }\end{array}$ & & \\
\hline Not sharing a needle & .94 & 1.00 & .11 & .97 \\
\hline Having just 1 sexual partner & .90 & .86 & .56 & .88 \\
\hline Using condom during sexual intercourse & .82 & .95 & $.04^{*}$ & .88 \\
\hline Implementing VCT program in the prison & .70 & .91 & $.02^{*}$ & .80 \\
\hline $\begin{array}{l}\text { Taking a herbal medicine before having } \\
\text { sexual intercourse }\end{array}$ & .66 & .84 & .06 & .74 \\
\hline Implementing MMT program in the prison & .56 & .72 & .11 & .63 \\
\hline $\begin{array}{l}\text { Taking antibiotics before having sexual inter- } \\
\text { course }\end{array}$ & .50 & .72 & $.03^{*}$ & .60 \\
\hline Mosquito fogging & .38 & .67 & $.00^{* *}$ & .52 \\
\hline Sit on different toilet seats & .40 & .63 & $.03^{*}$ & .51 \\
\hline $\begin{array}{l}\text { Using a wooden stick when touching HIV/ } \\
\text { AIDS inmates' belongings }\end{array}$ & .46 & .53 & .48 & .50 \\
\hline $\begin{array}{l}\text { HIV infection can be prevented by immuniza- } \\
\text { tion }\end{array}$ & .44 & .56 & .26 & .50 \\
\hline Isolation room for inmates with HIV/AIDS & .22 & .33 & .26 & .27 \\
\hline
\end{tabular}

Note. ${ }^{*} p<.05 * * p<.01$ 
Furthermore, most of the officers know that using a sterile needle (97\%), faithfulness (88\%), and condom use (88\%) can prevent HIV transmission. However, they seem unfamiliar with knowledge related to precautionary tools to prevent HIV transmission from the inmates to them. The majority of the officers (73\%) think that inmates living with HIV should live in an isolation room.

\section{Discussion}

The objective of this study was to examine the extent to which officers' knowledge regarding HIV/AIDS correlated to their attitude towards inmates living with HIV. Indeed, HIV/AIDSrelated knowledge in several domains was strongly related to the attitude towards inmates living with HIV. These results suggest that the more knowledgeable the officers are about HIV/AIDS-related issues, the less likely they are to respond in an unfavorable manner to inmates living with HIV. These results support the findings of studies conducted in western countries (Mclntryre et al., 1995; Rotily et al., 2001).

Further analyses suggest that the prison officers in this study have suboptimal knowledge about HIV transmission modes, HIV prevention, and the nature of the disease. For example, regarding the HIV transmission subscale, most of the officers demonstrated knowledge regarding the most common transmission routes (semen or vaginal fluids, and also blood), but seem to have an incorrect understanding about other casual HIV transmission routes, such as oral transmission and skin penetration routes. Most of them incorrectly believe that saliva and mosquito biting can transmit the virus. These results are quite similar to findings from a study conducted by Dillon and Allwright (2005). This condition may be due to the fact that information about HIV transmission and prevention in Indonesia focuses on promoting condom use and sterile needles (WHO, 2007) but tends not to emphasize details about other casual transmissions such as sharing a toothbrush or kissing. As a result, there are many incorrect beliefs related to HIV transmission modes among the officers.

It can be concluded from the HIV prevention subscale that officers have limited knowledge regarding universal precautions that can protect them from contracting the virus from inmates. They appear to have insufficient knowledge regarding blood-borne infection control policies, guidelines, and practices. For example, half of the officers believe that there is a vaccine that stimulates their immune systems to prevent HIV infection. Thus, they have misconceptions regarding several tools that can prevent HIV infections from occupational exposure within penal settings.

Moreover, the results from the general HIV/AIDS-related knowledge subscale suggest that the officers tend to have an incomplete understanding about the virus and the disease. On the one hand, the majority of them know the nature of the disease but on the other hand, 
many of them still do not know the up-to-date psychological and medical treatment options currently available, such as VCT, MMT, or Antiretroviral therapy (ARV). These findings are quite similar to the results from a previous study that was conducted among factory workers in Indonesia (Sasaki, Andryansyah, Moazzam, \& Kazuhiro, 2011). This lack of knowledge may become an obstacle in promoting VCT, MMT, and ARV in both Indonesian penal institutions and other working settings.

The final objective of this study was to examine a possible knowledge differentiation between the officers who have a more positive attitude towards inmates living with HIV and those who have a more negative attitude. The results demonstrate that the officers who have better understanding about HIV/AIDS tend to have more favorable attitudes towards inmates living with HIV compared to those who have less accurate knowledge.

These findings suggest that providing officers with complete and up-to-date HIV/AIDSrelated information can be useful in assisting them with evaluating their personal risk for contracting HIV from inmates within the penal system. As a result, the officers' attitudes towards inmates living with HIV may improve the living conditions of these prisoners.

The study has a number of limitations. Firstly, the sample size was limited and was restricted to only one Indonesian narcotics prison. Having larger samples from different types of prisons could yield more widely generalizable results and provide a more complete picture of Indonesian prison officers' HIV/AIDS-related knowledge and attitudes. Therefore, a replication of this study among more and different prison types (e.g. general prisons versus narcotics prisons) seems warranted. Secondly, due to the cross sectional nature of the study, no conclusions can be drawn on the causal relation between attitude and knowledge. To assess the causal relation or effect of knowledge on attitude, a further study is required with a different research design, such as a longitudinal study or a randomized controlled trial.

The results of the present study provide detailed information concerning common misconceptions of HIV/AIDS that could be addressed in an educational program. Prison officers have to attend educational programs or workshops regularly and can be stimulated to actively learn about the disease from the most updated resources, such as videos or books. As a consequence, commitment from the prison authorities is also needed. Proper policies, sufficient educational programs as well as the most updated materials need to be made available within the prison. Ideally, this would result in prison officers making a genuine contribution to improving the living circumstances of inmates with HIV in Indonesia. 



\section{CHAPTER 4}

\section{Factors Associated}

with Teachers' Intention to Teach HIV/AIDS-related Topics:

An Application of the Theory of Planned Behavior

Based on: Hinduan, Z. R., Sumintardja, E., Kok, G. J., \& Hospers, H. J. Factors associated with teachers' intention to teach HIV/AIDS-related topics: An application of the theory of planned behavior. Under review. 



\section{Factors Associated with Teachers' Intention to Teach HIV/AIDS-related Topics: An Application of the Theory of Planned Behavior}

\section{Abstract}

Schools in Indonesia have been recognized as a major channel for HIV/AIDS prevention programs. Unfortunately, teachers' commitment to implementing the programs is still varied. The purpose of this study was to apply the Theory of Planned Behavior (TPB) in explaining the variability of teachers' intention to teach Drug Education (DE) and Sexual Reproductive Health (SRH). The results might yield ideas for how to increase their motivation. From 25 junior high schools in Bandung, Indonesia, 316 teachers participated in this cross sectional study by filling in a self-reported questionnaire. All TPB variables significantly correlate with the teachers' intention to teach DE and SRH. The hierarchical regression analysis also shows that attitude and perceived behavioral control are the most salient factors in predicting the target behaviors. There are several internal and external factors that can limit the teachers' motivation to teach these two sensitive topics. Most of the theoretical constructs of TPB have a positive impact on the intention to teach HIV/AIDS-related topics among teachers. Training for teachers and the availability of a comprehensive curriculum are needed to ensure their willingness to teach the topics.

Keywords: teachers, drug education, sexual reproductive health, adolescent

\section{Introduction}

Currently, intravenous drug use (IDU) is a serious threat to the health and well-being of the young generation in Indonesia. It is estimated that in this country there are more than one million intravenous drug users (IDUs) (United Nations Development Programme (UNDP), 2009). A study that involved 210 IDUs in Bandung, one of the cities in Indonesia that is most affected by IDU, showed that most of the IDUs are male (92\%) and that, on average, they had started using substances when they were $14( \pm 3)$ years old. About four years after that, they had started using intravenous substances (Iskandar et al., 2010). This study also found that most of them started to use substances in the schools' canteens or toilets. 
Within the student population, it is very common to share syringes and needles with other students (World Health Organization (WHO), 2005). As a consequence, if a student has a blood borne infection, such as HIV or Hepatitis C, the infection will spread quickly to other students. It is estimated that the prevalence of HIV among IDUs in Bandung Indonesia is as high as 43\% (Joint United Nations Programme on HIV/AIDS (UNAIDS), 2009). There were 3,871 HIV/AIDS cases reported in Bandung by December 2012 (Bandung Municipality, 2008).

In addition to the injecting route, IDUs also put themselves at risk of HIV infection through unprotected sex. Most IDUs have multiple sex partners and many of them often sell sex to finance their drug dependence while some buy sex as well (U.S. Agency for International Development (USAID), 2007). Unfortunately, condom promotion is still controversial in Indonesia, especially when it is targeted at young people. Only $11 \%$ of young people (1519 years old) report that they could get condoms on their own (UNAIDS, 2009). Another study in 2009 mentions that $62 \%$ of young adolescents (age $<25$ years) do not use condoms during sexual intercourse, including during their first sexual intercourse (Statistics Indonesia, 2008; UNAIDS, 2009). As a result many adolescents are at risk of becoming infected with HIV or other STIs or becoming unintentionally pregnant.

In Indonesia, educational sectors, especially public schools, have been recognized as a major channel for HIV/AIDS prevention programs (United Nations Educational, Scientific, and Cultural Organization (UNESCO), 2010; United Nations Children's Fund (UNICEF), 2009). There are several programs that intend to increase the students' knowledge of HIV risk behavior. Papua is the first province in Indonesia that has implemented these prevention programs. These programs have led to an increase in condom use among young adolescents (UNICEF, 2009). However, since in Papua the HIV epidemic is mostly driven by unsafe sex and less by intravenous substance use, the Papua program concentrates on Sexual Reproductive Health (SRH) topics but does not include Drug Education (DE). Thus, for other regions, a new design that modifies the existing SRH curricula is needed, especially for Bandung where the main HIV/AIDS transmission route is through intravenous substance use (UNDP, 2009).

From the socio ecological perspective, health-related behavior is influenced by individual, intrapersonal, organizational, community, societal, and supranational factors. Each factor should be included in health promotion efforts (McLeroy, Bibeau, Steckler, \& Glanz, 1988). The Intervention Mapping protocol, a strategy that helps program planners in making balanced decisions during program development, suggests the importance of recognizing the social environments of a target group during the development and the implementation of a program (Bartholomew, Parcel, Kok, \& Gottlieb, 2011). Students are mainly influenced by familial factors as well as by their school (Reinaerts, de Nooijer, Candel, \& de Vries, 2007). As a result, in promoting healthy behavior for junior high school students, the involvement and commitment of schools - more specifically teachers - is very important in ensuring 
the effectiveness of a school-based intervention. Previous studies have shown that teacher involvement and commitment are positively related to program implementation and the attainment of the program's goals (Orpinas \& Horne, 2004; O'Donnell et al., 1998).

In Indonesia, the involvement of teachers in HIV prevention programs is still limited, due to a lack of awareness of the health problems (including HIV), as well as the shame related to teaching sensitive topics such as drug education and sexual reproductive health education (UNESCO, 2010; UNICEF, 2009). Few teachers in schools are well-trained on SRH topics and they are seldom involved in the program development process from the start. There are also limited resources in schools to get up-to-date information regarding DE and SRH topics. This is also the case in Bandung.

Focus group discussions (FGDs) among teachers were held as a preparation for the present study. The FGDs revealed that the teachers in general felt uneasy about teaching DE and $\mathrm{SRH}$ and tended to omit these "sensitive" subjects from their classes. However, there were also a few teachers who felt confident and were willing to teach these subjects. Majority of the teachers had never been trained on the two topics. According to trained teachers, the available training programs were sporadically organized by non-governmental organizations. The speakers in the training programs were representatives from local health offices and/or police officers. The main objective of these half-day programs was to increase the HIV/AIDS-related knowledge among the teachers. The available trainings might not be intended to increase their skills in facilitating the two topics. The readiness to teach DE and $\mathrm{SRH}$ among those trained teachers was varied among those trained teachers.

To study the variation of teachers' willingness to teach these sensitive topics (conceptually called intention) the Theory of Planned Behavior (TPB) was chosen. The TPB has been shown to be effective in explaining intentions to perform volitional behavior in several contexts such as in the health context (i.e. smoking cessation (Hoie, Moan, Rise, \& Larsen, 2012) and condom use (Potard et al., 2012)), in the ecological context (Chen \& Tung, 2010), in the context of driving behavior (Leandro, 2012), and in the educational context (White, Thomas, Johnston, \& Hyde, 2008). In behavior change research and practice, TPB is the most used and strongest founded theoretical model for predicting a range of behavior (Ajzen, 2011; Armitage \& Conner, 2001). A meta-analysis of 87 TPB studies applied to health behavior reported that TPB accounted for $41 \%$ of the variance in behavioral intentions (Godin \& Kok, 1996) and $44 \%-62 \%$ of the variance in behavior for a broad range of behaviors (Ajzen, 2011). Another meta-analysis indicated that about 30 percent of the variance in behavior can be explained by the combined effect of intention and perceived behavioral control, the two cornerstones of the TPB (Millar \& Shevlin, 2003).

According to TPB, individuals make reasoned behavioral decisions based on their plans or intentions (Godin \& Kok, 1996). There are three components that affect intention: 
(1) attitude towards the behavior; (2) perceived subjective norm (SN); and (3) perceived behavioral control (PBC). Attitude towards the behavior refers to one's evaluation, which can be positive or negative, of behaving in a given way. The SN reflects one's perception of expectations from significant others with regard to adopting a given behavioral trait. The FGDs revealed that for the teachers, both school management and students' parents were their significant people who determined their teaching habits at schools.

The last component, PBC, is related to people's belief that they possess the specialized skills, resources, and opportunities needed to behave in a given way (Ajzen, 2011; Conner \& Armitage, 1998). The latter construct is quite identical to the concept of self-efficacy from Bandura (Conner \& Armitage, 1998; Millar \& Shevlin, 2003). Moreover, several authors place emphasis on the importance of control factors, as part of PBC, that can inhibit the behavior or are known as perceived barriers (Nemme \& White, 2010; Cortoos, Scheurs, Peetermans, DE Witte, \& Gert, 2012). The control factors can be internal factors (i.e. lack of knowledge or facilitating skills) and external factors (i.e. lack of facilities or limited time) for the teachers.

The application of the TPB theory in this study suggests that teachers' intentions to teach DE and SRH is influenced by their attitude towards teaching HIV/AIDS-related topics; their perception of the social expectation of both management and the parents; and their personal belief in how much control they have over teaching these sensitive topics. In general, the more favorable the attitudes, the more influential the subjective norm and the greater the perceived behavioral control, the more likely it is that teachers have an intention to teach HIV/AIDS-related topics in their classroom.

In sum, the purpose of this study was to apply the TPB in explaining intentions to teach DE and SRH among teachers and to identify factors that may explain variability in teachers' intentions to teach $\mathrm{DE}$ and $\mathrm{SRH}$ in order to develop ideas regarding increasing their motivation. This study also compared barriers that were perceived by the trained teachers and the non-trained ones. These perceived barriers may contribute to the intention to teach these HIV/AIDS related topics.

\section{Methods}

\section{Participant Characteristics}

From 25 junior high schools in five different educational districts in Bandung, West Java, Indonesia, 360 teachers were recruited. They were junior high school teachers who were responsible for teaching physical education, religion, civic and citizenship education, and biology. These subjects might generally address HIV/AIDS-related topics for junior high school students. Teachers who were involved in school health unit and in guidance and counseling were also included since they were expected to share HIV/AIDS related topics in schools. 


\section{Procedure}

In the city of Bandung, there are five different geographical areas. Several schools, that were categorized as high and low achievement schools in each area, were selected. To obtain a representative sample, all related teachers from the selected schools were invited to join this study. Research assistants visited the schools and asked the teachers to participate in the study. Teachers who agreed to participate were invited to come to a teacher's room where they received a questionnaire in an envelope. The teachers first received general information about the study from the assistants, after which they were asked to sign the informed consent form. Only those who consented participated in this study. Anonymity was guaranteed. Data collection was conducted between May and June 2009. Standing Committee on Ethics in Health Research of the Faculty of Medicine, Padjadjaran University - Hasan Sadikin Hospital Bandung had approved this study.

\section{Measures}

Before the quantitative data collection was performed on all participants, the preliminary FGDs among selected teachers had been conducted. From the discussions, several common factors were revealed. The questionnaire, then, was developed based on the results of these FGDs.

1. Demographic information (i.e. age, gender and educational level).

2. Intention to teach $D E$ and $S R H$. Respondents were asked to rate their intention to teach SRH related topics (2 questions) and their intention to teach DE (3 questions). A sample item was "I plan to teach about the risks of teenage pregnancy". The response format for the scale was a 6-point Likert scale, ranging from $1=$ strongly disagree to $6=$ strongly agree. The correlation between the SRH items was .83 and the internal consistency of the DE scale was .68. A higher score on this scale indicated a higher intention to teach HIV/AIDS related topics.

3. Attitude toward teaching $S R H$ and DE. This scale measured teachers' personal attitudinal beliefs in teaching both SRH-related topics (5 items) and DE (4 items). A sample item was "I think it is valuable to describe the health risks of teenage pregnancy". The response format for the scale was a 6-point Likert scale, ranging from $1=$ strongly disagree to $6=$ strongly agree. The reliabilities were high for both $\mathrm{SRH}$ and DE subscale (.76 and .74, respectively). Higher scores on this scale indicated a more favorable attitude towards teaching HIV/AIDS related topics

4. Subjective norm. The preliminary FGDs revealed that students' parents and school management were the significant people for teachers in teaching the two topics. This scale asked teachers to judge whether or not the significant others would want them to teach SRH (5 questions) and DE (4 questions). A sample item was "The parents of my 
students think that I should provide information regarding sexuality for the students". The response format for the scale was a 6-point Likert scale, ranging from $1=$ strongly disagree to $6=$ strongly agree. Chronbach's as were .77 and .80 for the SRH subscale and DE subscale, respectively.

5. Perceived behavioral control. In this scale, teachers were asked to rate their perception of the extent to which they were able to teach SRH (5 questions) and DE (4 questions). A sample item was "I think I am capable ofteaching drug related topics". The response format for the scale was a 6-point Likert scale, ranging from $1=$ strongly disagree to $6=$ strongly agree. The internal consistency reliability coefficient for the SRH subscale was .81 and for DE subscale was .86. A higher score on this scale represented a higher degree of perceived behavioral control.

6. Perceived Barriers. In this scale, both internal factors (5 questions) and external factors (4 questions) that hindered the teachers from teaching DE and SRH were asked. A sample item was "What is the probability that limited time will make your teaching less effective if you have to teach Sexual Reproductive Health to your students?" The response format for the scale was a 6-point Likert scale, ranging from 1 indicating highly unlikely and 6 indicating highly likely. The internal consistency coefficient for the SRH subscale was .89 and for DE subscale was .87. A higher score indicated the more recognition by the respondents of the selected barriers.

Naturally, all questions were posed in the Indonesian language. However, for the purpose of this article the questions were translated into English by a professional translator. Next, another professional translator translated the English questions back to the Indonesian language, which were then checked by the research team to ensure there was no loss of meaning or inadequate translations.

\section{Statistical Analysis}

Data were analyzed using SPSS version 17. Bivariate and regression analyses were computed. A hierarchical regression analysis was performed on the intention to teach DE and SRH. Finally, independent sample t-tests were conducted to compare the differences in mean score of perceived barriers among trained and non-trained teachers.

\section{Results}

\section{Sociodemographic Data}

From 25 schools in Bandung, 316 teachers completed the questionnaire. Teachers' mean age was 41.55 years (range: 19-62 years, SD =9.12). The mean duration of working (as a teacher) was 16.32 years (range: $1-41$ years, $S D=8.74$ ). Slightly more than half of respondents were 
female teachers. Most teachers had a bachelor degree and a teaching certificate. The percentage of biology teachers, physical education teachers, civic and citizenship teachers, and religion teachers were $31.65 \%, 14.24 \%, 16.46 \%$ and $19.30 \%$, respectively. The remainders taught other subjects but, in addition, they participated in the school health unit or in the guidance and counseling unit. Only $31.01 \%$ of them had attended training related to these issues.

\section{Descriptive Statistics}

Table 1 and 2 presents the means, standard deviations, and inter-correlations among study variables. The reliability estimates for all scales were above .70, except for intention to teach DE (.68). In general, the teachers had a relatively high intention to teach DE (Table 1). Moreover, all study variables (attitude, subjective norm [parents and school management], and perceived behavioral control), except the perceived barriers (external factors) had substantial correlations with the teachers' intention to teach DE to their students. Both subjective norms (parents and school management) had a strong relationship with teachers' attitude toward teaching $D E(r=.82$ and $r=.68$, respectively). The two subjective norm measures were also highly correlated $(r=.75)$. The educational level had no significant association with all TPB variables, except with perceived behavioral control to teach DE. Finally, perceived barriers (external factors) had significant correlations with attitude, subjective norm (parents), and perceived behavioral control.

Table 1 : Descriptive Statistics for Teaching Drug Education ( $N=316)$

\begin{tabular}{|c|c|c|c|c|c|c|c|c|c|c|}
\hline Variables & M & SD & Range & 1 & 2 & 3 & 4 & 5 & 6 & 7 \\
\hline \multicolumn{11}{|l|}{ Control Variable } \\
\hline 1. Educational level & .88 & .40 & $0-2$ & - & & & & & & \\
\hline \multicolumn{11}{|l|}{ Dependent Variable } \\
\hline 2. Intention to teach $\mathrm{DE}$ & 15.41 & 2.31 & $3-18$ & .04 & - & & & & & \\
\hline \multicolumn{11}{|l|}{ Independent Variable } \\
\hline $\begin{array}{l}\text { 3. Attitude toward } \\
\text { teaching DE }\end{array}$ & 21.19 & 2.77 & $4-24$ & .12 & $.56^{* *}$ & - & & & & \\
\hline $\begin{array}{l}\text { 4. Subjective norm } \\
\text { (parents) }\end{array}$ & 21.02 & 2.90 & $4-24$ & .08 & $.53^{* *}$ & $.82^{* *}$ & - & & & \\
\hline $\begin{array}{l}\text { 5. Subjective norm } \\
\text { (school management) }\end{array}$ & 21.12 & 2.68 & $4-24$ & .09 & $.43^{* *}$ & $.68^{* *}$ & $.75^{* *}$ & - & & \\
\hline $\begin{array}{l}\text { 6. Perceived behavioral } \\
\text { control }\end{array}$ & 18.73 & 3.06 & $4-24$ & $.16^{* *}$ & $.32^{* *}$ & $.31^{* * *}$ & $.30^{* *}$ & $.38^{* *}$ & - & \\
\hline $\begin{array}{l}\text { 7. Perceived barriers } \\
\text { (External Factors) }\end{array}$ & 13.64 & 4.94 & $4-24$ & .03 & .08 & $.12^{*}$ & $.13^{*}$ & .09 & $.12^{*}$ & - \\
\hline
\end{tabular}

Note. ${ }^{*} p<.05 \quad * * p<.01$ 
Similar to the DE description, in general teachers also had a relatively high intention to teach SRH (Table 2). In addition, all TPB variables had substantial correlations with the teachers' intention to teach SRH (ranging from $r=.41$ to $r=.58$ ), except for perceived barriers (external factors). Both subjective norms were highly intercorrelated $(r=.72)$. Educational level had a significant relationship with attitude and perceived behavioral control. Perceived barriers had no significant correlation with other variables.

Table 2 : Descriptive Statistics for Teaching Sexual Reproductive Health $(N=316)$

\begin{tabular}{|c|c|c|c|c|c|c|c|c|c|c|}
\hline Variables & M & SD & Range & 1 & 2 & 3 & 4 & 5 & 6 & 7 \\
\hline \multicolumn{11}{|l|}{ Control Variable } \\
\hline 1. Educational level & .88 & .40 & $0-2$ & - & & & & & & \\
\hline \multicolumn{11}{|l|}{ Dependent Variable } \\
\hline $\begin{array}{l}\text { 2. Intention to teach SRH } \\
\text { effectively }\end{array}$ & 9.92 & 1.94 & $2-12$ & .08 & - & & & & & \\
\hline \multicolumn{11}{|l|}{ Independent Variable } \\
\hline $\begin{array}{l}\text { 3. Attitude toward } \\
\text { teaching SRH }\end{array}$ & 23.68 & 4.10 & $5-30$ & $.12^{*}$ & $.58^{* *}$ & - & & & & \\
\hline $\begin{array}{l}\text { 4. Subjective norm } \\
\text { (parents) }\end{array}$ & 23.34 & 4.15 & $5-30$ & .06 & $.50^{* *}$ & $.81^{* *}$ & - & & & \\
\hline $\begin{array}{l}\text { 5. Subjective norm } \\
\text { (school management) }\end{array}$ & 23.74 & 4.06 & $5-30$ & .09 & $.41^{* *}$ & $.71^{* *}$ & $.72^{* *}$ & - & & \\
\hline $\begin{array}{l}\text { 6. Perceived behavioral } \\
\text { control }\end{array}$ & 17.83 & 3.39 & $5-24$ & $.17^{* *}$ & $.48^{* *}$ & $.50^{* *}$ & $.44^{* *}$ & $.52^{* *}$ & - & \\
\hline 7. Perceived barriers & 14.90 & 5.24 & $5-24$ & .01 & -.01 & -.04 & -.01 & .00 & .03 & - \\
\hline
\end{tabular}

Note. ${ }^{*} p<.05 \quad * * p<.01$

\section{Factors related to the Intention to Teach DE and SRH}

Beside the correlational analyses, two hierarchical regression analyses were conducted to examine the effect of the attitude, subjective norm (parents), subjective norm (school management) and perceived behavioral control on teachers' intention to teach DE and SRH. In these regression analyses, the predictors from the TPB were entered in Step 1 and the educational level and perceived barriers (external barriers) were entered in Step 2. Since the correlations between predictors were high, collinearity diagnostics were run. However, no significant multicollinearity was detected. 
According to Table 3, the TPB variables (attitude, SN school management, SN parents, and PBC), when considered together, significantly predicted the teachers' intention to teach DE after controlling educational level and perceived barriers. The percentage of explained variance was $36 \%$ with attitude as the most salient variable $(\beta=.37, p<.01)$. The addition of educational level and perceived barriers (external factors) insignificantly improved the model's predictive power.

\section{Table 3 : Summary of Correlation and Hierarchical Regression for Variables Predicting Intention to Teach Drug Education $(N=316)$}

\begin{tabular}{l|c|c}
\hline \multicolumn{1}{c|}{ Variables } & R & Beta \\
\hline Step 1 & $.56^{* *}$ & $.37^{* *}$ \\
\hline Attitude & $.53^{* *}$ & $.21^{*}$ \\
\hline Subjective Norm (Parents) & $.43^{* *}$ & -.04 \\
\hline Subjective Norm (School Management) & $.32^{* *}$ & $.16^{* *}$ \\
\hline Perceived Behavioral Control & & .36 \\
\hline$R^{2}$ & .08 & -.01 \\
\hline Step 2 & .04 & -.04 \\
\hline Perceived Barrier (External Factors) & & .36 \\
\hline Educational Level & & \\
\hline$R^{2}$ &
\end{tabular}

Note. $* p<.05 \quad * * p<.01$

The hierarchical regression analysis (Table 4) showed that attitude was the most salient variable in predicting the intention to teach SRH $(\beta=.44, \mathrm{p}<.01)$, followed by perceived behavioral control $(\beta=.28, p<.01)$. There was no evidence for additional significant effect of both the control variable and perceived barriers (external factors). The final solution explained 39 percent of the variability in teachers' intention to teach SRH. 
Table 4 : Summary of Hierarchical Regression for Variables Predicting Intention to Teach Sexual Reproductive Health $(N=316)$

\begin{tabular}{l|c|c}
\hline \multicolumn{1}{c|}{ Variables } & R & Beta \\
\hline Step 1 & $.58^{* *}$ & $.43^{* *}$ \\
\hline Attitude & $.50^{* *}$ & .10 \\
\hline Subjective Norm (Parents) & $.41^{* *}$ & -.11 \\
\hline Subjective Norm (School Management) & $.48^{* *}$ & $.28^{* *}$ \\
\hline Perceived Behavioral Control & & .39 \\
\hline $\mathrm{R}^{2}$ & & .02 \\
\hline Step 2 & .01 & .02 \\
\hline Perceived Barrier (External Factors) & .08 & .39 \\
\hline Educational Level & & \\
\hline $\mathrm{R}^{2}$ & & \\
\hline
\end{tabular}

Note. ${ }^{*} p<.05 \quad * * p<.01$

\section{Barriers in Teaching}

We also investigated perceived barriers in teaching both DE and SRH among the trained and non trained teachers. Both internal factors (limited knowledge, uncomfortable feelings, etc.) and external factors (limited time, no final exam, etc.) were included. Table 5 displays the mean scores broken down by training experience.

The fact that there were no final exams for these HIV/AIDS related topics was perceived as a main barrier in teaching DE by the non trained teachers but not by the trained teachers $(p$ $<$.01). The same holds for limited time and knowledge as well as not being included in the curriculum. The non trained teachers tended to perceive these factors as barriers in teaching DE while the trained teachers did not perceive them as barriers $(p<.05)$. Furthermore, the non trained teachers perceived some internal factors (limited skills and knowledge) as well as external factors (limited time and facilities) as barriers to teaching SRH. 
Table 5 : Perceived Barriers based on Teachers' Training Experiences in Drug Education and Sexual Reproductive Health $(N=316)$

\begin{tabular}{|c|c|c|c|c|c|c|c|c|}
\hline & \multicolumn{4}{|c|}{ Drug Education } & \multicolumn{4}{|c|}{ Sexual Reproductive Health } \\
\hline & \multicolumn{3}{|c|}{ Mean Scores } & \multirow[b]{2}{*}{$\begin{array}{c}\mathbf{p} \\
\text { value }\end{array}$} & \multicolumn{3}{|c|}{ Mean Scores } & \multirow[b]{2}{*}{$\begin{array}{c}\mathbf{p} \\
\text { value }\end{array}$} \\
\hline & $\begin{array}{c}\text { With } \\
\text { Training } \\
(\mathbf{n}=97)\end{array}$ & $\begin{array}{l}\text { Without } \\
\text { Training } \\
(n=219)\end{array}$ & $\begin{array}{c}\text { Overall } \\
\text { Mean } \\
\text { Score }\end{array}$ & & $\begin{array}{c}\text { With } \\
\text { Training } \\
(n=55)\end{array}$ & $\begin{array}{l}\text { Without } \\
\text { Training } \\
(n=261)\end{array}$ & $\begin{array}{c}\text { Overall } \\
\text { Mean } \\
\text { Score }\end{array}$ & \\
\hline $\begin{array}{l}\text { Limited } \\
\text { knowledge }\end{array}$ & 3.06 & 3.47 & 3.34 & * & 3.38 & 3.93 & 3.83 & * \\
\hline Limited skills & 3.16 & 3.44 & 3.36 & ns & 3.29 & 3.83 & 3.74 & * \\
\hline $\begin{array}{l}\text { Afraid of difficult } \\
\text { questions }\end{array}$ & 3.43 & 3.53 & 3.50 & ns & 3.24 & 3.51 & 3.47 & ns \\
\hline $\begin{array}{l}\text { Uncomfortable } \\
\text { feeling }\end{array}$ & 3.74 & 3.50 & 3.58 & ns & 3.51 & 3.69 & 3.66 & ns \\
\hline $\begin{array}{l}\text { Afraid of } \\
\text { unwanted } \\
\text { responses }\end{array}$ & 3.01 & 3.38 & 3.27 & ns & 3.64 & 3.77 & 3.75 & ns \\
\hline Limited time & 3.20 & 3.63 & 3.50 & * & 3.36 & 3.89 & 3.80 & * \\
\hline $\begin{array}{l}\text { Not Included in } \\
\text { the curriculum }\end{array}$ & 3.06 & 3.49 & 3.36 & * & 3.31 & 3.72 & 3.65 & ns \\
\hline Limited facilities & 3.29 & 3.53 & 3.46 & ns & 3.18 & 3.98 & 3.84 & $* *$ \\
\hline $\begin{array}{l}\text { Not included in } \\
\text { final exam }\end{array}$ & 2.98 & 3.61 & 3.42 & $* *$ & 3.35 & 3.74 & 3.67 & ns \\
\hline
\end{tabular}

$* p<.05 * * p<.01$ (Range of the scores $=1-6$ )

\section{Discussion}

This study investigated the use of the Theory of Planned Behavior in predicting teachers' intentions to teach DE and SRH in their classes. In line with the theory, results from the univariate analyses show that there are significant correlations of all theoretical constructs with the behavioral intention to teach the two subjects as shown in Table 2 and 3. These results indicate that in comparison to teachers with lower intention, teachers with higher intentions have more favorable attitudes towards teaching HIV/AIDS-related topics, perceive stronger social influence from both the students' parents and the school managements to do so and are more likely to believe that they have control over the these teaching responsibilities. 
Although all TPB variables make significant contributions to the prediction of the behavior, further analysis shows that the attitude towards teaching $\mathrm{DH}$ and towards teaching SRH are the strongest predictors of the intention to teach the subjects. These results suggest that the teachers' evaluations of the instrumental/practical outcomes (i.e. useful, harmful) and affective outcomes (i.e. interesting, uncomfortable) in teaching these two topics dominate the teachers' intention to teach (Ajzen, 2011; Ajzen, 2001). The more favorable the evaluation from the teachers of the outcomes of the behavior, the stronger their intention to behave in the targeted way.

Besides attitude, the perceived behavioral control also significantly predicts the teachers' intentions to teach $\mathrm{DE}$ and $\mathrm{SRH}$. It means that the teachers intend to be engaged in teaching those topics that they feel they are capable of teaching (Ajzen, 2002). Finally, although SN (both parents and school management) appears to be less strong than the two other TPB variables in predicting the intention, $\mathrm{SN}$ still has positive correlations with intention to teach $\mathrm{DE}$ and $\mathrm{SRH}$. This condition suggests that the social influence from parents and school management is also important in increasing teachers' intention teach the topics in their classes. Furthermore, all TPB variables predict $36 \%$ and $39 \%$ of the variance in the intention to teach $\mathrm{DE}$ and $\mathrm{SRH}$, respectively.

As mentioned before, this study also characterized several internal and external factors that can hinder the teachers from teaching HIV/AIDS-related topics. Several results can be discussed from these measurements. First of all, perceived barriers do not predict teachers' intention to teach $\mathrm{DE}$ and SRH. One possible explanation is that it is very difficult for individuals to assess actual barriers that can hinder or facilitate them to perform a certain behavior in advance (Ajzen, 1986). Most teachers had no experience in teaching a comprehensive DE and SRH in their schools and only about $31 \%$ of them had participated in DE- and SRH-related training at the time we collected the data. They may not be familiar with the future challenges and benefits of teaching the topics to the students. As a result, their ability to validly recognize and assess the actual barriers to teaching DE and SRH (both external and internal) in the future may be quite limited.

Secondly, the trained teachers seem to be more ready to teach SRH. They tend to see themselves as having the basic skills and knowledge needed to teach these sensitive topics, while non trained teachers may not have those basic skills and knowledge. For this reason, non trained teachers require additional training, time, and facilities to be able to teach SRH in their classes. Thirdly, both trained and non trained teachers also perceive that it is important for the school management to include the SRH as a part of their official school curriculum.

Furthermore, the teachers are also afraid of unwanted responses from their students. This is reasonable, since 13-year-old to 15-year-old students are often associated with sensation 
seeking (Mahalik et al., 2013; Rivis, Sheeran, \& Armitage, 2011). This sensation seeking may lead to the initiation of some risky behavior such as substance use, violence, or early sexual intercourse. SRH is also a broad topic. It covers the reproductive organs, sexually transmitted diseases, condom use, dating and relationships, sexual orientation, sexual activities, etc (Askelson et al., 2011). The teachers are afraid that those broad topics may stimulate the students to initiate risky sexual behavior. This fear is not evidence-based. Many previous studies found that the SRH does not increase the sexual activities among young people (Kohler, Manhart, \& Lafferty, 2008; Kirby, 2002).

Finally, compared to the trained teachers, the non trained teachers tend to perceive several factors, such as limited time, not being included in current curriculum, and no final exam as the external barriers to teaching DE. They also perceive their limited/out-of-dated knowledge as a personal factor that can hinder them from teaching the DE topics in their classes.

This study has several limitations, particularly: (1) the cross sectional design that was employed limits the possibility to establish a causal relationship between the three beliefs and the intentions; (2) the use of a self-report questionnaire might encourage the respondents to present themselves in a socially desirable manner; and (3) a limited sample size of teachers in each subject. Having larger samples for each subject can enrich the discussion as well as providing a more complete picture of the specific possibilities and problems faced by the teachers in teaching DE and SRH. Therefore, in future studies, a replication on a larger number of teachers in each subject seems warranted.

Even though there are several limitations in this study, it can be concluded that all theoretical constructs of the Theory of Planned Behavior have a positive impact to the intention to teach SRH and DE among teachers of junior high schools. This study also provides detailed information regarding several internal and external factors that are perceived by teachers as barriers in teaching DE and SRH.

The implication of this study is that training experiences that may change teachers' evaluations of the effects of teaching DE and SRH may positively influence the teachers' desire to teach these sensitive topics. The training should also improve their skills and update their knowledge. Moreover, in addition to those personal factors there are also several environmental factors that need to be addressed by relevant stakeholders, such as integrating the two HIV/AIDS-related topics into the curriculum. This kind of curriculum needs to allocate enough time and also needs be included in the final exam, so that the teachers can evaluate their students' progress. Participation from the school management and students' parents is also needed since the teachers are also concerned about their opinions. 



\section{CHAPTER 5}

\section{Development of a School-based Drug Education Program in Indonesia}

Based on: Hinduan, Z. R., Riyanti, E., Kok, G. J., \& Hospers, H. J. Development of a schoolbased drug education program in Indonesia. Under review. 



\section{Development of a School-based Drug Education Program in Indonesia}

\section{Abstract}

To describe the systematic development of a school-based intervention program that aims to prevent the initiation of substance use among secondary school students in Indonesia, the Intervention Mapping (IM) framework was used. The six steps of the framework were conducted in developing the prevention program. In each IM step, the participation of the students as well as their significant others was needed to ensure that the program would be suitable for the local context and to ensure the commitment of all stakeholders in implementing the program. Applying Theory of Planned Behavior as a basic behavioral theory, this program aimed to increase the knowledge, attitudes, perceived behavioral control, and subjective norms of the students. The IM framework guides the development, implementation, and evaluation of a school-based drug education program in a systematic way by applying theory, evidence and additional research. Important and changeable sociocognitive determinants of substance-free behavior among the students are targeted in this intervention program. The IM framework helps to identify significant cognitive and social aspects that need to be considered in developing an intervention program in Indonesia.An active participation of relevant stakeholders and a proper policy are needed. In the future, it might be feasible to select teaching methods that are easy to implement but effective in affecting determinants needed to change the students' behavior.

Keywords: drug education, schools, Intervention Mapping, adolescent, Indonesia

\section{Introduction}

The use of tobacco, alcohol, and other substances is common among young people in Indonesia. The initiation of substance use among adolescents in this country begins at an early age. A survey performed on 4.635 students (13-15 years old) reported that almost $40 \%$ of the students used tobacco and approximately $30 \%$ of them started using tobacco before the age of 10 (Aditama et al., 2008). A study in Bandung revealed that most young people used their first substances in their schools' toilets or canteens (Iskandar et al., 2010). 
Public schools have been considered a strategic setting for drug education programs for young people in this country (MacDonald et al., 2011; United Nations Educational, Scientific, and Cultural Organization (UNESCO), 2010). However, a survey on 3,319 Indonesian students in 2009 showed that only half of them had been exposed to drugs-related information in their schools (World Health Organization (WHO), 2009). Moreover, the available programs focus only on increasing students' knowledge of the effects and consequences of substance use (UNESCO, 2010; WHO, 2009). In-depth interviews with teachers in several public schools in Bandung, which were conducted prior to the program development reported on in this paper, showed that usually drug-related facts were only communicated, mostly by police officers, in the introductory week of $7^{\text {th }}$ grade, or were sporadically embedded in other subjects such as biology, physical education, or religion.

The available programs in Indonesia have several limitations. First, the information-only approach is unlikely to change students' behavior, as an effective drug education program should also address life skills, attitude development, awareness, and assertiveness regarding social influences (Bohman et al., 2004; Stead et al., 2010). Second, the available programs might have involved discussions between students and teachers or police officers but the interaction among students themselves is limited. According to a previous meta-analysis, this approach is less effective in developing appropriate attitudes and refusal skills (i.e. assertive communication and negotiation skills) of the students (Tobler et al., 2000). Third, the delivery agents of the available programs might not be suitable in facilitating the program. Trained teachers and/or peer educators might produce larger effects on the students' behavior than untrained facilitators (Gottfredson \& Wilson, 2003).

Thus, the limited effectiveness of the available school-based drug education programs in Bandung schools has formed the basis for developing a new, rights-based and participatory curriculum. The aim of the present paper is to describe the development and implementation of a school-based drug education program in Bandung, West Java, Indonesia

\section{The Intervention Mapping}

Reviews of reviews have suggested that there are several characteristics of effective (school) prevention programs, such as being theory and evidence-based; integrating local norms and beliefs; using multiple teaching methods; having trained program implementers and targeting both individuals and their environment (Nation et al., 2003; Peters, Kok, Ten Dam, Buijs, \& Pauulussen, 2009). By developing an effective prevention program that addresses cognitive and behavioral skills of the students, it might be expected that in the future those students can apply those skills to prevent risky behavior such as using intravenous substances or engaging in unsafe sexual interourse (Peters et al., 2009). In order to address the effectiveness criteria described above, the Intervention Mapping (IM) framework was chosen. 
Figure 1 : Intervention Mapping Steps and Tasks

\begin{tabular}{|c|c|c|}
\hline \multirow{7}{*}{ Evaluation } & $\begin{array}{l}\text { Step } 1 \\
\text { Need Assessment }\end{array}$ & $\begin{array}{l}\text { Establish a participatory planning group } \\
\text { Conduct a need analysis } \\
\text { Assess community capacity } \\
\text { Specify program goals for health and quality of life }\end{array}$ \\
\hline & $\begin{array}{l}\text { Step } 2 \\
\text { Matrices }\end{array}$ & $\begin{array}{l}\text { State outcomes for behavior and environmental change } \\
\text { State performance objectives } \\
\text { Select important and changeable determinants } \\
\text { Create a matrix of change objectives }\end{array}$ \\
\hline & $\begin{array}{l}\text { Step } 3 \\
\text { Theory-based } \\
\text { intervention methods } \\
\text { and practical } \\
\text { application }\end{array}$ & $\begin{array}{l}\text { Generate program ideas with the planning group } \\
\text { Identify theoretical methods } \\
\text { Choose program methods } \\
\text { Select or design practical applications } \\
\text { Ensure that applications address change objectives }\end{array}$ \\
\hline & $\begin{array}{l}\text { Step } 4 \\
\text { Intervention Program }\end{array}$ & $\begin{array}{l}\text { Consult intended participants and implementers } \\
\text { Create program themes, scope, sequence, and materials } \\
\text { list } \\
\text { Prepare design documents } \\
\text { Review available program materials } \\
\text { Draft program materials and protocols } \\
\text { Pretest program materials and protocols } \\
\text { Produce materials and protocols }\end{array}$ \\
\hline & $\begin{array}{l}\text { Step } 5 \\
\text { Adoption and } \\
\text { Implementation }\end{array}$ & $\begin{array}{l}\text { Identify potential adopters and implementers } \\
\text { Reevaluate the planning group } \\
\text { State program use outcomes and performance } \\
\text { objectives } \\
\text { Specify determinants for adoption and implementation } \\
\text { Create a matrix of change objectives } \\
\text { Select methods and practical applications } \\
\text { Design interventions for adoption and implementation }\end{array}$ \\
\hline & $\begin{array}{l}\text { Step } 6 \\
\text { Evaluation Plan }\end{array}$ & $\begin{array}{l}\text { Review the program logic model } \\
\text { Write effect evaluation questions } \\
\text { Write evaluation questions for changes in the } \\
\text { determinants } \\
\text { Write process evaluation questions } \\
\text { Develop indicators and measures } \\
\text { Specify evaluation design }\end{array}$ \\
\hline & & \\
\hline
\end{tabular}

(Source: Bartholomew, Parcel, Kok, Gottlieb, \& Fernadez, 2011) 
IM is a comprehensive framework for planning, developing, implementing, and evaluating a theory and evidence-based health promotion program (Bartholomew, Parcel, Kok, Gottlieb, \&Fernadez, 2011). The IM framework provides six systematic steps (see Figure 1). Each step has several tasks that need to be accomplished by health promotion officers (HPOs). IM also acknowledges the importance of the social environment of a target group during the development and the implementation of a program. IM has been applied in the development of various health-related programs, such as in a school-based smoking cessation program (Dalum, Schaalma, \& Kok, 2012), a computer-based safer injection program for drug users (IDUs) (Gagnon, Godin, Alary, Bruneau, \& Otis, 2010), and a school-based sexual reproductive health program (Mkumbo et al., 2009).

\section{Methods}

\section{Step 1: Need Assessment}

The aim of our need assessment was to identify the relevant personal and environmental factors influencing substance use related behavior among young people in Bandung. The respondents of our need assessment were the students, the teachers, and other relevant stakeholders (the parent's associations, the schools' management, the officials from the local education office, Board of Narcotics, the local heath office, the youth centre, the AIDS Commission, and other related non-governmental organizations (NGOs)). Although in Indonesia there are five recognized religions (Islam, Catholicism, Protestantism, Buddhism, and Hinduism), Bandung is considered one of the most dominant Islamic areas in Indonesia (Bianchi, 2004). As a result, Islamic religious leaders were also invited to the meetings in order to ensure that the intended program would be socio-culturally relevant (Nation et al., 2003; Peters et al., 2009).

Several methods were employed in this phase. Based on the initial review of the literature, several focus group discussions (FGDs) among the students and the teachers were also conducted. Results from those two methods were used as a foundation in developing a selfreported questionnaire for the teachers. Parallel, in-depth interviews with school managers and officials from the local educational office were also conducted to explore environmental factors that affected the initiation of substance use among the students, followed by a stakeholder meeting with other stakeholders. Finally, a meeting with the Mayor of the City of Bandung, the Head of the Local Educational Office (as a policy maker for all public schools in Bandung), and the Head of the Bandung AIDS Commission was held in order to get their commitment and input in developing the program.

The Theory of Planned Behavior (TPB) was used as the main etiological theory that guides the discussions. The TPB has shown to be effective in explaining intentions to perform 
volitional behavior in several contexts, including in smoking cessation (Hoie, Moan, Risem, \& Larsen, 2012) and the TPB variables accounted for $41 \%$ of the variance in behavioral intentions (Armitage \& Connor, 2001). According to this theory, individuals make behavioral decisions based on their conscious plans/intentions (Ajzen, 1991). There are three components that determine intention, namely attitudes towards the behavior, subjective norm, and perceived behavioral control.

From five junior high schools in five different educational districts in Bandung, 93 students were recruited randomly to participate in the FGDs. Six FGDs were conducted with boys only groups and six with girls only groups. These gender-based FGDs were intended to ensure that the girls would also actively participate in the discussions. The participation in the discussion was voluntary. In this discussion several issues were explored, such as substance use-related knowledge, outcome evaluation of using illicit substances, social influences, and factors that hinder and support the students in using substances.

Then, two FGDs were conducted with six teachers participating in each group. The respondents were responsible for teaching Physical education, Religious education, Science, Civics and Citizenship, Guidance and Counseling, and also School Health Units. These teachers were expected to teach drug-related topics in their schools. All of them worked in the same schools. To get more comprehensive data of the teachers from other schools, a self-reported questionnaire was developed. The topics in the questionnaire were based on the results of the FGDs. Teachers from 25 public schools of the five different educational districts in Bandung were invited to fill out the questionnaire that assessed the factors that determine their drug education-related teaching in their classes. In this survey, 314 teachers participated voluntarily.

\section{Step 2: Matrices}

After determining the behavioral and environmental outcomes based on the results from the previous step, it is important to subdivide the outcomes into specific performance objectives (POs) for each behavioral and environmental outcome, using theories and evidence. The aims of determining the individual POs are, in this case to identify the expected performances of the students who participate in the program, as well as to assess whether the expected performances are suitable for the targeted group. Several crucial principles from the Theories on Coping (Lazarus, 1993), Theories of Self-regulation (Lazarus \& Folkman, 1991; Thorensen \& Kirmil-Gray, 1983), and The Relapse Prevention Theory (Marlatt \& Gordon, 1985) were applied to determine several essential sub parts of the behavior of our targeted outcomes. Furthermore, the aims of determining the environmental performance objectives are to select the significant agents who have to contribute in modifying the environments of students as well as to identify targeted actions for these agents. 
Then, important and changeable determinants of each outcome need to be selected. Determinants are individual factors that are associated with the performance of the students' and the environmental agents' behavior. The list of determinants was derived from TPB variables. These determinants, in combination with the POs, are referred to as the change objectives (COs) that would be influenced by the intervention. The evidence from the initial need assessment and relevant empirical studies was used to establish their importance (the strength of the association) and relevant theories were used to determine the level of changeability. The final task in this step is to create a comprehensive matrix of COs (Bartholomew et al., 2011). This matrix not only serves to define objectives for the program but also to later evaluate the effectiveness of the program.

\section{Step 3: Theory-based Intervention Methods and Practical Applications}

In this program some basic methods were applied to change the students' drug-related behavior. First, methods of active learning and participation were used. Contrary to lecturing, which is the most popular teaching method in Indonesia, these two teaching methods assure that students will be highly engaged in their classes and will learn from their experiences in doing these activities. Then, the method of modeling was also adopted in this program, expecting that students could learn desired actions from an appropriate model. Modeling was primarily employed to improve skills and self-efficacy (Bartholomew et al., 2011).

Feedback and reinforcement/disapproval were also adopted in this program. These two methods provide the students with information regarding the extent to which they accomplish the activities as well as reinforcement or disapproval to promote or discourage selected behaviors (Bartholomew et al., 2011). Fear arousal methods were left out of this program. According to the literature, threatening information is not effective in changing students' behavior (Paglia \& Robin, 1999) because it may lead to defensive behavior, except when the self-efficacy of the students is high (Peters, Ruiter, \& Kok, 2012).

\section{Step 4: Intervention Program}

This step started with consultations with all relevant stakeholders. Then, workshops for program developers were conducted. In these workshops, a logical sequence was discussed, as well as the timing, content, teaching tools, and program themes of the curriculum, so that these would be suitable for the students and user-friendly for teachers. Another workshop was conducted with teachers and students to get feedback as well as to try out the proposed program. In this workshop, the graphic designers were also invited. They worked together with the students to design the characters for the program (Bartholomew et al., 2011). 


\section{Step 5: Adoption and Implementation}

The main goal of this phase is to ensure complete implementation with fidelity toward the intended methods, as well as sustainability of the program. Several activities were conducted to ensure the sustainability of the program implementation in public schools in Bandung. The partnership with relevant stakeholders from the beginning of the program's development provided an opportunity to develop their sense of ownership of the program.

\section{Step 6: Evaluation Plan}

Table 1 shows the evaluation plan for the intended program. The evaluation methods would be direct observations, in-depth interviews, and a self-reported questionnaire. Both teachers and students would be actively involved in the evaluation process. Relevant feedback from them would be included in the revisions of the program. In the impact evaluation, only a post-test of the baseline and short term effects would be measured. The HPOs and representatives from the youth center would do the daily monitoring in the pilot schools.

\section{Table 1 : Evaluation Process}

\begin{tabular}{|c|c|c|c|c|}
\hline Type & $\begin{array}{c}\text { Measurement } \\
\text { Tools }\end{array}$ & Sources & Objectives & Timing \\
\hline \multirow{3}{*}{$\begin{array}{l}\text { Process: } \\
\text { from the } \\
\text { implementers } \\
\text { of the } \\
\text { program: the } \\
\text { teachers and } \\
\text { the students }\end{array}$} & $\begin{array}{l}\text { Direct } \\
\text { observation }\end{array}$ & $\begin{array}{l}\text { Selected classes } \\
\text { (30\% of the classes) }\end{array}$ & $\begin{array}{l}\text { To monitor the } \\
\text { learning processes } \\
\text { (time, flow, etc.) }\end{array}$ & $\begin{array}{l}\text { During each } \\
\text { lesson, once a } \\
\text { week }\end{array}$ \\
\hline & $\begin{array}{l}\text { In-depth } \\
\text { Interviews }\end{array}$ & All teachers & $\begin{array}{l}\text { To get information } \\
\text { related to teachers' } \\
\text { feelings, difficulties, } \\
\text { time, etc. }\end{array}$ & $\begin{array}{l}\text { After the session, } \\
\text { once a month }\end{array}$ \\
\hline & $\begin{array}{l}\text { A self-reported } \\
\text { questionnaire }\end{array}$ & $\begin{array}{l}\text { Selected students ( } 3 \\
\text { students per class) }\end{array}$ & $\begin{array}{l}\text { To get information } \\
\text { related to students' } \\
\text { feeling, content } \\
\text { relevance, etc. }\end{array}$ & $\begin{array}{l}\text { After the session, } \\
\text { once a week }\end{array}$ \\
\hline $\begin{array}{l}\text { Impact: on the } \\
\text { intention to } \\
\text { use drugs and } \\
\text { determinants: } \\
\text { knowledge, } \\
\text { attitude, skills, } \\
\text { social norm }\end{array}$ & $\begin{array}{l}\text { A self-reported } \\
\text { questionnaire }\end{array}$ & $\begin{array}{l}\text { A non-randomized } \\
\text { control group } \\
\text { pre- and post- } \\
\text { test design, with } \\
10 \text { intervention } \\
\text { schools and } 10 \\
\text { comparison schools }\end{array}$ & $\begin{array}{l}\text { To compare the } \\
\text { achievability } \\
\text { of the planned } \\
\text { objectives with a } \\
\text { measurement of } \\
\text { baseline and short } \\
\text { term effects. }\end{array}$ & $\begin{array}{l}\text { Before and } \\
\text { after the } \\
\text { implementation } \\
\text { (Week } 1 \text { and 13) }\end{array}$ \\
\hline
\end{tabular}

The Standing Committee on Ethics in Health Research of the Faculty of Medicine, Padjadjaran University - Hasan Sadikin Hospital Bandung had approved this study through an ethical clearance no. 94/FKUP-RSHS/KEPK/kep./EC/2009. 


\section{Results}

\section{Step 1: Need Assessment}

The results from the FGDs among the students showed that the majority of the 8th grade students, especially the female students, had not yet used any substances. However, somewhat less than half of the male students had started using substances, especially tobacco. Among them, there were also several students who had started to smoke marijuana, had inhaled glue, and had consumed alcohol.

Several factors influenced the smoking behavior among the students. First of all, the male students saw tobacco use as an important way to reduce their stress, make friends, and increase their self-confidence. Moreover, many of the students lived with family members who were smokers. However, the majority of their parents forbade tobacco use. Best friends and older brothers were the significant influence of smoking.

Furthermore, most of the male and female students mentioned that they did not have appropriate skills to refuse drug offers. This might be related to the fact that Indonesian adolescents are used to speak unassertively, especially to their elders (Mulder, 1998). This situation might lead them to initiate substance use. Finally, factors that hindered them from starting using any substances were health risks and religious reasons. The results from our need assessment were quite in line with the results from previous studies in other areas in Indonesia (e.g. Aditama et al., 2008; Kristanti, 1995; Ng, Weinehall, \& Ohman, 2007; Smet, Maes, De Clercq, Haryanti, \& Winarno, 1999; WHO, 2009).

Teachers mentioned that they had taught their students about the risks of substance use in their classes but not much about appropriate attitudes and necessary skills. The main teaching method was didactic presentations of basic knowledge. Teachers had a high motivation to facilitate drug education programs in their classes. The results from the survey showed that their teaching behaviors were influenced by their outcome evaluations of the drug education program and perceived behavioral control of the targeted behavior $(\beta=.37$ and .16 , respectively, $\mathrm{p}<.01$ ). Unfortunately, almost $70 \%$ of the teachers did not have an updated knowledge and the relevant skills to teach about this issue (Hinduan et al., 2009; Hinduan, Sumintardja, Kok, \& Hospers, in preparation).

The other stakeholders mentioned that there were no substance abuse-related policies for public schools in Bandung yet. Public buildings, including schools, were not smoke-free environments. As an unintended result, students might see many people, including their teachers, use tobacco around the schools. Furthermore, based on the literature, although the national health law now prohibits smoking in educational facilities, there is no real punishment for those who violate the law. Students are also continuously exposed to tobacco advertisements in public media such as the television, radio, and printed materials. There 
is no law that prohibits tobacco advertising although the appearance of the advertisements is somewhat controlled. Advertisements do not show the tobacco products but usually display images such as "solidarity among young people" or "being sociable and up-to-date guys". Tobacco advertisements on television and radio are limited to the hours between 21.30 and 05.00 (Global Tobacco Free Kids, 2012; Ng et al, 2007). Furthermore, the price of the tobacco products in Indonesia is much lower than in other countries and there is no law banning tobacco sponsorships, even for youth events such as a student music festival (Global Tobacco Free Kids, 2012; WHO, 2011).

Finally, all stakeholders, including the students, agreed that a drug education program for public schools in Bandung was needed to prevent the negative effects of substance use, including HIV transmission through intravenous substance use. The general objective of the intended program would, therefore, be to prevent the initiation of tobacco, alcohol, and other substances use among secondary school students in Bandung (Table 2).

\section{Table 2 : The Targeted Outcomes}

\section{The behavioral outcomes:}

Students will not start consuming tobacco, alcohol or other substances

Students will quit smoking (for those who have already used tobacco)

\section{The environmental outcomes:}

Provide a drug education program in public schools in Bandung

Provide a drugs-free environment for the students

\section{Step 2: Matrices}

The second step of IM is to specify performance and change objectives. To ensure the effectiveness of the program, the program has to change and focus on the specific behavior of the target group (Table 3) and its social environment (Table 4). 


\section{Table 3 : Individual Performance Objectives}

\section{Performance Objective 1:}

Students will not start consuming tobacco, alcohol and other substances

Plan/Decide to maintain abstinence from tobacco, alcohol, and other substances

Identify substance use-related temptations

Generate ways to resist temptation

Use the appropriate coping strategies in resisting temptation

Evaluate and adjust the coping strategies used

Maintain being abstinent from drugs

\section{Performance Objective 2:}

Students will quit smoking (for those who have already smoked cigarettes)

Decide to quit smoking

Identify a smoking related temptation

Generate ways to resist temptation

Use the appropriate coping strategies in resisting temptation

Evaluate and adjust the coping strategies used

Maintain smoking cessation

\section{Table 4 : Examples of Environmental Performance Objectives}

Environmental outcome 1 : Public (junior high) schools in Bandung provide drug education for their 8th grade students

The teachers facilitate the drug education program in their classes every week

The school management implement the drug education program

The local educational office supports and controls the program implementation

Environmental outcome 2 : Schools provide a drugs-free environment for the students

The teachers do not smoke in school areas

The school managements develop school policies to prevent drug use

The importance and changeability for each personal determinants were also rated (Table 5). The importance of the determinants is rated based on specific evidence while the changeability is rated based on general evidence (Bartholomew et al., 2011). 
Table 5 : The Importance (I) and Changeability (C) of Personal Determinants

\begin{tabular}{l|l|l|l}
\hline $\begin{array}{c}\text { Personal } \\
\text { Determinants }\end{array}$ & I & C & \multicolumn{1}{|c}{ Evidence for Importance } \\
\hline Attitude & ++ & + & $\begin{array}{l}\text { Precondition for smoking temptation and } \\
\text { cessation (Ng et al., 2007), sensation seeking of } \\
\text { substance use (Puente, Gutierrez, Abellanm, \& } \\
\text { Lopez, 2008), intention to quit smoking (Høie et } \\
\text { al., 2012) }\end{array}$ \\
\hline $\begin{array}{l}\text { Perceived Behavioral } \\
\text { Control }\end{array}$ & ++ & ++ & $\begin{array}{l}\text { Precondition for nicotine dependence (Bricker, } \\
\text { Liu, Ramey, \& Peterson, 2012) and for being } \\
\text { smoking free (Murnaghan et al., 2009) }\end{array}$ \\
\hline $\begin{array}{l}\text { (Perceived) Social } \\
\text { Norm }\end{array}$ & ++ & + & $\begin{array}{l}\text { Precondition for adolescents starting to smoke } \\
\text { (Ng et al., 2007), for smoking(Mercken, Steglich, } \\
\text { Sinclair, Holliday, \& Moore, 2012; Vitória, } \\
\text { Salgueiro, Fatima, Silva, \& de Vries, 2011), for } \\
\text { smoking cessation (Høie et al., 2012), and for } \\
\text { smoking onset and maintenance (Smet et al., } \\
\text { 1999) }\end{array}$ \\
\hline
\end{tabular}

Note. Range : + to +++

The last result from this step is a comprehensive matrix of change objectives. Table 6 shows the example of the matrix of the intended program. 
Table 6 : Matrix of Change Objectives (Examples)

\begin{tabular}{|c|c|c|c|c|}
\hline \multirow{2}{*}{$\begin{array}{c}\text { Performance } \\
\text { Objectives }\end{array}$} & \multicolumn{4}{|c|}{ Determinants } \\
\hline & $\begin{array}{l}\text { Knowledge and } \\
\text { Risk Perception }\end{array}$ & Attitude & $\begin{array}{c}\text { Skills and Self } \\
\text { Efficacy }\end{array}$ & $\begin{array}{c}\text { Perceived Social } \\
\text { Norm }\end{array}$ \\
\hline \multicolumn{5}{|c|}{ PO 1: Students will not start using any drugs } \\
\hline $\begin{array}{l}\text { 1. Decide to } \\
\text { maintain } \\
\text { abstinence from } \\
\text { drugs }\end{array}$ & $\begin{array}{l}\text { List negative } \\
\text { effects of drug use } \\
\text { next to positive } \\
\text { ones }\end{array}$ & $\begin{array}{l}\text { Recognize that } \\
\text { benefits of being } \\
\text { drug abstinent } \\
\text { is personally } \\
\text { relevant }\end{array}$ & & $\begin{array}{l}\text { Recognize that } \\
\text { the number } \\
\text { of friends who } \\
\text { do not use } \\
\text { drugs exceeds } \\
\text { the number of } \\
\text { friends who use } \\
\text { drugs }\end{array}$ \\
\hline $\begin{array}{l}\text { 2. Identify a drug } \\
\text { userelated } \\
\text { temptation }\end{array}$ & $\begin{array}{l}\text { List situations } \\
\text { that cause } \\
\text { smoking initiation }\end{array}$ & & $\begin{array}{l}\text { Express } \\
\text { confidence in } \\
\text { monitoring } \\
\text { their own } \\
\text { feeling }\end{array}$ & \\
\hline
\end{tabular}

PO 2: Students will quit smoking

\begin{tabular}{l|l|l|l|l}
\hline $\begin{array}{l}\text { 1. Generate ways } \\
\text { to resist smoking } \\
\text { temptation }\end{array}$ & $\begin{array}{l}\text { Acknowledge that } \\
\text { it is important to } \\
\text { have strategies to } \\
\text { refuse the offer to } \\
\text { smoke }\end{array}$ & $\begin{array}{l}\text { List the steps } \\
\text { of assertive } \\
\text { communication }\end{array}$ & $\begin{array}{l}\text { State that } \\
\text { their friends } \\
\text { have smoking } \\
\text { cessation aids (i.e. } \\
\text { smoking patch) } \\
\text { easily available }\end{array}$ \\
\hline $\begin{array}{l}\text { 2. Maintain } \\
\text { cessation }\end{array}$ & $\begin{array}{l}\text { Mention the } \\
\text { positive and } \\
\text { negative side } \\
\text { effects of smoking } \\
\text { cessation }\end{array}$ & $\begin{array}{l}\text { Explain that the } \\
\text { negative side } \\
\text { effects of the } \\
\text { cessation do not } \\
\text { last forever } \\
\text { Realize that they } \\
\text { must work hard } \\
\text { to maintain the } \\
\text { cessation }\end{array}$ & $\begin{array}{l}\text { Express } \\
\text { confidence } \\
\text { in the ability } \\
\text { to maintain } \\
\text { cessation }\end{array}$ & $\begin{array}{l}\text { Acknowledge } \\
\text { that many of } \\
\text { their friends did } \\
\text { not continue to } \\
\text { smoke }\end{array}$ \\
\hline
\end{tabular}




\section{Step 3: Theory based Intervention Methods and Practical Applications}

\section{Table 7 : Selected Examples of Determinants, Theoretical Methods, Theoretical Parameters, and Practical Strategies}

\begin{tabular}{|c|c|c|c|}
\hline Determinants & Theoretical Methods & $\begin{array}{l}\text { Theoretical } \\
\text { Parameters }\end{array}$ & Practical Strategy \\
\hline \multirow[t]{2}{*}{$\begin{array}{l}\text { 1. Knowledge/ Risk } \\
\text { Perception }\end{array}$} & $\begin{array}{l}\text { Discussion (Theory } \\
\text { of Information } \\
\text { Processing) (Petty, } \\
\text { Barden, \& Wheeler, } \\
\text { 2009) }\end{array}$ & $\begin{array}{l}\text { Teachers listen to the } \\
\text { students to make } \\
\text { sure that the correct } \\
\text { schema are activated }\end{array}$ & $\begin{array}{l}\text { Debating about positive } \\
\text { and negative side effects } \\
\text { of smoking cessation }\end{array}$ \\
\hline & $\begin{array}{l}\text { Scenario-based } \\
\text { risk information } \\
\text { (precaution-adoption } \\
\text { Process Model) } \\
\text { (Mevissen, Meertens, } \\
\text { Ruiter, Feenstra, \& } \\
\text { Schaalma, 2009) }\end{array}$ & $\begin{array}{l}\text { Imagery } \\
\text { Multiple scenarios are } \\
\text { provided } \\
\text { Plausible scenarios } \\
\text { with a cause and an } \\
\text { outcome }\end{array}$ & $\begin{array}{l}\text { Discussing several cases } \\
\text { depicting how one can } \\
\text { unintentionally become } \\
\text { a drug user }\end{array}$ \\
\hline 2. Attitude & $\begin{array}{l}\text { Anticipated regret } \\
\text { (Theory of Planned } \\
\text { Behavior) (Richard, van } \\
\text { der Plight, \& de Vries, } \\
\text { 1995) }\end{array}$ & $\begin{array}{l}\text { Stimulation of } \\
\text { imagery } \\
\text { Assumes a positive } \\
\text { intention to avoid the } \\
\text { risky behavior }\end{array}$ & $\begin{array}{l}\text { Teachers ask students } \\
\text { to write down their } \\
\text { feelings after imagining } \\
\text { using tobacco while not } \\
\text { intending to do so }\end{array}$ \\
\hline \multirow[t]{2}{*}{ 3. Skills } & $\begin{array}{l}\text { Guided practice (Social } \\
\text { Cognitive Theory) } \\
\text { (McAlister, Perry, \& } \\
\text { Parcel, 2008) }\end{array}$ & $\begin{array}{l}\text { Sub skill } \\
\text { demonstration, } \\
\text { instruction and } \\
\text { enactment with } \\
\text { individual feedback } \\
\text { Supervision from an } \\
\text { experienced person }\end{array}$ & $\begin{array}{l}\text { Role playing in assertive } \\
\text { communication with } \\
\text { teachers providing } \\
\text { feedback }\end{array}$ \\
\hline & $\begin{array}{l}\text { Goal setting (Goal- } \\
\text { Setting Theory) } \\
\text { (Latham \& Locke, 2007) }\end{array}$ & $\begin{array}{l}\text { Achievable and } \\
\text { challenging goals } \\
\text { Commitment to } \\
\text { reaching the goals }\end{array}$ & $\begin{array}{l}\text { A worksheet on students' } \\
\text { personal goals after } \\
\text { finishing junior high } \\
\text { schools }\end{array}$ \\
\hline 4. Subjective Norm & $\begin{array}{l}\text { Visible expectations } \\
\text { (Theory of Planned } \\
\text { Behavior) (Ajzen, 1991) }\end{array}$ & $\begin{array}{l}\text { Positive expectations } \\
\text { from significant } \\
\text { others are available }\end{array}$ & $\begin{array}{l}\text { The students read a } \\
\text { comic that shows the } \\
\text { discussion among virtual } \\
\text { peer educators on how } \\
\text { quitting cigarettes has a } \\
\text { positive impact on their } \\
\text { friends }\end{array}$ \\
\hline
\end{tabular}


Table 7 shows examples of theoretical methods and their parameters that were applied in the program. For example, the method discussion from the Elaboration Likelihood Model (ELM) (Petty, Barden, \& Wheeler, 2009), was applied as a debating activity among the students. The topic included positive and negative side effects of smoking cessation, aiming to increase students' knowledge about smoking cessation. In line with the theoretical parameters, the discussion activity is actively moderated by the teachers to ensure that the correct schemas are activated (Bartholomew et al., 2011).

\section{Step 4: Intervention Program}

In this phase, it was determined that the program would be implemented for 8th grade students (13-14 years old) in all public schools in Bandung during the regular teaching time as a local content. The twelve sessions with a duration of 40 minutes each proved to be feasible for implementation. The guidance and counseling teachers would facilitate the program and the school management would assure the availability of time for this program. Because the availability of computers and audiovisual aids (i.e. laptop and projection equipment) in the schools was limited, the program would be a paper and pencil-based curriculum.

The theme of the program would be HEBAT! (An Indonesian word for GREAT!). It is an abbreviation of "Hidup Sehat Bersama Sahabat!" (Healthy Living with My Buddies!). Besides a trained teacher, peer educators were recognized as effective delivery agents for a prevention program in schools (Stead et al., 2010). As a result, there were two characters in the program that served as the students' virtual peer educators and led the students through all activities. The characters were a girl and boy of the same age named "Fajar" and "Putri". There were a lot of colors, attractive illustrations and games so that the students could be motivated to process the materials.

As mentioned previously, Islamic values dominantly influence the behavior of students in Bandung, including their drug free-related behavior. According to Islam and some other religions, drug use, including tobacco use, is forbidden. As a result, some relevant verses from the Koran and other holy books were included in the information kit for teachers and students to make the program more relevant to subjective social norms.

Printed materials consisted of teaching tools for the teachers (i.e. information kit, modules, and teaching aids) and learning tools for the students (i.e. information kit and worksheets). The information kit for teachers was more comprehensive than the learning tools for the students, so that the teacher could get advanced knowledge and instruction about the related topics. The learning tools were student-friendly, not too complex to fit their cognitive capacities, attractive, and convincing. 
Before the printing, the final drafts of the books were tried out in several classes in the selected schools to ensure the right time allocation, user-friendliness, comprehensiveness, language, and the level of participation of the students. The pilot project was conducted in a period of six months in five selected public schools from five different districts in Bandung.

All the guidance and counseling teachers of these five schools were trained and facilitated by medical doctors, psychologists, and the HPOs. This training is very important in ensuring the effectiveness of the implementation in a way that will be complete and in line with the intentions of the program developers (Nation et al., 2003; Peter et al., 2009). Adult learning principles were adopted in this training. The concept of adult learning refers to self-directed learning processes while the instructors of this learning process take the position of a facilitator instead of a teacher (Knowles, Holton, \& Swanson, 1998). Five basic principles of adult learning are: self-directed, experience-centered, motivated by internal incentives, stimulated by an actual situation, and problem-focused (Gravani, 2012). As a result, the teachers actively participated in sharing their own experiences to stimulate learning from others' experiences.

\section{Step 5: Adoption and Implementation}

Collaboration with the local educational office, the local AIDS commission, and a state university was enforced to ensure ownership and sustainability in the long term. They were committed to implement the HEBAT! program in all junior high schools in Bandung, and to provide resources, including financial support, in order to maintain the implementation of this program.

Sustainability also required training for trainers. The aim of this training was to improve the skills of the guidance and counseling teachers from the pilot schools so that they could become master teachers. The master teachers were trained in advanced and up-to-date knowledge on related topics and in facilitating skills for adult learners. The aim of this activity was to provide a pool of well-trained facilitators who would conduct the teacher training in the future. It was expected that the number of teachers who could facilitate the HEBAT! program would increase and that they would become the future implementers of this program. Finally, the youth center, an NGO concerned with adolescents in Bandung, was also chosen to be one of the implementers of the program. This NGO played an important part in the evaluation phase.

\section{Step 6: Evaluation}

Results from the process evaluation showed that both students and teachers were happy with the program. Most of the students mentioned that the topics of the program were suitable for their actual problems and helped them to understand the issues and to gain the necessary 
skills to avoid the temptation to use any substances. The teachers revealed the good quality of the relationship between them and their students as one of the impacts of this program. The students shared their problems with the teachers. However, some teachers mentioned their difficulties in facilitating some of the active learning activities applied in this program. It appears that the teacher training prior to the implementation of the program was not sufficient enough to increase their self confidence in facilitating some of the student-centered activities and in providing feedback to the young adolescents. Complex preparation before and during the class also affected the teachers' approach to teaching. They tended to ignore the teaching manuals and engaged in the traditional teaching methods, such as lecturing. This teachercentered method is known as an effective way to increase the students' knowledge but not to gain attitudinal changes (Virginia et al., 1993).

Results from the impact evaluation will be discussed in another paper (see Hinduan et al., in preparation). However, it can be concluded that the program did increase the degree of knowledge and perceived behavioral control of the students in performing substancefree-related behavior. The students' attitude, perceived SN, and intention increased but the increase was not statistically significant which might be due to, among other things, the ceiling effects of the baseline data.

\section{Discussion}

This paper describes the application of Intervention Mapping (IM) in planning, developing, implementing, and evaluating a school-based drug education program in Bandung, Indonesia. Although this framework was originally developed and applied in Western countries, we found that this framework is also suitable for the Indonesian context. This might be due to the social and ecological aspects that underpin the framework, so the program is adjusted to the Indonesian culture. For example, collectivist culture is very dominant in this country. It is therefore very important for people in this culture to maintain a good relationship with their in-group (family, ethnic group, and nation) (Triandis, 2001). This is in line with the results of the need assessment (step 1 of IM). The substance use-related behavior among the students might directly or indirectly be influenced by their significant others (best friends and older brothers), and by cultural and religious practices. As a result, in developing health promotion programs at schools in Indonesia, it is important to involve the relevant stakeholders, such as the parent's associations, the local governments and the religious leaders right from the start so that the intended program will be suitable for the students, the school, and their environments.

In the development of the program, the Theory of Planned Behavior was used as a basic behavioral theory. Although this theory is criticized as an approach that stresses the importance of individual cognitions of a behavior (Burke, Joseph, Pasick, \& Barker, 
2009; Pasick et al., 2009), we found that all of the constructs of this theory are crucial in understanding the drug-related health behavior among the students in Indonesia. In this program development, we found that it is more likely that the students' normative, attitudinal, and control beliefs were important in affecting the students' behavior.

Additionally, the IM framework enables the HPOs to evaluate the impact of the program. Theories provide the causal process of behavior change (Michie, Johnston, Francis, Hardeman, \& Eccles, 2008). As a result, the theory-based determinants that were chosen in this program can be evaluated empirically. Each specific change objective in Table 5 will be evaluated so that the HPOs can monitor and also modify the program in the future. For example, in the pre- and post-test, the students will be asked to mention one negative side effect of smoking cessation.

However, we also faced several challenges in applying this framework in this context. The first challenge relates to the time and financial restraints of developing a program that focuses on a single behavioral domain, which is substance use. Although the IM framework can guide the HPOs in developing an effective prevention program, it might not be easy to redo the IM process on another single health problem in the future, especially in a developing country with a limited educational budget like Indonesia. However, it might be feasible and efficient to use the IM framework in developing an integrated program that can address multiple health problems and risk behavior among young people, such as substance abuse, sexual reproductive health, or aggressive behavior (Peters et al., 2009).

Also, we found that it was reasonably challenging to develop a teaching method that meets the theoretical parameters for use as well as fitting the actual conditions of public schools in Indonesia. Teachers in the Indonesian public schools need to handle 45-50 students in each of their classes. Therefore, a teaching strategy that requires the teachers to assist their students individually was excluded from this program. We also used the virtual peer educator as a role model and a comic instead of a video to provide modeling and help students discuss relevant topics, since the audio-visual aids in the schools are limited. These limitations in relation to teaching methods and materials might affect the results of the interventions.

Despite difficulties in applying the IM framework in the Indonesian setting, it can still be concluded that the framework can guide the planning, development, implementation, and evaluation of HEBAT! in a systematic way, ensuring that it is likely to be effective by meeting several effective principles of a prevention program. Both the cognitive factors and social context that underlie the drug use behavior among the students could, therefore, be addressed in a way that they effectively contribute to the behavior change of students and the establishment of an enabling environment. 



\section{CHAPTER 6}

Effectiveness of

a Substance Use

Prevention Program

for Students in

Indonesia:

A Pre- and Post-test Impact

Evaluation

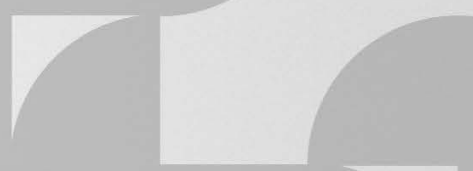

Based on: Hinduan, Z. R., Fitriana, E., Kok, G. J., \& Hospers, H. J. Effectiveness of substance use prevention program for students in Indonesia: A pre- and post-test impact evaluation. Under review. 



\section{Effectiveness of a Substance Use Prevention Program for Students in Indonesia: A Pre- and Post-test Impact Evaluation}

\section{Abstract}

The use of tobacco and other substances is quite popular among young people in Indonesia. A systematic school-based prevention program was developed to reduce the intention to consume illicit substances among the $8^{\text {th }}$ grade students in several public schools in Bandung, Indonesia. This study presents an empirical impact evaluation of this program. To evaluate the effectiveness of the prevention program in changing various behavioral determinants of substance-free behavior, a non-randomized two-group study was conducted among 3,027 students in a comparison group and 3,200 students in an intervention group. The respondents filled out a self-reported questionnaire before and immediately after the implementation. A series of analyses of covariance was conducted with pre-test scores as covariates. A preliminary analysis had indicated that all variables, except knowledge, significantly predicted the students' intention to perform the substance-free behavior. Perceived behavioral control appeared to be the most salient variable in predicting the behavioral intention. Compared to the comparison group, the intervention group showed significant improvements in knowledge and perceived behavioral control but not in attitude, perceived subjective norm, and intention. This study shows the impact of the substance use prevention program among junior high school students. The implementation failures of the teachers in this program suggest the need for teacher training and program improvement so that the program can be much easier for the teachers to use. Other areas of improvement are discussed to increase the effectiveness of the program as well as the implications for other health planners in developing a systematic prevention program in the future.

Keywords: impact evaluation, TPB, prevention program, students, substance use 


\section{Introduction}

Substance use, especially tobacco use, is common among young people in Indonesia. Several studieson more than 3,000 students, aged 13-15 years, in Indonesia show that more than $30 \%$ of them have smoked tobacco and $30 \%$ of the current smokers had started smoking before the age of 10 (Aditama et al., 2008; World Health Organization-South East Asia Regional Office (WHO-SEARO), 2009). Focus group discussions with 93 students aged 13-14 years in Bandung-Indonesia, which were held prior to this study, showed that almost half of the male students had used tobacco products. A small number of the male students had also consumed alcohol and marijuana, and inhaled glue. The majority of the female students had never smoked nor used other substances.

To address the substance use problems in Bandung, a school-based substance use prevention program, called HEBAT! (an Indonesian word for GREAT!), was developed in 2010. HEBAT is an abbreviation of "Hidup Sehat Bersama Sahabat" (healthy living with my buddies). The program targeted $8^{\text {th }}$ grade students of all public schools in Bandung. This program was implemented in regular teaching time as a part of the school curriculum. Trained guidance and counseling teachers were responsible for facilitating this program. A school-based prevention program was chosen because it is compulsory for young people in this country to attend nine years of basic education (elementary and junior secondary schools) (United Nations Educational, Scientific, and Cultural Organization(UNESCO), 2010; Ministry of Education, 1997). It was expected that the program would reach many young people in Bandung as almost $96 \%$ of them attend junior secondary schools (Ministry of Education, 1997).

The HEBAT! Program was developed using the Intervention Mapping (IM) protocol and aimed: (1) to prevent the early initiation of substance use; and (2) to decrease smoking among the students. The IM protocol stresses the importance of the incorporation of theoretical insights and empirical evidence in developing a prevention program (Bartholomew, Parcel, Kok, Gottlieb, \& Fernandez, 2011). According to previous reviews, a theory-based program development promotes the effectiveness of prevention programs (Hanbury, Wallace, \& Clark, 2001; Nation, et al., 2003; Peters, Kok, Ten Dam, Buijs, \& Paulussen, 2009). The IM approach helps program developers to understand the causal determinants of the targeted behavior and allows the theoretical assumptions to be tested, so that the intended intervention can be evaluated and improved (Mitchie et al., 2008).

The Theory of Planned Behavior (TPB) (Ajzen, 1991) was used as the main etiological theory in developing the HEBAT! program. This theory explains the determinants in predicting the health-related behavioral intentions (Armitage \& Conner, 2001; Godin \& Kok, 1996), i.e. the intention to use illicit substances. More recent studies on tobacco use have confirmed that the TPB can successfully explain the variance in the intentions of young people to use 
tobacco products (Higgins \& Conner, 2003; Mercken, Steglich, Sinclair, Holliday, \& Moore, 2012; Moan \& Rise, 2005; Murnaghan et al., 2009)

According to TPB, the substance-free behavior of the students is directly influenced by their intention and their perceived behavioral control (PBC) (Ajzen, 2002; Fishbein \& Ajzen, 2010). The intention is a motivational factor that influences behavior and is determined by a combination of the attitude towards the behavior, perceived subjective norms (SN), and PBC (Ajzen, 2002; Fishbein \& Ajzen, 2010). Attitude towards substance-free behavior refers to the students' behavioral beliefs about the consequences of substance-free behavior for themselves. These consequences can be perceived as positive or negative by the students. SN refers to the students' perceived social pressure to perform the substance-free behavior, based on normative beliefs. PBC refers to the students' perceived level of control over performing the substance-free behavior, based on control beliefs (Ajzen, 2002; Fishbein \& Ajzen, 2010).

In line with the theory, results from the focus group discussions focusing on the need assessment (the first IM step) showed that there are a various personal determinants that affect the early initiation of substance use among the students, especially for smoking. The first main determinant was SN. On the one hand, smoking students had started to smoke because they perceived expectations to start smoking from their significant others, especially their best friends and older brothers. On the other hand, the non-smoking students mentioned that they did not want to smoke since they did not want to disappoint their parents who forbade them from smoking. These results had suggested that the social normative factor played an important role in predicting the intention both to smoke and to remain abstinent from smoking among the students in this context. The results are in line with the results reported from comparable studies on adolescents in several countries (Mercken et al, 2012; Ng, Weinehall, \& Ohman, 2007; Page, Suwanteerangkul, Ricks, \& Kemeny, 2011; Smet, Maes, De Clercq, Haryanti, \& Winarno, 1999; Vitoria, Salgueiro, Fatima, Silva, \& De Vries, 2011).

The most significant influences on their smoking were their best friends and older brothers, whereas the influences for non-smokers were their parents. A previous study related to non-smoking among students in schools has showed that the teacher is also a significant influence on young people to remain abstinent (Murnaghan et al., 2009). As a result, the teachers were incorporated as one of the factors in this study.

The second determinant of smoking behavior among the students was their attitude towards smoking or their belief that smoking has positive or negative consequences for them (Fishbein \& Ajzen, 2010). The male smoking students explained that smoking helped them to be a "man", to get more friends, and to increase their self-confidence. These positive evaluations of smoking are comparable to various research results that have been reported 
from other countries. For example, a study in one of the Asian countries has indicated that smoking can increase the popularity of male adolescents in their schools (Page et al., 2011), whereas studies in western countries have reported that risky behavior enables female students to maintain their ideal weight (French \& Perry, 1996; Potter, Pederson, Chan, Aubut, \& Koval, 2004). However, non-smoking students mentioned that smoking would have negative impacts on their health and, as healthy students, they would achieve their future dreams. This negative evaluation of smoking on health among the students was in line with several studies in western countries (Jensen \& Overgaard, 1993; Piko, 2001). Based on the results of our focus group discussions and several comparable studies (Lee, Johnson, Rice, Warren, \& Chen, 2013; Otten, Warner, Vitaro, \& Engels, 2008), it can be concluded that the behavioral beliefs regarding the consequences of smoking appear to be one of the predictors of smoking among young people.

The last factor that determined the students' behavioral intentions was their personal beliefs related to how much control they have over performing the substance-free behavior, PBC (Ajzen, 2002; Fishbein \& Ajzen, 2010). In this study's context, the PBC beliefs relate to both internal factors (e.g. lack of assertive communication skills in refusing drug offers, especially from older people) and external factors (e.g. the facts that tobacco products are easy to get in Bandung and are relatively cheap). The results are in line with the studies on adolescents in other countries (Lotrean, Mesters, \& De Vries, 2013; Thrul, Stemmler, Buhler, \& Kuntsche, 2013).

The three theoretical constructs of the TPB were used in developing the HEBAT! program. The aims of the program were to change the students' attitude towards substance use, $\mathrm{SN}, \mathrm{PBC}$, and their intention to use substances. According to the TPB, the change in the intention will then change the behavior (Ajzen, 2002; Fishbein \& Ajzen, 2010). Although knowledge of substance use-related topics is not one of the TPB constructs, some authors suggest that knowledge is a precondition for the development of attitude (Ajzen, Joyce, Sheikh, \& Cote, 2011; Bartholomew et al., 2011; Mikolajczak, Kok, \& Hospers, 2008). As a result, knowledge was included as another personal determinant in the HEBAT! program.

The program comprises 12 sessions with the duration of 40 minutes for each session. There are four main topics that aim to (1) develop the students' self-esteem and self-identity as healthy adolescents; (2) introduce the roles of their social environment and how to deal with the social influences; (3) introduce the risks of substance use among young people; and (4) plan and set the students' goals for the future. As mentioned before, the TPB served as the etiological theory in the development of the HEBAT! program. The TPB stimulates the program developers' focus on the causes of smoking among young people (Nation et al., 2003). Since the theory does not provide any practical method for behavioral change (Michie et al., 2008), other basic behavioral change methods, such as facilitation (Bandura, 1986), feedback (Mullen, Mains, \& Velez, 1992), and selected active learning activities 
(Petty, Barden, \& Wheeler, 2009) were applied in changing the determinants of the students as suggested by the IM protocol (Bartholomew et al., 2011).

This present study aimed to test the effectiveness of the HEBAT! program in preventing substance use and in eliminating smoking among junior high school students in Bandung through changing their: (1) attitudes towards the behavior; (2) perceived subjective norm; (3) perceived behavioral control; (4) intentions to perform the behavior; and (5) knowledge. This study also examined the personal determinants associated with the students' intention to avoid substance use based on the pre-test data.

It was hypothesized that:

1. The students' intentions to avoid substance use will be predicted by their attitude towards substance-free behavior, SN, and PBC.

2. Immediately after the intervention (6 months), the students, who were engaged in the HEBAT! program in their schools, will show better outcomes on the relevant determinants (attitude, SN, PBC, intention and knowledge) of substance use-related behavior (cigarettes, alcohol and other substances) than the students from the comparison schools.

\section{Methods}

\section{Participant Characteristics}

Participants of this study were all $8^{\text {th }}$ grade students in 20 public schools in Bandung. The intervention group consisted of the students from 10 schools who participated in the HEBAT! program, whereas the comparison group consisted of the students from 10 other schools that did not implement the prevention program. The intervention schools represented schools in five educational districts in the city. The comparison schools, which have similar academic characteristics, were selected to be the waiting list control group. These comparison schools were willing to implement the program in the following year after this study. There was no incentive for participation. The questionnaire did not contain questions about respondents' identity, except their student number. This information was needed to match the pre- and post-test data. However, the respondents were assured that only the researchers had access to the raw data.

\section{Procedure}

The intervention schools had been selected based on the schools' willingness to adopt this program and also the availability of an adequate time allocation to implement the program in their schools. As a result, a randomized control trial could not be employed 
in this study. A pre-test-post-test design was conducted to examine the effectiveness of the HEBAT! program among junior high school students in Bandung. This kind of design is very prevalent in educational settings (McMillan \& Schumacher, 2009). The program was implemented in approximately six months. The pre-test measurement was taken a week before the implementation of the program (July 2011) and the post-test measurement was taken immediately (a week) after the completion of the HEBAT! program in each school (December 2011).

Data collection was conducted in each class using a self-administered questionnaire. The research team came to each class and gave the questionnaire to each student. The respondents first received general instructions from the researchers on how to complete the questionnaire, and were then asked to individually complete the questionnaire. After completion, they were asked to return the questionnaire. Participation in this study was voluntary and the study was approved by the Standing Committee on Ethics in Health Research of the Faculty of Medicine, Padjadjaran University - Hasan Sadikin Hospital Bandung with the reference number of 94/FKUP-RSHS/KEPK/kep./EC/2009.

\section{Measures}

1. Demographic information, such as age, gender, and details of the schools. Gender was included since previous studies have suggested the need for gender-specific intervention for smoking-related behavior (Grogan, Conner, Fry, Gough, \& Higgins, 2009; Mercken, Snijders, Steglich, Vertiainen, \& de Vries, 2010).

2. Intention to stay away from drugs. Respondents were asked to rate their intention to stay away from any illicit substances (6 questions). A sample item was "In the next 6 months, I will not to smoke a cigarette". The response format for this scale was a 6 -point scale, ranging from $1=$ strongly disagree to $6=$ strongly agree. The internal consistency reliability coefficient of this scale was .91 (Cronbach's alpha). A higher score on this scale indicated a higher intention to keep away from drugs.

3. Attitude toward substance-free behavior. This scale measured students' outcome evaluation of substance-free behavior (6 items). A sample item (negative item) was "By smoking cigarettes I can maintain my weight". The response format for this scale was a 6 -point scale, ranging from $1=$ strongly disagree to $6=$ strongly agree. The reliability was high for this scale (.89). Higher scores on this scale indicated a more favorable attitude towards substance free-related behavior.

4. Perceived subjective norm (SN). This scale asked students to judge whether or not their parents and their teachers would want them to keep away from drugs (6 items). A sample item was "My parents think that I should never try to smoke a cigarette". 
The response format for this scale was a 6-point scale, ranging from $1=$ strongly disagree to $6=$ strongly agree. The correlation was .87 .

5. Perceived behavioral control (PBC). In this scale, students were asked to rate their perception of the extent to which they were able to stay away from substance use 6 items). A sample item was "I think I am capable of saying "no" if someone offers me a substance". The response format for this scale was a 6-point scale, ranging from $1=$ strongly disagree to $6=$ strongly agree. The internal consistency reliability coefficient for the subscale was .86. A higher score of this scale represented a higher degree of perceived behavioral control over staying away from substances.

6. Substance-use related knowledge. This scale asked the students several questions related to substance use (12 items). A sample item was "Are the negative effects of the light cigarettes similar to the effects of the normal cigarettes?" The internal consistency coefficient for the subscale was .65. The response format was true/false/do not know. Correct answers were scored 1. The incorrect and do-not-know answers were scored 0. The number of correct responses for the scale was computed. A higher score indicated more knowledge.

All questions were posed in the Indonesian language. However, for the purpose of this article the questions were translated into English.

\section{Statistical Analysis}

Hypothesis 1 was tested using the hierarchical regression analysis. Intention served as the dependent variable and the other constructs served as the independent variables. In the first step, all TPB constructs were included and then knowledge and gender were included in the regression equation in the second step. Gender was included since the gender differences might also relate to substance use among the students (Mazanov \& Bryne, 2007; Park, 2006). In each step, the effect of adding a predictor was tested for significance; betas and changes in $R^{2}$ were examined.

To evaluate changes in the attitude, SN, PBC, intention, and knowledge among students over time (hypothesis 2), a series of analyses of covariance (ANCOVAs) were conducted with pre-test scores as covariates. The purpose of this procedure was to adjust initial group differences that could not be controlled in this study. The research group (the intervention and the comparison) served as the fixed factor. 


\section{Results}

\section{Hypothesis 1: Factors that Predict the Students' Intention}

\section{Descriptive statistics.}

Table 1 presents the means, standard deviations, and inter-correlations among study variables. In this analysis, the pre-test results from comparison and intervention groups were combined. The table shows that the students had a relatively high intention to keep away from any substances. This is also true for the three TPB variables (attitude, SN, and PBC). However, the mean score of substance use-related knowledge was not high. Moreover, all study variables, except knowledge, had substantial correlations with the students' intention to avoid substance use. The three TPB variables were relatively highly intercorrelated ( $r$ $=.27-.37$ ), but the correlations between knowledge and the three TPB variables were extremely low $(r=.01-.03)$.

Table 1 : Intercorrelations among Variables for All Students at the Baseline $(N=6,447)$

\begin{tabular}{l|c|c|c|c|c|c|c|c|c} 
& Mean & SD & Range & Gender & Knowledge & Attitude & SN & PBC & Intention \\
\hline $\begin{array}{l}\text { \% of } \\
\text { female } \\
\text { students }\end{array}$ & 53.80 & - & - & - & & & & & \\
\hline Knowledge & 0.37 & 0.17 & $0-1$ & .01 & - & & & & \\
\hline Attitude & 5.32 & 0.53 & $1-6$ & $-.10^{* *}$ & $.03^{*}$ & - & & & \\
\hline SN & 5.52 & 0.62 & $1-6$ & $-.12^{* *}$ & -.02 & $.29^{* *}$ & - & & \\
\hline PBC & 5.16 & 0.58 & $1-6$ & $-.16^{* *}$ & .01 & $.29^{* *}$ & $.32^{* *}$ & - & \\
\hline Intention & 5.17 & 0.53 & $1-6$ & $-.16^{* *}$ & .01 & $.27^{* *}$ & $.32^{* *}$ & $.37^{* *}$ & - \\
\hline
\end{tabular}

\section{Factors related to the Intention to Stay away from any Substances}

A hierarchical regression analysis was conducted to examine the effects of the attitude, SN, and PBC on the students' intention to keep away from any substances. The data used in this analysis were the results from the pre-test. In this regression analysis, the TPB predictors were entered in Step 1. Gender and knowledge were entered in Step 2. Table 2 presents the standardized beta $(\beta)$ values. The three components of TPB were significantly attributed to students' intention to staying away from any substances-use-related behavior. Gender also differentiated the students' intention to avoid substance use. The female students' intention was higher than the male students'. However, both gender and knowledge did not significantly add to the prediction of the students' intentions. 


\section{Table 2 : Summary of Hierarchical Regression for Variables Predicting Intention at the Baseline $(N=6,447)$}

\begin{tabular}{l|c|c}
\hline \multicolumn{1}{c|}{ Variables } & R & Beta \\
\hline Step 1 & $.27^{* *}$ & $.14^{* *}$ \\
\hline Attitude & $.32^{* *}$ & $.19^{* *}$ \\
\hline Subjective Norm & $.37^{* *}$ & $.27^{* *}$ \\
\hline Perceived Behavioral Control & & $.20^{* *}$ \\
\hline $\mathrm{R}^{2}$ & $.27^{* *}$ & $.13^{* *}$ \\
\hline Step 2 & $.32^{* *}$ & $.19^{* *}$ \\
\hline Attitude & $.37^{* *}$ & $.26^{* *}$ \\
\hline Subjective Norm & $-.16^{* *}$ & $-.08^{* *}$ \\
\hline Perceived Behavioral Control & .01 & .01 (ns) \\
\hline Gender (F=1, M=2) & & $.21^{* *}$ \\
\hline Knowledge & & .01 (ns) \\
\hline $\mathrm{R}^{2}$ & &
\end{tabular}

Note. ${ }^{*} p<.05 * * p<.01$

\section{Hypothesis 2: Effects of HEBAT! Program}

\section{Baseline data collection.}

In the baseline data collection, 3,143 students from the comparison group (48.80\%) and 3,304 students from the intervention group (51.20\%) participated by completing a selfadministered questionnaire in their classes. Age in the intervention group ranged from 10 to 15 years with a mean age of 12.91 years $(S D=.49)$ and age in the comparison group ranged from 10 to 16 years with a mean age of 12.95 years $(\mathrm{SD}=.56)$.

To investigate whether the two groups were equivalent at baseline, a chi-square test and a series of independent samples t-tests were conducted. The results showed that the students in both groups had a high score on all TPB sub scales but a relatively low score on the knowledge subscale (Table 3). The table also shows that there were significant differences between the two groups on all measures, except for knowledge and PBC. The scores of intervention groups were significantly higher on attitude, $\mathrm{SN}$, and intention. As a result, to determine whether the program was indeed having effects (Hypothesis 2), a series of analyses of covariance (ANCOVAs) were conducted by taking these pre-test differences into account. 
Table 3 : Characteristics of the Samples at the Baseline

\begin{tabular}{l|c|c|c|c|c|c|c}
\hline \multicolumn{1}{c|}{ Variables } & \multicolumn{2}{c|}{$\begin{array}{c}\text { Comparison } \\
\text { Group } \\
(\mathbf{N}=\mathbf{3 1 4 3 )}\end{array}$} & Range & \multicolumn{2}{c|}{$\begin{array}{c}\text { Experimental } \\
\text { Group } \\
\text { (N=3304) }\end{array}$} & Range & P value \\
\hline \% of female students & 53.60 & & & 54.00 & & & $\mathrm{~ns}$ \\
\hline $\begin{array}{l}\text { Mean (SD) } \\
\text { knowledge }\end{array}$ & 0.37 & $(0.17)$ & $0-1$ & 0.37 & $(0.17)$ & $0-1$ & $\mathrm{~ns}$ \\
\hline Mean (SD) Attitude & 5.30 & $(0.53)$ & $1-6$ & 5.34 & $(0.52)$ & $1-6$ & $* *$ \\
\hline Mean (SD) SN & 5.50 & $(0.63)$ & $1-6$ & 5.54 & $(0.61)$ & $1-6$ & $*$ \\
\hline Mean (SD) PBC & 5.15 & $(0.58)$ & $1-6$ & 5.17 & $(0.57)$ & $1-6$ & $\mathrm{~ns}$ \\
\hline Mean (SD) Intention & 5.56 & $(0.55)$ & $1-6$ & 5.59 & $(0.52)$ & $1-6$ & $* *$ \\
\hline
\end{tabular}

Note. $* p<.05 \quad * * p<.01$

The numbers of students of the comparison and intervention groups who participated in the post-test data collection were 3,027 and 3,200, respectively $(6,227$ students in total, yielding a loss to follow-up of $3.4 \%$ ). The unavailability for the post-test data collection was primarily due to absenteeism, missing data, or school transfer.

Table 4 presents an overview of the analyses of covariance (ANCOVAs), including the mean scores and standard deviations (SDs) on the dependent variables at pre-test and posttest for both comparison and intervention groups and the $\mathrm{F}$ test statistics for the group effects on the post-tests after statistical control for the pre-test scores of the two groups. Furthermore, the analyses revealed a significant effect of the intervention on knowledge $(\mathrm{F}(6,186)=2031.07, \mathrm{p}<.00)$ and $\operatorname{PBC}(\mathrm{F}(6,186)=7.21, \mathrm{p}<.00)$ where the increase in the intervention group was larger compared to the comparison group. This represents a meaningful increase in students' knowledge and PBC after the implementation of the HEBAT! program. For the other TPB scales (attitude, SN and intention), no significant effects of the intervention were found, although the mean scores of the three variables of the intervention group in the post-test were higher than the scores in the pre-test. 
Table 4 : Summary of ANCOVA for Evaluating the Effectiveness of the HEBAT! Program

\begin{tabular}{|c|c|c|c|c|c|}
\hline \multirow{3}{*}{ Variables } & \multicolumn{2}{|c|}{$\begin{array}{l}\text { Comparison Group } \\
\qquad(\mathrm{N}=3027)\end{array}$} & \multicolumn{2}{|c|}{$\begin{array}{l}\text { Intervention Group } \\
\qquad(\mathrm{N}=3200)\end{array}$} & \multirow{3}{*}{$\mathbf{F}$} \\
\hline & Pre-test & Post-testa & Pre-test & Post-testa & \\
\hline & Mean & Mean & Mean & Mean & \\
\hline Knowledge & 0.36 & 0.35 & 0.37 & 0.55 & $2031.07^{* *}$ \\
\hline Attitude & 5.30 & 5.41 & 5.34 & 5.43 & .32 (ns) \\
\hline SN & 5.50 & 5.55 & 5.54 & 5.57 & .53 (ns) \\
\hline PBC & 5.15 & 5.17 & 5.17 & 5.21 & $7.21^{* *}$ \\
\hline Intention & 5.56 & 5.58 & 5.59 & 5.60 & .38 (ns) \\
\hline
\end{tabular}

Note. $* p<.05 \quad * * p<.01 \quad$ ns $=$ non significant

$a=$ approximately 6 months after pre-test

\section{Discussion}

This study identified the socio-cognitive factors that determine students' intentions to stay abstinent from any illicit substances before the implementation of the program (Hypothesis 1). The three TPB variables and knowledge and gender served as the predictors and students' intention as the dependent variable. The hypothesis is fully supported by the results. Attitude, SN, and PBC contribute to the students' intentions to avoid substance use. The more favorable their attitude and the stronger their perceived subjective norm and perceived behavioral control, the stronger their intention to perform the targeted behavior. In this study, PBC appears to be the strongest predictor of the students' intentions. It suggests that the perceived ability to apply skills needed to refuse drugs, such as assertive communication skills, is very important for the students to avoid substance use.

Substance-use related knowledge has a very small but significant association with attitude. However, the regression analysis reveals that the students' knowledge cannot predict the students' intention to be engaged in drug-free behavior. This result is in line with the results from previous studies (Mazanov \& Bryne, 2007; Mikolajczak et al., 2008; Park, 2006). Thus, the inclusion of knowledge in a prevention program might not directly change individuals' intention but might relate to their attitude. Finally, specific gender correlated with intention, albeit with a very small impact. Therefore, gender-based intervention programs may not be necessary among the majority of non-drug-using students in Indonesia.

Moreover, this study also tested the effectiveness of the HEBAT! program in preventing substance useand eliminating smoking among junior high school students in Bandung, 
through changing their knowledge, attitudes towards substance free behavior, $\mathrm{SN}, \mathrm{PBC}$, and intentions to stay away from drugs (hypothesis 2). The findings of this study indicate that the hypothesis is partially supported: the prevention program delivered to the $8^{\text {th }}$ grade students had positive effects on their knowledge and $\mathrm{PBC}$ but not on their attitude, $\mathrm{SN}$, and intention to keep away from any substance. Compared to students in the comparison group, those in the intervention group showed a significant increase in their knowledge and perceived skills after participating in the HEBAT! program. This result suggests that after participating in the program, the students are more certain they have the required knowledge, skills, and resources to perform the behavior that helps them maintain their abstinence from any illicit substances. They perceive that they have the skills to refuse drugs when offered. It may be expected that the increase in PBC may lead to an increase in the students' efforts and persistence to avoid substance use because $\mathrm{PBC}$ also turned out to be the most important predictor of non-smoking intentions.

Although our findings are not fully in line with the results from previous TPB-based intervention studies on sexuality-related behavior among young adolescents, as only PBC is affected by the intervention program (Armitage \& Talibudeen, 2010; Caron, Godin, Otis, \& Lambert, 2004; Hill \& Abraham, 2008), the results from this immediate impact evaluation are partly in line with the results of a meta-analytic study of the outcomes of HIV prevention intervention (Albarracin, Durantini, \& Earl, 2006). According to the study, immediately after the implementations, knowledge and the three TPB predictors tend to increase significantly whereas the behavioral intentions tend to remain the same. However, our study has found that there were no significant differences in the students' attitude and SN.

There are several possible explanations for this outcome. The high scores of attitude and SN in the pre-test measurement may have led to the ceiling effects. It might also relate to the fact that a self-reported questionnaire was employed in this study.

Further interviews with several trained teachers were conducted to explore some additional explanations for these atypical results. According to them, they sometimes felt uncertain of how to facilitate their students' participation in active learning activities or on how to provide feedback to the students. Several teachers indicated that they skipped the selected active learning activities and relied on traditional teaching methods, such as lecturing.

Another reason for the limited effects relates to the fact that active learning activities are time consuming in preparation and implementation in the class (Mathie et al., 1993). As a result, some teachers thought that lecturing was more efficient. However, with this type of teaching method, the students can acquire and retain knowledge efficiently but their attitude, SN, and intention are less likely to change (Rasmussen, 1956).

We also re-evaluated some of teaching strategies that were employed in this intervention program. It was concluded that some strategies might be sufficient in changing students' 
knowledge and skills but might not be sufficient in changing their attitude, SN, and intention. In the initial development of this program, the teaching methods that required the teachers to assist their students individually were limited due to the fact that a teacher must facilitate the program among almost 50 students in each class. For example, a class debate, instead of small and supervised group discussions, was chosen for this program. As a result, this classical teaching strategy might not significantly affect the students' attitude, $\mathrm{SN}$, and intention but might affect their knowledge and PBC.

This study had several strengths and limitations, including: (1) this program was treated as one of regular school courses. Accordingly, most of the students participated in all sessions during the period of 6 months; (2) the sample size was quite large. It means that this study had sufficient power to ensure the group differences after the implementation of the program; and (3) this study included a comparison group to ensure its internal validity. Given the high level of attendance of the students in this program, the sample size, and the inclusion of the comparison group, it can be concluded that the results of this study do represent the true effects of the intervention program among the students. Nevertheless, this study also had several limitations due to: (1) a random assignment of school participants to the two groups was not feasible to employ. Consequently, there might be several uncontrolled variables that may affect the study's results; (2) this study used self-report measurement tools. Data collection was also conducted in the classes and each student was asked to put their student number. These conditions might have increased social desirability in filling out the questionnaire; and (3) the research design employed in this study might yield potential problems with external validity (Borden \& Abbot, 2014). Thus, the generalization of the results is limited. Future studies might overcome these limitations.

Despite the limitations of this study, it can be concluded that PBC, attitude, SN, but not knowledge, positively predict students' intention to keep away from substance use. PBC appears to be the most salient determinant of the behavior. This study also confirmed that the HEBAT! program contributes to the increase of the students' knowledge and perceived skills needed to avoid substance use. This preliminary study suggests several areas for improvement, especially related to making the program easier for the teachers as well as in conducting a feasible teacher training. We hope that these findings can encourage further efforts to develop an effective substance prevention program, especially in the contexts that have similar characteristics with this study's context, such as in a collectivist culture where a teacher needs to teach many students in one class. Moreover, conducting long term evaluation to evaluate the retention of the intervention's effects seems reasonable. 



\section{CHAPTER 7}

\section{General Discussion}





\section{General Discussion}

An integration of biomedical approaches and social-behavioral approaches is urgently needed to ensure the effectiveness of HIV prevention programs in a diverse population (Coates, Richter, \& Caceres, 2008; Hosek, 2013). Behavioral changes are needed since HIV is a behavior-related disease. Various individual behaviors are accountable for the spread of the virus, especially intravenous substance use and unsafe sex. Thus, behavioral sciences play a significant role in modifying: (1) risk behavior of targeted groups, including intravenous drug users or female sex workers; and (2) the undesirable behavior of the related social environments, including stigmatization of people living with HIV by health care workers (HCWs) or prison officers. In designing effective behavioral intervention for those groups, it is important to identify significant determinants that underlie each targeted behavior (Ajzen, 2006; Fishbein \& Ajzen, 2010). Thus, this dissertation aims to increase our knowledge about (1) the socio-cognitive determinants of various HIV prevention-related behaviors and (2) the development of a comprehensive behavioral intervention program based on the Intervention Mapping framework.

The first study presented in this dissertation identified specific health symptoms and sociocognitive determinants that can be used by the health care workers (HCWs) to identify patients with HIV and their stage of the disease. This study also examines potential barriers in engaging the test (chapter 2). Next, HIV-related misconceptions among prison officers and their relationship with their attitude towards inmates with HIV were studied in a narcotics prison (chapter 3). Using the Theory of Planned Behavior (TPB), we conducted two different studies on teachers and students in junior high schools. The study on teachers aimed to identify personal determinants of teaching behavior (chapter 4) whereas the study on the students aimed to identify factors that determined substance-free behavior (chapter 6). The subsequent chapters present a study that describes a program development using the Intervention Mapping (IM) protocols (chapter 5) and a study that evaluated the effectiveness of the program in achieving its initial goals (chapter 6). Finally, in this general discussion, we will address the main findings from the five studies and provide recommendations for future research as well as for prevention policies and practices. 


\section{Predicting Personal Determinants}

\section{Health factors.}

Health symptoms are indicators of a person's perceived health-related quality of life (Justice et al., 2001; Kroenke, 2003; Kroenke \& Price, 1993). These symptoms play a key role for both patients and HCWs. For the patients, the symptoms are the reasons to present for treatment and care, whereas for the HCWs, the symptoms are important health indicators of their patients and can be used as a diagnostic tool. Thus, to promote provider initiated testing and counseling (PITC) among Indonesian health care facilities, as suggested by World Health Organization (WHO) (2007), the HCWs must be aware about HIV-associated symptoms. The first study in this dissertation (chapter 2) identified the most common HIVrelated health symptoms and socio-cognitive determinants among patients in the tertiary referral hospital in West Java, one of the provinces in Indonesia with the highest number of HIV cases (Ministry of Health (MoH), 2013).

By comparing the health symptoms of patients with HIV and those without HIV, it was shown that a combination of two specific symptoms (chronic diarrhea and oral thrush) and HCV co-infection had a high predictive value of HIV infection among the patients. Another study in this referral hospital that was conducted by Wisaksana et al. (2010) has confirmed part of these results. The majority of HIV patients with a history of intravenous drug use (IDU) have HCV co-infections. Furthermore, to predict the stage of the disease of infected patients, a comparison was made between characteristics of patients with higher (more than 50) and lower (less than 50) CD4 cell counts (a marker of the level of immunosuppression). Lower CD4 cell counts were found among the patients who were diagnosed through PITC procedure and who had extreme weight loss. The results suggested that the PITC patients were already at the later stage of the disease at the time they were diagnosed.

The results from this study implied that several health symptoms could be used as an indicator in identifying patients with: (1) HIV infection; and (2) lower levels of immunosuppression. HCWs in the health facilities could use this knowledge to proactively identify patients who potentially present late for HIV testing, so that proper treatment and care could be started.

Lastly, to identify the barriers for seeking HIV testing among patients, the personal characteristics of VCT and PITC patients who came to the hospital were also compared. The results showed that compared to VCT patients, PITC patients had a lower degree of HIVrelated knowledge, lower educational level, and higher degree of risk perception. These results confirmed our preliminary assumptions about HIV testing-related barriers: (1) lack of information on HIV testing and/or HIV associated health symptoms; and (2) the absence of prevention awareness in this population. Accordingly, they remain largely undiagnosed and present late for HIV treatment and care. These results confirmed the results of two 
qualitative studies about barriers of HIV testing among African immigrants in a western country (Manirankunda, Loos,Debackaere, \& Nöstlinger, 2012; Manirankunda, Loos, Alou, Colebunders, \& Nöstlinger, 2009). As a result, in up-scaling HIV testing in Indonesia, a practical educational program also needs to be developed, which is aimed to increase: (1) HIV testing-related knowledge; and (2) prevention awareness in the general population, especially for those with a lower educational level.

\section{Behavioral determinants.}

\section{Knowledge and Behavior.}

Studies on knowledge were presented in chapter 3 and chapter 6 . Firstly, a study in a correctional setting revealed that attitudes towards inmates with HIV were rated more negative among prison officers with a lower degree of HIV-related knowledge, compared to those with a higher degree of knowledge. This result aligns with the results of two studies among nursing students in two other countries (Lohrmann et al., 2000; Qu, Zhang, Guo, \& Sun, 2010). In these studies, students with a high level of knowledge tended to have more positive attitudes towards patients with HIV. In addition, they were also more willing to care for the patients.

The results of our study also showed that the most salient type of knowledge that predicted attitudes was HIV transmission-related knowledge, followed by HIV prevention-related knowledge. Various HIV transmission-related misconceptions were identified. Although the majority of respondents had correct knowledge relating to the most common HIV transmission modes (semen, vaginal fluids, and blood), they also believed that saliva is one of the transmitting modes of the disease. They apparently thought that kissing and sharing a toothbrush could spread the virus. Various misconceptions related to aerial routes (including sneezing and talking) and skin routes (including sweating and hand shaking) significantly differentiated officers with a positive attitude from those with a more negative attitudes.

Moreover, although the majority of the prison officers had correct knowledge about the most common HIV prevention strategies, especially condom use, having just one sexual partner or uncontaminated needle use, this study had also identified various misconceptions about prevention strategies. Half of the officers believed that to prevent the spread of the virus, someone should get immunization, use instruments (including wooden sticks) when touching the inmates and their belongings, and use mosquito fogging. These results suggested that they did not know how to take the necessary precautions in handling inmates with HIV in their workplace.

Unfortunately, the majority of these officers (with both positive and negative attitudes) perceived isolation rooms for the inmates with HIV as an effective way to prevent the 
spread of the virus within their prison. This kind of opinion is risky. Previous studies have suggested that social isolation of inmates with HIV will lead the other inmates to take higher risks as they might refuse to be engaged in HIV testing (Babalola, 2007; Parker \& Aggleton, 2003; Joint United Nations Programme on HIV/AIDS(UNAIDS), 2004).

Similar to the results that have been reported by two previous studies on prison officers in the United Kingdom (Dillon \& Allwright, 2005; McMahon, 1993), the majority of the officers in this narcotics prison also had a low degree of HIV-related knowledge. There was a strong indication that the officers did not have proper knowledge regarding the updated medical efforts in controlling the disease, as half of them had incorrect knowledge about (1) methadone maintenance therapy (MMT), (2) current medicine for this disease and its coinfections, and (3) the correct health symptoms of the disease. As the key players in caring for inmates in Indonesian correctional settings (Djauzi, 2009), prison officers needed to increase their HIV-related knowledge by updating their knowledge about the disease. By implementing evidence-based interventions, their HIV-related misconceptions and negative attitude towards inmates with HIV may be reduced and their willingness to take care the infected people may increase.

Lastly, the significant positive relationship between knowledge and attitude was also confirmed by our last study, which was conducted among students regarding substancefree behavior (chapter 6). The study illustrated that the more knowledgeable the students, the more positive their attitude towards substance-free behavior. However, further analysis revealed that knowledge did not significantly add to the prediction of the students' intentions to perform the substance-free behavior. It means that there was no direct effect of the students' degree of knowledge on their readiness to perform the correct behavior. This result is in line with various previous studies on knowledge and behavioral change (Ajzen et al., 2007; Mazanov\& Bryne, 2007; Park, 2006).

The above results have suggested that there is no direct effect of knowledge on changing intentions to perform desired behavior. However, the inclusion of knowledge in an intervention program aimed to promote healthy behavior is important as the increase of knowledge may affect attitudes towards the behavior of the targeted group. According to the TPB, the change in the attitude and two other factors will change the intentions to perform the intended behavior (Ajzen \& Manstead, 2007; Fishbein \& Ajzen, 2010).

\section{Beliefs and Behavior.}

Among various social psychology theories, the TPB is frequently used in developing HIVrelated intervention programs (Armitage \& Talibudeen, 2010; Albarracin, Durantini, \& Earl, 2006; Bowen, Williams, McCoy, \& McCoy, 2001). According to this theory, a combination of three salient beliefs (behavioral, normative and control) plays a central role in predicting 
the intention to perform a targeted behavior (Ajzen, 1991; Fishbein \& Ajzen, 2010). Using the TPB as a basic theory, two quantitative studies (chapters 4 and 6) and a qualitative study (chapter 5) on students and teachers were conducted. The two quantitative studies showed that the three TPB variables together significantly explained $34 \%, 36 \%$, and $20 \%$ of the variance of the intention to teach $\mathrm{DE}$, to teach $\mathrm{SRH}$, and to perform substance-free behavior, respectively.

The cross sectional study among students revealed that those with lower intention to remain substance-free were more likely to believe that (1) they did not have sufficient resources (both personal and environmental) to carry out the behavior; (2) the substance-free behavior gave them more negative results than the positive ones; and (3) their significant others did support their substance use behavior. These results align with the results from the previous drug use-related studies among adolescents (Hoei, Moan, \& Risem, 2012; Malmberg et al., 2012) and the results from our focus group discussions (Chapter 5).

The results from the focus group discussions showed that: first, the students urgently need a life skills education program, particularly in relation to refusal-skills. This result is similar to the result of a smoking-related study among South African adolescents (Panday, Reddy, Ruiter, Bergstro, \& de Vries, 2007). Unlike those African students who needed coping skills to help them to solve various problems related to social influences; the Indonesian students need training aimed at developing their assertive communication skills. It was expected that they could communicate assertively in refusing drug offers from others, especially from the former students of their schools. Second, for the using students, substance use was seen as a way to reduce their stress, to make friends, and to increase their self-confidence, whereas for the non-user students, the substance use behavior was seen as a sin and unsafe for their health. Third, for those who had already consumed a substance (mostly tobacco, marijuana, glue, and alcohol), their best friends and their older brothers were seen as their most significant influences in initiating the risky behavior while for those who had not consumed any substances their parents were perceived as their most significant influence in avoiding the initiation of substance use. The most salient normative factors among adolescents in this Indonesian context and in this substance use-related behavior are relatively similar with the factors among Norwegian adolescents in engaging in protected sex (Myklestad \& Rise, 2008). The results support the assumption that the significant others of different populations and behavior are relatively the same for students (Fishbein \& Ajzen, 2010).

Furthermore, the study on teachers found that the teachers with higher intention to teach DE and SRH were more likely to believe that: (1) teaching the two topics had more positive outcomes than negative ones for their students; (2) their personal and environmental resources could help their efforts to carry out the teaching; and (3) their significant others (the school's management and the parents of their students) approved of their teaching 
in the class. The results align with the results from a study related to teachers' intention to teach HIV/AIDS education (Burak, 1994). Our study had also identified personal and environmental factors that are perceived as barriers by the teachers to performing the targeted behavior, especially: limited knowledge and skills in handling difficult questions (personal barriers) and the absence of these two topics in the official curriculum of their schools (environmental barriers).

As the three TPB variables have a high predictive value of behavior, the interventions aimed to modify risky behavior needed to change these three types of beliefs (behavioral, normative and control). Moreover, the results from the study among students showed that PBC appeared to be the most salient determinant in predicting non-smoking whereas the results from the study among teachers show that attitude was the most salient determinant in predicting DE and SRH teaching. These results are in line with the theory; it is expected that the weight of these three determinants of intention varies from one behavior to another and from one population to another (Fishbein \& Ajzen, 2010). Therefore, the main focus on each intervention would be different for those two target groups. It was very important to increase the skills and self-efficacy to refuse any drug offer for the students whereas increasing the awareness of the positive outcomes of teaching DE and SRH was the most essential one for the teachers.

\section{Modifying Behavioral Determinants}

\section{The development of a prevention program.}

The development process of the prevention program called HEBAT! program using the Intervention Mapping framework is described in the fourth study of this dissertation (chapter 5). Almost all of the six required steps of the IM framework could be adapted and implemented in the development of the program in this context.

The social ecological paradigm had been applied throughout this program's development. The program aimed to prevent the initiation of substance use among the 8th grade students at the public schools in Bandung. On the one hand, this single health-related behavior was influenced by determinants from various ecological levels (Bartholomew, Parcel, Kok, Gottlieb, \& Fernandez, 2011). On the other hand, the implementation of this intervention program at the individual level had various effects on other related ecological levels. The guidance and counseling teachers especially, played a central role as facilitators of the program; the headmasters of the schools allocated time for implementing the program; the mayor of the city through the local educational office allocated some funds and passed a regulation to implement this program in all public schools in this city; and the religious leaders and other related NGOs supported the implementation of this program. These 
kinds of relationships also accommodated the importance of "in-group" feeling among this collectivist culture (Triandis, 2001). Opinions from all related stakeholders were incorporated in almost every step of the program development. By maintaining these positive relationships among the stakeholders, it was also expected that in the future this program would be adopted by the participating institutions.

However, it was challenging to ensure that this program contained theoretical methods and teaching strategies that were capable of producing the planned behavioral modifications, as most of the classes in Indonesian public schools comprise almost fifty students. It might be difficult for a teacher to perform individual supervision of their students. Thus, compared to a small group-based activity, a class-based activity seemed more feasible for the teachers in this study's context. A paper-and-pencil-based prevention program was also chosen since the access to technologies, especially internet and computer, were limited. As a result, these conditions might have influenced the effectiveness of the program in changing the determinants of the intended behavior.

\section{The evaluation of the program.}

A non-randomized control group pre-test and post-test design was employed to evaluate the effectiveness of this prevention program in achieving its initial goals (chapter 6). Using a self-reported questionnaire, data from 3,143 students from the comparison group and 3,304 students from the intervention group were collected before and immediately after the implementation of the HEBAT! program. The program was implemented in approximately six months. The results partially supported the initial hypotheses. The program had significant positive impacts on the PBC and knowledge but not on the other TPB variables. These findings suggest that the students had updated knowledge concerning the substanceuse-associated issues and that they were more certain about having the required skills and resources to perform the intended behavior

Based on this immediate evaluation, the program was more successful in achieving the increase of knowledge and PBC than in achieving the increase of the intention to perform substancefree behavior among the students. These results are partially in line with the conclusions from a meta-analytic study of the outcomes of HIV prevention interventions (Albarracin et al, 2006). According to this study, immediately after the intervention, the intentions to perform the intended behavior remain the same while the knowledge and the motivational components tend to increase. However, the results of our study also showed that there were no significant increases in attitudes towards behavior and perceived social norms.

Various explanations could be given for these results. The fact that the scores of the two determinants in the baseline were high might have led to the ceiling effects. As the majority of the $8^{\text {th }}$ grade students had not initiated any substance use, the students might have held 
very favorable attitude and $\mathrm{SN}$ in the baseline data collection. Thus, this prevention program was unlikely to have a further effect on these two determinants (Ajzen, 2006). In addition, we had conducted additional focus group discussions among the teachers. Results from the discussions implied various difficulties among the teachers in facilitating the active learning activities, including: (1) a lack of self-efficacy in facilitating the activities and in providing the feedback to their students; and (2) the nature of the active learning activities that are time consuming in the preparation and during the class duration (Virginia et al., 1993). As a result, the teachers sometimes relied on the traditional teaching methods, especially lecturing, which might be effective in increasing the knowledge but not effective in increasing the positive attitude and SN (Rasmussen, 1956). The previous meta-analytic study also concludes that the behavioral interventions employing the passive teaching strategies are not as effective as the interventions employing various active teaching strategies, such as modeling and role playing, in changing the motivational components of their targeted populations (Albarracin et al., 2006).

As a final point, the results in this evaluation study suggested the need to revise the current teaching strategies to increase the effectiveness and the feasibility of the implementation of the program. To revise the current strategies, the developers must match the ideal and the practical teaching strategies (Schaalma \& Kok, 2009). To ensure the teachers' mastery of the various teaching strategies, a comprehensive teacher training program might be needed prior to the implementation of a future program.

\section{Strengths and Limitations}

Various strengths and limitations of the studies should be noted. The strengths are: (1) using multiple methods (including a self-reported questionnaire, an interview and a focus group discussion) as the key methods for obtaining data on the selected behavioral determinants. As a result, the tendencies to project themselves in a socially desirable manner among the research respondents were cross-checked; (2) using an elicitation process as a guide in developing the questionnaires to ensure the accuracy, cultural relevancy and reliability; (3) considering a large number of participants, an inclusion of a comparison group and a high level of attendance, the evaluation study (chapter 6) represented the true effects of the intervention program among the students; (4) the studies presented in this dissertation can be considered as an exploratory study because of the limited number of studies in the HIV prevention context conducted in this population.

However, there are various limitations of the studies: (1) the first three studies have relied on a single-occasion method that may limit the possibility of establishing a causal relationship among study variables; (2) The results of our first two studies came from a small number of participants and from a single institution, which might weaken its external validity. Therefore, 
the generalization of the results is restricted for other populations. However, we believe that the results can be used as baseline data to develop specific intervention programs that target the study populations and/or other populations with similar characteristics; (3) the participants could not be randomly assigned in our last study (chapter 6), which might affect the internal validity of the study; (4) considering the broad topics with a varying populations in these studies, a firm conclusion of all studies together cannot be drawn.

\section{Suggestions for Future Research}

In Indonesia, there is a shift in the main route of HIV transmission from intravenous drug use to sexual transmission $(\mathrm{MoH}, 2013$; UNAIDS, 2012). It is expected that the current characteristics of the people with HIV in this country might be different to the characteristics found in our first study of this dissertation (chapter 2). Therefore, a new study, aimed to examine the common HIV characteristics (including their health symptoms and coinfections, demographic data, and socio-cognitive determinants) needs to be conducted, preferably with a higher number of respondents from various health care facilities in various locations in Indonesia. The study might have a better external validity, so that the results can be generalized beyond it's study sample.

Results from our last study (chapter 6) indicated that there is a vast need to develop a comprehensive intervention program using the IM framework to increase the teachers' motivational components and intention to facilitate the program. Step 1 of the IM framework (a need assessment) needs to be conducted among the teachers to examine the underlying determinants that predict their intention. Based on the results in the assessment, the specific outcomes, the performance objectives (POs), and the change objectives (COs) of the intended intervention can be established. Therefore, to increase the intention to perform the effective teaching behavior among the teachers, a specific intervention program needs to be developed and implemented.

Since the teachers need the simple teaching strategies in delivering the program (chapter 6), it would be beneficial to conduct a new comprehensive study to assess the effectiveness of various teaching strategies employed in the program to increase behavioral determinants of the substance-free behavior among the students. To ensure that the research findings can be directly applied by the program implementers, the new study needs to use a truly random sample (Bordens \& Abbot, 2014). Moreover, the results from the meta-analytic study conducted by Albarracin et al. (2006) have suggested that in the immediate impact evaluation, the behavioral intention tends to remain stable, but overtime the intention tends to increase. Thus, a follow up study needs to be conducted to verify the conclusion as well as to assess the retention of knowledge and other motivational factors among the participating students over time. 
Although we used multiple methods and strategies in obtaining data from our research participants, there are various indicators of a high degree of social desirability in filling out the self-report questionnaires among the study participants. Therefore, it is important to control the social desirability by guaranteeing the anonymity of the respondents, including asking for a personal code, e.g. hobbies instead of a personal identification, e.g. a student number.

\section{Practical Implications}

Based on the studies presented in this dissertation, it can be suggested that:

1. As the key player in up-scaling the HIV testing in the health care facilities in Indonesia, it is very important for the HCWs and other health-related students to regularly update their knowledge about the latest research findings in HIV/AIDS, especially about the health symptoms and other determinants of people with HIV. A commitment from the management of the health care facilities as well as the related medical schools is needed to ensure the availability of the latest materials, dissemination of research, and conducting related seminars about this disease within their organizations. Wellestablished policies are needed to ensure the effectiveness of the PITC procedure within the health care facilities.

2. To promote HIV testing to the general population, especially among those with lower educational level, practical information about the test needs to be made available in the communities. The information must be communicated in a simple language with limited medical jargon, so that the target group can easily understand the message. Further studies might be beneficial to examine the most effective message in promoting the HIV testing among the groups as well as to examine the main barriers in conducting the HIV testing among the most-at-risk groups and the general population in community settings.

3. The prison officers are the key players in implementing HIV programs in Indonesian correctional settings. They are expected to have proper and updated knowledge about the disease. A regular educational program about the disease needs to be established for the officers in Indonesian prisons, especially in the narcotics prisons. To implement this mandatory program, it is essential to get instrumental support as well as proper policies from the prison authorities. The content of the programs needs to include (1) the updated medical efforts in controlling the disease; and (2) common misconceptions related to HIV transmission routes and prevention strategies tailored to this specific setting. By increasing their knowledge, it is expected that their attitude towards inmates with HIV will be more favorable and they can also take the necessary precautions in caring for inmates with HIV. However, our extended study has also indicated that 
the increase of knowledge will not be sufficient in changing their behavior towards the inmates with HIV. If needed, a different behavioral intervention program must be developed to change the undesired behavior. This new program needs to focus on modifying the three TPB beliefs instead of only improving the knowledge.

4. To increase the effectiveness of the HEBAT! Program in the future, it is very important to modify several teaching strategies of the program. On the one hand, the new strategies must meet the parameter for use as suggested by the IM protocol (Bartholomew et al., 2011). On the other hand, it must be attainable by the teachers. The teachers need to attend prior teacher training so that they can have proper skills and self-efficacy in the facilitating of the various active learning activities in their classes.

5. The studies presented in this dissertation have indicated that the IM framework is suitable for guiding the development of the intervention program in this study context as: (1) the socio-ecological perspective that underlies the framework properly facilitates the importance of the 'in-group' feeling in this community; (2) the systematic use of theory and evidence of this framework helps the program developers to identify specific socio-cognitive determinants of the targeted behavior and to select the proper teaching strategies to change the determinants; (3) the matrices in the framework help the developers to specify the performance and change objectives; to determine the content of the program; and to evaluate the effectiveness of the program. However, the future program development needs: (1) to address multiple health problems instead of a single health problem to ensure the efficiency of the program; (2) to balance the ideal and the practical change techniques to ensure the effectiveness and the feasibility of the program in modifying the selected behavioral determinants in the specific context. 


\section{References}

Aditama, T. Y., Pradono, J., Rahman, K., Warren, C. W., Jones, N. R., Asma, S., \& Lee, J. (2008). Linking Global Youth Tobacco Survey (GYTS) data to the WHO framework convention on tobacco control: The case for Indonesia. Preventive Medicine, 47, 11-14. doi: 10.1016/j. ypmed.2008.05.003

Afriandi, I., Aditama, T. Y., Mustikawati, D., Oktavia, M., Alisjahbana, B., \& Riono, P. (2009). HIV/ AIDS and intravenous drug use in Indonesia: Epidemiology and national response. Acta Medica Indonesiana, 41, 75-78.

Ajzen, I. (2011). The Theory of Planned Behavior: Reactions and reflections. Psychology and Health, 26, 1113-1127. doi: 10.1080/08870446.2011.613995

Ajzen, I., \& Manstead, A. S. (2007). Changing health-related behaviours: An approach based on the Theory of Planned Behaviour. In M. Hewstone, H. A. W. Schut, J. B. F. De Wit, K. Van Den Bos, M. S. Stroebe, \& S. Margaret (Eds.), The scope of social psychology: Theory and applications (pp. 43-63). New York: Psychology Press.

Ajzen, I. (2006). Constructing a TPB questionnaire: Conceptual and methodological considerations. Retrieved from: http://www.uni-bielefeld.de/ikg/zick/ajzen $\% 20$ construction $\% 20 a \% 20 t p b \% 20$ questionnaire.pdf

Ajzen, I. (2005). Attitudes, personality, and behavior. Maidenhead: Open University Press.

Ajzen, I. (2002). Perceived behavioral control, self-efficacy, locus of control, and the theory of planned behavior. Journal of Applied Social Psychology, 32,665-685. doi: 10.1111/j.1559-1816.2002. tb00236.x

Ajzen, I. (2001). Nature and operation of attitude. Annual Review of Psychology, 52, 27-58. doi: 10.1146/annurev.psych.52.1.27

Ajzen, I. (1991). The theory of planned behavior. Organizational Behavior and Human Decision Processes, 50, 179-211. doi: 10.1016/0749-5978(91)90020-T

Ajzen, I. (1988). Attitudes, personality, and behavior. Chicago: Dorsey Press.

Ajzen, I. (1985). From intentions to actions: A theory of planned behavior. In J. Kuhl \& J. Beckman (Eds.), Action-control: From cognition to behavior (pp. 11-39). Heidelberg: Springer.

Ajzen, I., Joyce, N., Sheikh, S., \& Cote, N. G. (2011).Knowledge and the prediction of behavior: The role of information accuracy in the Theory of Planned Behavior. Basic and Applied Social Psychology, 33,101-117. doi: 10.1080/01973533.2011.568834

Ajzen, I.,\& Madden, T. J. (1986). Prediction of goal-directed behavior: Attitudes, intentions, and perceived behavioral control. Journal of Experimental Social Psychology, 22, 453-474. doi: 10.1016/0022-1031(86)90045-4

Albarracín, D., Durantini, M. R., \& Earl, A. (2006). Empirical and theoretical conclusions of an analysis of outcomes of HIV-prevention interventions.Current Direction of Psychological Science, 15, 7378. doi: 10.1111/j.0963-7214.2006.00410.x 
Albrecht, S. A., Higgins, L. W.,\& Lebow, H. (2000). Knowledge about the deleterious effects of smoking and its relationship to smoking cessation among pregnant adolescents. Adolescence, 35, 709-716.

Armitage, C. J.,\& Conner, M. (2001). Efficacy of the theory of planned behavior: A meta-analytic review. British Journal of Social Psychology, 40, 471-499. doi:10.1348/014466601164939

Armitage, C. J., \& Talibudeen, L. (2010). Test of a brief theory of planned behavior-based intervention to promote adolescent safe sex intentions. British Journal of Psychology, 101, 155-172. doi:10.1348/000712609X431728

Askelson, N. M., Campo, S., Smith, S., Lowe, J. B., Dennis, L., \& Andsager, J. (2011). Assessing physicians' intentions to talk about sex when they vaccinate nine year-old to 15-year-old girls against HPV. Sex Education: Sexuality, Society and Learning, 11, 431-441. doi: 10.1080/03630241003705094

Babalola, S. (2007). Readiness for HIV testing among young people in Northern Nigeria: The roles of social norm and perceived stigma. AIDS and Behavior, 11, 759-769. doi: 10.1007/s10461-0069189-0

Bandung Municipality. (2008). Peringatan Hari AIDS. Retrieved from: http://www.bandung. go. $\mathrm{id} / ? \mathrm{fa}=$ berita.detail\&id $=1986$.

Bandura, A. (1986). Social foundations of thought and action: A social cognitive theory. Engelwood Cliffs, NJ: Prentice Hall.

Bartholomew, L. K., Parcel, G. S., Kok, G., Gottlieb, N. H., \& Fernandez, M. E. (2011). Planning health promotion program. San Francisco: Jossey-Bass.

Bianchi, R. R. (2004). Guests of God: Pilgrimage and politics in the Islamic world. New York: Oxford University Press.

Badan Pusat Statistik (BPS) - Statistics Indonesia and Macro International. (2008). Indonesia Young Adult Reproductive Health Survey 2007. Retrieved from: http://www.measuredhs.com/pubs/pdf/ FR219/FR219.pdf.

Bohman, T.M., Barker, E. D., Bell, M. L., Lewis, C. M., Holleran, L., \& Pomeroy, E. (2004). Early intervention for alcohol use prevention and vehicle safety skills: Evaluating the protecting you/protecting me curriculum. Journal of Child and Adolescent Substance Abuse, 14, 17-40. doi:10.1300/J029v14n01_02

Booth, R. E., Zhang Y, \& Kwiatkowski, C. F., (1999). The challenge of changing drug and sex risk behaviors of runaway and homeless adolescents. Child Abuse and Neglect, 23, 1295-1306. doi: 10.1016/S0145-2134(99)00090-3

Borden, K. S., \& Abbott, B. B. (2014). Research Design and Methods. New York: McGraw-Hill.

Bowen, A. M., Williams, M., McCoy, H. V., McCoy, C. B. (2001). Crack smokers' intention to use condoms with loved partners: Intervention development using thetheory of reasoned action, condom beliefs, and processes of change. AIDS Care, 13, 579-594.doi: 10.1080/09540120120063214

Bricker, J. B., Liu, J., Ramey, M., \& Peterson, A.V. (2012). Psychosocial factors in adolescent nicotine dependence symptoms: A sample of high school juniors who smoke daily. Substance Use and Misuse, 47, 640-648. doi: 10.3109/10826084.2011.647221

Burak, L. J. (1994). Examination and prediction of elementary school teachers' intentions to teach HIV/AIDS education. AIDS Education and Prevention, 4, 310-321. 
Burke, N. J., Joseph, G., Pasick, R. J.,\& Barker, J. C. (2009). Theorizing social context: Rethinking behavioral theory. Health Education \& Behavior, 36, 55-70. doi: 10.1177/1090198109335338

Caron, F., Godin, G., Otis, J., \& Lambert, L. D. (2004). Evaluation of a theoretical based AIDS/STD peer education program on postponing sexual intercourse and on condom use among adolescents attending high school. Health Education Research, 19, 185-197. doi: 10.1093/her/cyg017

Chen, M., \& Tung, P. (2010). The moderating effect of perceived lack of facilities on consumers' recycling intentions. Environmental Behavior, 42, 824-844. doi:10.1177/0013916509352833

Coates, T. J., Kamenga, M. C., Sweat, M. D., \& De Zoysa, I. (2004). Efficacy of voluntary HIV counseling and testing in individuals and couples in Kenya, Tanzania, and Trinidad: A randomized controlled trial. Lancet, 356, 103-112. doi:10.1016/S0140-6736(00)02446-6

Coates, T. J., Richter, L., \& Caceres, C. (2008). Behavioural strategies to reduce HIV transmission: how to make them work better. The Lancet, 372, 669-684.doi:10.1016/S0140-6736(08)60886-7

Conner, M., \& Armitage, C. J. (1998). Extending the theory of planned behavior: A review and avenues for further research. Journal of Applied Social Psychology, 28, 1429-1464. doi: 10.1111/ j.1559-1816.1998.tb01685.x

Corby, N. H., Enguídanos, S. M., \& Kay, L. S. (1996). Development and use of role model stories in a community level HIV risk reduction intervention. Public Health Reports, 111 (54). doi: 10.1300/ J023v09n01_05

Cortoos, P. J., Schreurs, B. H. J., Peetermans, W. E., De Witte, L., \&Gert, K. L. (2012). Divergent intentions to use antibiotic guidelines: A theory of planned behavior survey. Medical Decision Making, 32, 145-153. doi: 10.1177/0272989X11406985

Cox, C. L., Miller, E. H., \& Mull, C. S. (1987). Motivation in health behavior: Measurements, antecedents, and correlates. Advance in Nursing Science, 9, 1-15.

Dalum,P., Schaalma, H., \& Kok, G. (2012). The development of an adolescent smoking cessation intervention: An intervention mapping approach to planning. Health Education Research, 27, 172-181. doi: 10.1093/her/cyr044

Derlega, V.J., Winstead, B. A., \& Brockington, J. E. (2008). AIDS stigma among inmates and staff in a USA state prison. International Journal of STD and AIDS, 19, 259-263. doi: 10.1258/ ijsa.2007.007141

Dillon, B., \& Allwright, S. (2005). Prison officers' concerns about blood borne viral infections. Howard Journal of Criminal Justice, 44, 29-40. doi: 10.1111/j.1468-2311.2005.00353.x

Djauzi, S. (2009). Health situation in Indonesian penitentiary. Acta Medica Indonesiana, 41, 4-5.

Dolan, K., Kite, B., Black, E., Aceijas, C., \& Stimson, G.V. (2007). HIV in prison in low-income and middleincome countries. Lancet Infectious Diseases, 7, 32-41. doi:10.1016/S1473-3099(06)70685-5

Dursin, R. (2004, May). Prison officials' ignorance hampers drive versus HIV/AIDS. IPS News. Retrieved from: http://ipsnews2.wpengine.com/2004/05/indonesia-prison-officials-ignorancehampers-drive-vs-hiv-aids/ (accessed 22 November 2012)

Fishbein, M., \& Ajzen, I. (2010). Predicting and changing behavior: The reasoned action approach. New York: Psychology Press. 
Ford, K., Wirawan, D. N., Sumantera, G. M., Sawitri, A. A. S., \& Stahre, M. (2004). Voluntary HIV testing, disclosure, and stigma among injection drug users in Bali, Indonesia. AIDS Education and Prevention, 16, 487-98.

French, S. A., \& Perry, C. L. (1996). Smoking among adolescent girls: Prevalence and etiology. Journal of the American Medical Women Association, 51,25-28.

Gagnon, H., Godin, G., Alary, M., Bruneau, J., \& Otis, J. (2010). A randomized trial to evaluate the efficacy of a computer-tailored intervention to promote safer injection practices among drug users. AIDS Behaviour, 14, 538-548. doi: 10.1007/s10461-009-9651-x.

Global Tobacco Free Kids. (2012). Indonesia Tobacco Policy Status. Retrieved from: http://global. tobaccofreekids.org/files/pdfs/en/Indonesia_tob_policy_en.pdf. accessed October 162012.

Godin, G., \& Kok, G. (1996). The theory of planned behavior: A review of its applications to health-related behaviors. American Journal of Health Promotion, 11, 87-98. doi:10.4278/0890-1171-11.2.87

Gottfredson, D. C.,\& Wilson, D. B. (2003). Characteristics of effective school-based substance abuse prevention. Prevention Science, 4, 27-38. doi: 10.1023/A:1021782710278

Granich, R., Gilks, C. F., Dye, C., Cock, K., \& Williams, B. (2008). Universal voluntary HIV testing with immediate antiretroviral therapy as a strategy for elimination of HIV transmission: A mathematical model. Lancet, 373, 48-57. doi: 10.1016/S0140-6736(08)61697-9

Gravani, M. N. (2012). Adult learning principles in designing learning activities for teacher development. International Journal of Lifelong Education, 31, 419-432. doi: 10.1080/02601370.2012.663804

Grogan, S., Conner, M., Fry, G., Gough, B., \& Higgins, A. (2009). Gender differences in smoking: A longitudinal study of beliefs predicting smoking in 11-15 years old. Psychology and Health, 24,301-316. doi: 10.1080/08870440701746586

Gu, J., Laub, J. T. F., Chenc, X., Liud, C., Liud, J., Chene, H., ... Li, Z. (2009). Using the theory of planned behavior to investigate condom use behaviors among female intravenous drug users who are also sex workers in China. AIDS Care, 21, (967-975). doi: 10.1080/09540120802657548

Green, L. W., \& Kreuter, M. W. (1992). CDC's planned approach to community health as an application of PRECEED and an inspiration for PROCEED. Journal of Health Education, 23, 140147. doi: 10.1080/10556699.1992.10616277

Hanbury, A., Wallace, L. M., \& Clark, M. (2011). Multiple outcome measures and mixed methods for evaluating the effectiveness of theory-based behavior-change interventions: A case study targeting health professionals' adoption of a national suicide prevention guideline. Psychology Health and Medicine, 16,291-303. doi: 10.1080/13548506.2011.554561

Higgins, A., \& Conner, M. (2003). Understanding adolescent smoking: The role of the TPB and implementation intention. Psychology Health and Medicine, 8, 173-186. doi: 10.1080/1354850031000087555

Hill, C. A., \& Abraham, C. (2008). School-based, randomized controlled trial of an evidence-based condom promotion leaflet. Psychology and Health, 23,41-56. doi: 10.1080/08870440701619726

Hinduan, Z. R., Riyanti, E., Tasya, I. A., Pohan, M. N., Sumintardja, E. N., Astuti, S. R., . . Hospers, H. J. (2009). HIV prevention through drugs and sex education in junior high schools in Bandung West Java: The teachers' perspective. Acta Medica Indonesiana, 41, 6-11. 
Hinduan, Z. R., Sumintardja, E. N., Kok, G., \& Hospers, H. J. (2014). Factors associated with teachers' intention to teach HIV/AIDS-related topics: An application of the theory of planned behavior. Manuscript submitted for publication.

Høie, M., Moan, I.S., Risem, J., \& Larsen, E. (2012). Using an extended version of the theory of planned behavior to predict smoking cessation in two age groups. Addiction Research and Theory, 20, 42-54. doi: 10.3109/16066359.2011.557165

Hosek, S. G. (2013). HIV pre-exposure prophylaxis diffusion and implementation issues in nonclinical settings. American Journal of Preventive Medicine, 44, 129-132. doi: 10.1016/j. amepre.2012.09.032

Indonesia National AIDS Commission. (2011). The response to HIV and AIDS in Indonesia 20062011. Retrieved from: http://www.citizen.org/documents/Response_to_HIV_and_AIDS_in_ Indonesia_2006_2011.pdf

Indrati, A. R., van Crevel, R., \& Tjandrawati, A. (2009). Screening and diagnosis of HIV-infection in Indonesia: One, two or three tests?. Acta Medica Indonesia, 41, 28-32.

Iskandar, S., Basar, D., Hidayat, T., Siregar, I. M., Pinxten, L., van Crevel, R., . . De Jong, C. A. (2010). High risk behavior for HIV transmission among former intravenous drug users: A survey from Indonesia. BMC Public Health, 10 (472). doi: 10.1186/1471-2458-10-472

Jensen, E. J., \& Overgaard, E. (1993). Investigation of smoking habits among 14-17 year old boarding school pupils: Factors which influence smoking status. Public Health, 107, 117-123.

Joint United Nations Programme on HIV/AIDS. (2012). Global Report. Retrieved from: http://www. unaids.org/en/media/unaids/contentassets/documents/epidemiology/2012/gr2012/20121120_ unaids_global_report_2012_with_annexes_en.pdf

Joint United Nations Programme on HIV/AIDS. (2009). Republic of Indonesia Country Report on the Follow up to the Declaration of Commitment on HIVIAIDS. Retrieved from: http://www.unaids. org/en/dataanalysis/knowyourresponse/countryprogressreports/2009countries/indonesia_2009_ country_progress_report_en.pdf

Joint United Nations Programme on HIV/AIDS. (2009). Second Independent Evaluation 20022008 Country Visit to Indonesia: Summary Report. Retrieved from: http://www.unaids. org/en/media/unaids/contentassets/dataimport/pub/basedocument/2009/20090501_sie_ countrysummaryreport_indonesia_en.pdf.

Joint United Nations Programme on HIV/AIDS. (2008). Report on the global AIDS epidemic. Geneva: UNAIDS.

Joint United Nations Programme on HIV/AIDS. (2005). A review of vulnerable populations to HIV and AIDS in Indonesia. Jakarta: UNAIDS.

Joint United Nations Programme on HIV/AIDS. (2004). AIDS Epidemic Update 2004. Retrieved from: https://www.unaids.org/en/media/unaids/contentassets/dataimport/pub/report/2004/2004_ epiupdate_en.pdf

Joint United Nations Programme on HIV/AIDS/ World Health Organization. (2010). AIDS Epidemic Update 2009. Retrieved from: http://www.unaids.org/en/dataanalysis/epidemiology/2009aidsep idemicupdate/. 
Justice, A. C., Holmes, W., Gifford, A. L., Rabeneck e, L., Zackin, R., Sinclair, G., . . ., Wum, A. W. (2001). Development and validation of a self-completed HIV symptom index. Journal of Clinical Epidemiology, 54, 77-90. doi: 10.1016/S0895-4356(01)00449-8

Kamb, M. L., Fishbein, M., Douglas, J. M., Rhodes, F., Rogers, J., Bolan, G.,..., Peterman, T.A. (1998). Efficacy of risk-reduction counseling to prevent human immunodeficiency virus and sexually transmitted diseases: A randomized controlled trial. The Journal of American Medical Association, 280, 1161-1167. doi:10.1001/jama.280.13.1161

Kipp, W. E., Alibhai, A., Saunders, D., Konde-lule, J., \& Ruhunda, A. (2009). Public knowledge and attitude toward HIV/AIDS and antiretroviral therapy in Kabarole district Western Uganda. AIDS Care, 21, 118-124.

Kirby, D. (2002). The impact of schools and school programs upon adolescent sexual behavior. The Journal of Sex Research, 39, 27-33. doi: 10.1080/00224490209552116

Knowles, M. S., Holton, E. F., \& Swanson, R. A. (1998). The adult learner. The definitive classic in adulteducation and human resource development. Houston: Gulf Publishing Company.

Koblin, B. A. (2004). Effects of a behavioural intervention to reduce acquisition of HIV infection among men who have sex with men: The EXPLORE randomised controlled study. The Lancet, 364, 41-50. doi: 10.1016/S0140-6736(04)16588-4

Kohler, P. K., Manhart, L. E., \& Lafferty, W. E. (2008). Abstinence-only and comprehensive sex education and the initiation of sexual activity and teen pregnancy. Journal of Adolescent Health, 42, 344-351. doi: 10.1016/j.jadohealth.2007.08.026

Kristanti, C. M. (1995). Generasi muda dan masalah perilaku berisiko. Majalah Kesehatan Masyarakat Indonesia, 23, 92-97.

Kroenke, K. (2003). Patients presenting with somatic complaints: Epidemiology, psychiatric comorbidity and management. International Journal of Methods in Psychiatric Research, 12, 3443. doi: 10.1002/mpr.140

Kroenke, K., \& Price, R. K. (1993). Symptoms in the community: Prevalence, classification, and psychiatric comorbidity. Archives of Internal Medicine, 153, 2474-2482. doi:10.1001/ archinte.153.21.2474

Latham, G. P., \& Locke, E. A. (2007). New developments in and directions for goal-setting research. European Psychologist, 12, 290-300.doi: 10.1027/1016-9040.12.4.290

Lazarus, R.S. (1993). Coping theory and research: Past, present, and future. Psychosomatic Medicine, 55, 234-247.

Lazarus, R. S., \& Folkman, S. (1991). The concept of coping. In A. Monat \& R. S. Lazarus (Eds.), Stress and coping: An anthology (pp. 189-206). New York: Colombia University Press.

Leandro, M. (2012). Young drivers and speed selection: A model guided by the theory of planned behavior. Traffic Psychology and Behavior, 15, 219-232. doi: 10.1016/j.trf.2011.12.011

Lee, J., Johnson, C., Rice, J., Warren, C. W., \& Chen, T. (2013). Smoking belief and behavior among youth in South Korea, Taiwan and Thai. International Journal of Behavioral Medicine, 20, 319326.doi: 10.1007/s12529-012-9236-3 
Lohrmann, C., Èki, M. V. E, Suominen, Y., Muinonen, U., Dassen, T., \& Peate, I. (2000). German nursing students' knowledge of and attitudes to HIV and AIDS: Two decades after the first AIDS cases. Journal of Advanced Nursing, 31, 696-703. doi: 10.1046/j.1365-2648.2000.01326.x

Loeb, S. J., O'Neill, J., \& Gueldner, S. H. (2001). Health motivation: A determinant of older adults' attendance on health promotion programs. Journal of Community Health Nursing, 18, 151-165. doi: $10.1207 / 153276501750408907$

Lotrean, L. M., Mesters, I., \& de Vries, H. (2013). Why do Romanian junior high school students start to smoke?. Child: Care, Health \& Development, 39, 851-855. doi: 10.1111/j.13652214.2012.01428.x

MacDonald, J. M., Gagnon, A. J., Mitchell, C., Meglio, G. D., Rennick , J. E., \& Cox, J. (2011). Include them and they will tell you: Learning from a participatory process with youth. Qualitative Health Research, 21, 1127-1135. doi: 10.1177/1049732311405799

Mahaffey, K. J., \& Markus, D. K. (1995). Correctional officers' attitudes toward AIDS. Criminal Justice and Behavior, 22, 91-105.doi: 10.1177/0093854895022002001

Mahalik, J. R., Coley, L., Lombardi, R. M., Lynch, A. C., Markowitz, A. J., \& Jaffee, S. R. (2013). Changes in health risk behaviors for males and females from early adolescence through early adulthood. Health Psychology, 32, 685-694.

Mahendradhata Y., Ahmad, R. A., Kusuma, T. A., Boelaert, M., Van der Werf, M. J., Kimerling, M. E., \& Van der Styft, P. (2008). Voluntary counseling and testing prevalence among tuberculosis patients in Jogjakarta, Indonesia. Transaction of the Royal Society of Tropical Medicine and Hygiene, 102, 1003-1010. doi: 10.1016/j.trsmh.2008.04.042

Malmberg, M., Overbeek, G., Vermulst, A. A., Monshouwer, K., Vollenbergh, W. A. M., \& Engels, R. C. M. E. (2012). The theory of planned behavior: Precursors of marijuana use in early adolescence? Drug and Alcohol Dependence, 123, 22-28. doi: 10.1016/j.drugalcdep.2011.10.011

Manirankunda, L., Loos, J., Debackaere, P., \& Nöstlinger, C. (2012). "It Is Not Easy": Challenges for Provider-Initiated HIV Testing and Counseling in Flanders, Belgium. AIDS Education and Prevention, 24(5), 456-468. doi: 10.1521/aeap.2009.21.6.582.

Manirankunda, L., Loos, J., Alou, T. A., Colebunders, R., \& Nöstlinger, C. (2009). "It's better not to know": Perceived barriers to HIV voluntary counseling and testing among sub-Saharan African migrants in Belgium. AIDS Education \& Prevention, 21(6), 582-593. doi: 10.1521/ aeap.2009.21.6.582

Marks, G., Crepaz, N., Senterfitt, J. W., \& Janssen, R. S. (2005). Meta-analysis of high-risk sexual behavior in persons aware and unaware they are infected with HIV: Implications for HIV prevention programs. Journal of AcquiredImmune Deficiency Syndrome, 39, 446-453. doi: 10.1097/01.qai.0000151079.33935.79

Marlatt, G. A., \& Gordon, J. R. (1985). Relapse prevention: Maintenance strategies in the treatment of addictive behavior. New York: Guilford Press.

Mathie, V.A., Beins, B., Benjamin, L.T., Ewing, M.M., Hall, C.C., Henderson, B., ..., Smith, R.A. (1993). Promoting active learning in psychology courses. In T. V. McGovern (Ed.), Handbook for Enhancing Undergraduate Education in Psychology (pp. 183-214). Washington, DC: American Psychological Association. 
Mazanov, J., \& Byrne, D. G. (2007). Do you intend to smoke?: A test of the assumed psychological equivalence in adolescent smoker and non-smoker intention to change smoking behavior. Australian Journal Psychology, 59, 34-42. doi: 10.1080/00049530600944366

McAllister, A. L., Perry, C. L., \& Parcel, G. S. (2008). How individuals, environments, and health behaviors interact: Social cognitive theory. In K. Glanz, B. K. Rimmer, \& K. Viswanath (Eds.), Health Behavior and Health Education (pp. 169-188). San Francisco: Jossey-Bass.

McIntyre, D., Marquart, J., \& Brewer, V. (1995). Toward an understanding of the perception of HIV/ AIDS-related risk among prison officers. Journal of Criminal Justice, 27, 525-538. doi: 10.1016/ S0047-2352(99)00023-9

McKee, K. J., Markova, I., Power, K. G. (1995). Concern, perceived risk and attitudes towards HIV/ AIDS in Scottish prisons. AIDS Care, 7, 159-170. doi: 10.1080/09540129550126687

McLeroy, K. R., Bibeau, D.,Steckler, A., \& Glanz, K. (1988). Anecological perspectiveon health promotion programs. Health Education Quarterly, 15, 351-377. doi:10.1177/109019818801500401

McMillan, J. H., \& Schumacher, S. (2009). Research in education: Evidence-based inquiry. Essex: Pearson Education Limited.

Mercken, L., Snijders, T. A. B., Steglich, C., Vertiainen, E., \& de Vries, H. (2010). Smoking-based selection and influence in gender-segregated friendship networks: A social network analysis of adolescent smoking. Addiction, 105, 1280-1289. doi: 10.1111/j.1360-0443.2010.02930.x

Mercken, L., Steglich, C., Sinclair, P., Holliday, J., \& Moore, L. (2012).A longitudinal social network analysis of peer influence, peer selection, and smoking behavior among adolescents in British schools. Health Psychology, 31, 450-459. doi: 10.1037/a0026876

Mesquita, F., Winarso, I., Atmosukarto, I.I., Eka, B., Nevendorff, L., Rahmah, A., . . Angela, R. (2007). Public health the leading force of the Indonesian response to the HIV/AIDS crisis among people who inject drugs. Harm Reduction Journal, 4,1-6. doi: 10.1186/1477-7517-4-9

Mevissen, F. E. F., Meertens, R. M., Ruiter, A. A. C., Feenstra, H., \& Schaalma, H. P. (2009). HIV/ STI risk communication: The effects of scenario-based risk information and frequency-based risk information on perceived susceptibility to chlamydia and HIV. Journal of Health Psychology, 14, 78-87. doi: 10.1177/1359105308097948

Michie, S., Johnston, M., Francis, J., Hardeman, W., \& Eccles, M. (2008). From theory to intervention: mapping theoretically derived behavioral determinants to behavior change techniques. Applied Psychology: An International Review, 57, 660-680. doi: 10.1111/j.1464-0597.2008.00341.x

Mikolajczak, J., Kok, G., \& Hospers, H. J. (2008). Queermasters: Developing a theory and evidencebased internet HIV-prevention intervention to promote HIV-testing among men who have sex with men (MSM). Applied Psychology: An International Review, 57,681-697. doi: 10.1111/j.14640597.2008.00342.x

Millar, R., \& Shevlin, M. (2003). Predicting career information-seeking behavior of school pupils using the theory of planned behavior. Journal of Vocational Behavior, 62, 26-42. doi: 10.1016/S00018791(02)00045-3

Ministry of Education. (2009). Mutu pendidikan meningkat. Retrieved from: http://www.indonesia. go.id/in/pemerintah-daerah/provinsi-jawa-barat/1248-pendidikan/1491-mendiknas-mutupendidikan-meningkat 
Ministry of Education. (2003). Undang-undang Republik Indonesia nomor 20 tahun 2003. Retrieved from: http://luk.staff.ugm.ac.id/atur/UU20-2003Sisdiknas.pdf

Ministry of Education. (1997). Instruksi Menteri Pendidikan dan Kebudayaan Indonesia No. 9/U/1997 tanggal 24 November 1997 tentang Pencegahan HIV dan AIDS melalui Pendidikan dan Keputusan Menteri Pendidikan dan Kebudayaan Indonesia No. 303/U/1997 tanggal 24 November 1997 tentang Pedoman Pencegahan HIV dan AIDS melalui Pendidikan. Jakarta: Depdiknas

Ministry of Health. (2013). Laporan perkembangan HIV-AIDS triwulan III tahun 2013. Retrieved from: http://www.aidsindonesia.or.id/ck_uploads/files/Final\%20Laporan $\% 20$ HIV \% 20AIDS \% 20 Triwulan \%203\%202013.pdf

Ministry of Health. (2010). Estimate adult HIV vulnerable population 2009 report. Jakarta: Ministry of Health.

Ministry of Health. (2010). Mathematic model of HIV epidemic in Indonesia 2008-2014. Retrieved from: http://spiritia.or.id/Doc/model0814.pdf

Ministry of Health \& World Health Organization. (2003). Indonesia reproductive health profile. Jakarta: Ministry of Health.

Ministry of Justice and Human Rights, Directorate of Correction. (2010). HIV and syphilis prevalence and risk behavior study among prisoners in prison and detention centers in Indonesia. Retrieved from: http://www.spiritia.or.id/Doc/IBBSPrison2010.pdf

Mkumbo, K., Schaalma, H., Kaaya, S., Leerlooijer, J., Mbwambo, J., \& Kilonzo, G. (2009). The application of intervention mapping in developing and implementing school-based sexuality and HIV/AIDS education in a developing country context: The case of Tanzania. Scandinavian Journal of Public Health, 37, 28-36. doi: 10.1177/1403494808091345

Moan, I. S., \& Rise, J. (2005). Quitting smoking: Applying an extended version of the theory of planned behavior to predict intention and behavior. Journal of Applied Biobehavioral Research, 10, 3968. doi: 10.1111/j.1751-9861.2005.tb00003.x

Morineau, G., Bollen, L. J. M., Syafitri, R. I., Nurjannah, N., Mustikawati, D. E., \& Magnani, R. (2012). HIV prevalence and risk behaviors among injected drug users in six cities implications for future HIV prevention program. Harm Reduction Journal, 9 (37). doi: 10.1186/1477-7517-9-37

Mulder, N. (1998). Mysticism in Java: Ideology in Indonesia. Amsterdam: Pepin Press.

Mullen, P. D., Mains, D. A., \& Velez, R.(1992). A meta-analysis of controlled trials of cardiac patient education. Patient Education and Counseling, 19, 143-162.doi: 10.1016/0738-3991(92)90194-N

Murnaghan, D. A., Blanchard, C., Rodgers, W., La Rosa, J., Macquarrie, C., MacClelland,D., \& Gray, B. (2009). The influence of student-level normative, control and behavioral beliefs on staying smoke-free: An application of Ajzen's theory of planned behavior. Addiction Research and Theory, 17, 469-480. doi: 10.1080/16066350802011649

Myklestad, I., \& Rise, J. (2008). Predicting intentions to perform protective sexual behaviours among Norwegian adolescents. Sex Education: Sexuality, Society and Learning, 8, 107-124. doi: 10.1080/14681810701811886

Narcotics Board of Indonesia. (2004). Report result research narcotic problem in prisons. Jakarta: Narcotics Board of Indonesia. 
Nation, M., Crusto, C., Wandersman, A., Kumpfer, K.L., Seybolt, D., Morrissey-Kane, E., \& Davino, K. (2003). What works in prevention: Principles of effective prevention programs. American Psychologist, 58, 449-456. doi: 10.1037/0003-066X.58.6-7.449

Nemme, H. E., \& White, K. M. (2010). Texting while driving: Psychosocial influences on young people's texting intentions and behaviour. Accident Analysis and Prevention, 42, 1257-1265. doi: 10.1016/j.aap.2010.01.019

Nelwan, E. J., van Crevel, R., Alisjahbana, B., Indrati, A., Dwiyana, R. F., Nuralam, N., . . van der Ven, A. (2010). Human immunodeficiency virus, hepatitis B and hepatitis $C$ in an Indonesian prison: Prevalence, risk factors and implications of HIV screening. Tropical Medicine and International Health, 15, 1491-1498. doi: 10.1111/j.1365-3156.2010.02655.x.

Nelwan, E. J., Diana, A., van Crevel, R., Alam, N. N., Alisjahbana, B., Pohan, H. T., ..., Djaya, I. (2009). Indonesian prisons and HIV: Part of the problem, part of the solution?. Acta Medica Indonesiana, 41, 52-56.

$\mathrm{Ng}, \mathrm{N}$., Weinehall, L., \& Ohman, A. (2007). If I don't smoke, I'm not a real man' - Indonesian teenage boys' views about smoking. Health Education Research, 22, 794-804. doi: http://dx.doi. org/10.1093/her/cyl104

O’Donnell, J., Hawkins, J., Catalano, D., Abbott, R. F., Day, R. D., \& Edward, L. (1998). Preventing school failure, drug use, and delinquency among low-income children: Long-term intervention in elementary schools. American Journal of Orthopsychiatry, 65, 87-100. doi: 10.1037/h0079598

Orpinas, P., \& Horne, A. M. (2004). A teacher-focused approach to prevent and reduce students' aggressive behavior: The GREAT teacher program. American Journal of Preventive Medicine, 26, 29-38.doi: 10.1016/j.amepre.2003.09.016

Otten, R., Warner, B., Vitaro, F., \& Engels, R.C.M.E. (2008). Own and friends' smoking attitude and social preference as early predictors of adolescent smoking. Journal of Clinical Child and Adolescent Psychology, 37,808-819. doi: 10.1080/15374410802359619

Page, R. M., Suwanteerangkul, J., Ricks, R., \& Kemeny, M.(2011). Meanings of smoking among adolescents in Chiang Mai, Thailand. International Quarterly of Community Health Education, 32, 23-39. doi: 10.2190/IQ.32.1.d

Paglia, A., \& Robin, R. (1999). Preventing substance use problems among youth: A literature review and recommendations. The Journal of Primary Prevention, 20, 3-50. doi: 10.1023/A:1021302302085

Panday, S., Reddy, S. P., Ruiter, R. A. C., Bergstro, E., De Vries, CH. (2007). Determinants of smoking among adolescents in the Southern Cape-Karoo region, South Africa. Health Promotion International, 22(3). doi:10.1093/heapro/dam018

Park, E. (2006). School-based smoking prevention programs for adolescents in South Korea: A systematic review. Health Education Research, 21, 407-415. doi: 10.1093/her/cyl038

Parker, R., \& Aggleton, P. (2003). HIV and AIDS-related stigma and discrimination: A conceptual framework and implications for action. Social Science \& Medicine, 57, 13-24. doi: 10.1016/ S0277-9536(02)00304-0

Pasick, R. J., Burke, N. J., Barker, J. C., Joseph, G., Bird, J. A., Otero-Sabogal, R., . . Guerra, C. (2009). Behavioral theory in a diverse society: Like a compass on Mars. Health Education \& Behavior, 36, 11-35. doi: 10.1177/1090198109338917 
Perron, B. E., \& Howard, M. O. (2008). Perceived risk of harm and intentions of future inhalant use among adolescent inhalant users. Drug and Alcohol Dependence, 97, 185-189. doi: 10.1016/j. drugalcdep.2008.04.005

Peters, G-J. Y., Ruiter, R. A. C., \& Kok, G. (2012). Threatening communication: A critical re-analysis and a revised meta-analytic test of fear appeal theory. Health Psychology Review, 1, 1-24. doi:1 $0.1080 / 17437199.2012 .703527$

Peters, L. W., Kok, G., Ten Dam, G. T., Buijs, G. J., \& Paulussen, T. G. (2009). Effective elements of school health promotion across behavioral domains: A systematic review of reviews. BMC Public Health, 9 (182). doi: 10.1186/1471-2458-9-182

Petty, R. E., Barden, J., \& Wheeler, S. C. (2009). The elaboration likelihood model of persuasion: Developing health promotions for sustained behavioral change. In R. J. DiClemente, R. A. Crosby, \& Kegler, M.C. (Eds.). Emerging Theories in Health Promotion Practice and Research (pp. 185-214). San Francisco: Jossey-Bass.

Piko, B. (2001). Smoking in adolescence. Do attitudes matter?. Addictive Behaviors, 26, 201-207. doi: 10.1016/S0306-4603(00)00101-5

Potard, C., Courtois, R., Le Samedy, M., Mestre, B., Barakat, M. J., \& Reveillere, C. (2012). Determinants of the intention to use condoms in a sample of French adolescents. European Journal of Contraception and Reproductive Health Care, 17, 55-64. doi: 10.3109/13625187.2011.634455

Potter, B. K., Pederson, L. L., Chan, S. S. H., Aubut, J. L., \& Koval, J. J. (2004). Does a relationship exist between body weight, concerns about weight, and smoking among adolescents? An integration of the literature with an emphasis on gender. Nicotine \& Tobacco Research, 6, 397-425. doi: $10.1080 / 14622200410001696529$

Power, K. G., Markova, I., Rowlands, A., McKee, K. J., Anslow, P. J., \& Kilfedder, C. (1991). Sexual behaviour in Scottish prisons. British Medical Journal, 302, 1507-1508. doi: 10.1136/ bmj.303.6805.783-b

Puente, C. P., Gutiérrez, J. L., Abellánm, I. C. G., \& López, A. L. (2008). Sensation seeking, attitudes toward drug use, and actual use among adolescents: Testing a model for alcohol and ecstasy use. Substance Use and Misuse, 43, 1615-1627. doi: 10.1080/10826080802241151

Qu, B., Zhang, Y., Guo, H., \& Sun, G. (2010). Relationship between HIV/AIDS knowledge and attitude among student nurses: A structural equation model. AIDS Patient Care and STDs, 24, (59-63). doi: $10.1089=$ apc.2009.0190

Rasmussen, G. (1956). An evaluation of student-centered and instructor-centered method of conducting a graduate course in education. Educational Psychology, 47, 449-461.

Reinaerts, E., de Nooijer, J., Candel, M., \& de Vries, N. (2007). Explaining school children's fruit and vegetable consumption: The contributions of availability, accessibility, exposure, parental consumption and habit in addition to psychosocial factor. Appetite, 48, 248-258. doi: 10.1108/09654280810884188

Richard, R., van der Pligt, J., \& de Vries, D. (1995). Anticipated affective reactions and prevention of AIDS. British Journal of Social Psychology, 34, 9-21. doi: 10.1111/j.2044-8309.1995.tb01045.x

Rivis, A., Sheeran, P., \& Armitage, J. C. (2011). Intention versus identification as determinants of adolescents' health behaviours: Evidence and correlates. Psychology and Health, 26, 1128-1142. doi: 10.1080/08870440902850310 
Rotily, M., Weilandt, C., Sheola, B., Käll, M., van Haastrecht, K., Harry J., . . Rousseau, E. (2001). Surveillance of HIV infection and related risk behaviour in European prisons: A multicentre pilot study. European Journal of Public Health, 11, 243-250. doi: 10.1093/eurpub/11.3.243

Sasaki, Y., Andryansyah, A., Moazzam, A., \& Kazuhiro, K. (2011). Willingness to undergo HIV testing among factory workers in Surabaya, Indonesia. AIDS Care, 23, 1305-1313. doi: $10.1080 / 09540121.2011 .555745$

Sawitri, A. A. S., Sumantera, G. M., Wirawan, D. N., Ford, K., \& Lehman, E. (2006). HIV testing experience of drug users in Bali, Indonesia. AIDS Care, 18, 577-588. doi: 10.1080/09540121.2011.555745

Schaalma, H., \& Kok, G. (2009). Decoding health education interventions: The times are achangin'. Psychology and Health, 24, 5-9. doi:10.1080/08870440801995802

Smet, B., Maes, L., De Clercq, L., Haryanti, K., \& Winarno, R. D. (1999). Determinants of smoking behavior among adolescents in Semarang, Indonesia. Tobacco Control, 8, 186-191.

Smith, R. A. (1993). Promoting active learning in psychology courses. In T. V. McGovern (Ed.), Handbook for Enhancing Undergraduate Education in Psychology (pp. 183-214). Edited by McGovern TV. Washington, DC: American Psychological Association.

Solomon, S. S., Celentano, D. D., Srikrishnan, A. K., Vasudevan, C. K., Anand, S., Kumar, M. S., . . Mehta, S. H. (2009). Mortality among injection drug users in Chennai, India. AIDS, 23, 997-1004. doi: 10.1097/QAD.0b013e32832a594e

Song, A. V., Glantz, S. A., \& Halpern-Felsher, B. L. (2009). Perceptions of second-hand smoke risks predict future adolescent smoking initiation. The Journal of Adolescent Health, 45, 618-625. doi: 10.1016/j.jadohealth.2009.04.022

Stead, M., Stradling , R., MacNeil, M., MacKintosh, A. M., Minty, S., McDermott, L., \& Eadie, D. (2010). Bridging the gap between evidence and practice: A multi-perspective examination of real-world drug education. Drugs: Education, Prevention and Policy, 17, 1-20. doi: $10.3109 / 09687630802228341$

Suherman, H., Sodjakusumah, T., Puspitasari, T., \& Sumintardja, E. (2014). Barriers to VCT services among IDUs in community. Manuscript submitted for publication.

Thoresen, C. E., \& Kirmil-Gray, K. (1983). Self-management psychology and the treatment of childhood astma. Journal of Allergy and Clinical Immunology, 72, 596-610.

Thrul, J., Stemmler, M., Bühler, A., \& Kuntsche, E. (2013). Adolescents' protection motivation and smoking behaviour. Health Educational Research, 28, 683-691. doi:10.1093/her/cyt062

Tobler, N. S., Roona, M. R., Ochshorn, P., Marshall, D. G., Streke, A. V., \& Stackpole, K. M. (2000). School-based adolescent drug prevention programs: 1998 meta-analysis. The Journal of Primary Prevention, 20, 275-336. doi: 10.1023/A:1021314704811

Triandis, H. C. (2001). Individualism-collectivism and personality. Journal of Personality, 69, 907924. doi: 10.1111/1467-6494.696169

U.S. Agency for International Development. (2007). HIVIAIDS Health Profile: Indonesia. Retrieved from: http://transition.usaid.gov/our_work/global_health/aids/Countries/asia/indonesia_profile.pdf.

United Nations Development Programme. (2007). Project Fact: The Indonesian Partnership Fund for HIV and AIDS. Retrieved from: http://www.undp.or.id/factsheets/2007/MDG $\% 20 \mathrm{HIV} \% 20$ Nov2007.pdf 
United Nations Development Programme/United Nations General Assembly Special Session. (2009). Indonesia Country Report 2008. Retrieved from: http://www.undp.or.id/programme/pro-poor/ hiv-aids.asp.

United Nations Educational, Scientific, and Cultural Organization. (2010). Education Sector Response to HIV, Drugs and Sexuality in Indonesia. Retrieved from: http://unesdoc.unesco.org/ images/0018/001888/188887e.pdf.

United Nations Children's Fund. (2009). Children and AIDS. Retrieved from: http://www.unicef.org/ publications/files/Children_and_AIDS_Fourth_Stocktaking_Report_EN_120209.pdf.

United Nations Office of Drugs and Crime. (2006). Baseline assessment of the current status of resources, policies and services for intravenous drug use and HIVIAIDS in South and South East Asia: 2006. Melbourne: UNODC.

Vitória, P. D., Salgueiro, M., Fátima, Silva, S. A., \& de Vries, H. (2011). Social influence, intention to smoke, and adolescent smoking behavior longitudinal relations. British Journal of Health Psychology, 16, 779-798. doi: 10.1111/j.2044-8287.2010.02014.x

Waller, P. R., Crow, C., Sands, D., \& Becker, H. (1988). Health related attitudes and health promoting behaviors: Differences between health fair attenders and a community comparison group. American Journal of Health Promotion, 3, 17-24. doi: 10.4278/0890-1171-3.1.17

Winkelstein, W., Wiley, J.A., Padian, N.S., Samuel, M., Shiboski, S., Ascher, M. S., Levy, J. A. (1988). The San Francisco men's health study: Continued decline in HIV seroconversion rates among homosexual/bisexual men. American Journal of Public Health, 78, 1472-1474. doi: 10.2105/ AJPH.78.11.1472

World Health Organization. (2011). WHO Report on the Global Tobacco Epidemic 2011. Retrieved from: http://www.who.int/tobacco/surveillance/policy/country_profile/idn.pdf

World Health Organization. (2005). Summary Country Profile for HIVIAIDS Treatment Scale Up: Indonesia. Retrieved from: http://www.who.int/hiv/HIVCP_IDN.pdf

World Health Organization. (2007). HIV Prevention Care and Treatment in Prisons in the South-East Asia Region. Retrieved from: http://www.searo.who.int/LinkFiles/Publications_TreatmentinPrisons.pdf

World Health Organization, South East Asia Regional Office. (2009). Global Youth Tobacco Survey. Retrieved from: http://www.searo.who.int/LinkFiles/GYTS_IndonesiaFactsheet2009.pdf.

White, K. M., Thomas, I., Johnston, K. L., \& Hyde, M. K. (2008). Predicting attendance at peer-assisted study sessions for statistics: Role identity and the theory of planned behavior. Journal of Social Psychology, 148, 473-491. doi: 10.3200/SOCP.148.4.473-492

Wisaksana, R., Indrati, R. A., Fibriani, A., Rogayah, E., Sudjana, P., Djajakusumah. T., ..., van Crevel, R. (2010). Response to firstline antiretroviral treatment among HIV-infected patients with and without a history of injected drug use in Indonesia. Addiction, 105, 1055-1061. doi: 10.1111/j.1360-0443.2010.02898.x

Wisaksana, R., Alisjahbana, B., van Crevel, R., Kesumah, N., Sudjana, P., \& Sumantri, R. (2009). Challenges in delivering HIV-care in Indonesia: Experience from a referral hospital. Acta Medica Indonesiana, 41, 45-51. 


\section{Summary}

Samenvatting

Acknowledgements

About the Author

Publication List 



\title{
Summary
}

\begin{abstract}
A s a response to the HIV epidemic in Indonesia during the period of 2006 to 2008, implementation of HIV prevention strategies aimed to increase the coverage of HIV testing and to improve HIV-related knowledge among the most-at-risk groups and general population was very essential. However, there were several behavior-related issues among the targeted populations (i.e. late testing) and the program implementers (i.e. stigmatization) that might hinder the effectiveness of the implementation of the two strategies. The series of studies presented in this dissertation will focus on: (1) identifying the HIV preventionrelated determinants that underlying those unwanted behaviors; and (2) developing and evaluating an intervention program aimed to modify the behavioral determinants in one of the most-at-risk groups.
\end{abstract}

In this dissertation five different studies are presented. Chapter $\mathbf{1}$ introduces the HIV-related behavioral issues among the program implementers in health, correctional, and educational settings as well as the importance of behavioral theories in developing and evaluating a systematic HIV prevention program. This chapter ends with an overview of each study. All studies were conducted in Bandung, one of the cities in Indonesia that had the highest number of HIV cases. The use of intravenous substances was identified as the main HIV transmission route in this city during that period of time.

To upscale HIV testing among the most-at-risk group and among the general population, health care facilities in Indonesia need to promote provider initiated testing and counseling (PITC) to their patients. It is very important for health care workers (HCWs) to remain aware of the most common HIV-related personal characteristics. Chapter $\mathbf{2}$ describes a study aimed to examine the specific HIV-related health symptoms and socio-cognitive determinants among VCT and PITC patients in a tertiary referral hospital in West Java (Study 1). Data collection of this cross sectional study was conducted using a self-report questionnaire and blood sampling. The results of this study indicated that: (1) a combination of two specific symptoms (chronic diarrhea and oral thrush) and HCV co-infection had a high predictive value of HIV infection; (2) lower CD4 cell counts were found among the patients who were 
diagnosed through PITC procedure and who had extreme weight loss; and (3) the main HIV testing-related barriers for this study population were lack of knowledge and the absence of prevention awareness. The HCWs in this study context may use these results to proactively identify patients who potentially present late for testing. A proper educational program is needed for the general population, especially those with lower educational level, which is aimed to increase: (1) HIV testing-related knowledge; and (2) prevention awareness.

Chapter 3 describes a study among prison officers in a narcotics prison (Study 2). The prevalence of people with HIV in Indonesian prisons was significantly higher than in the general population. In this correctional setting, the officers are the key players in providing care and support for inmates with HIV. The aims of the study were to identify the specific misconceptions about the disease and to examine the relationship between knowledge and attitudes towards inmates with HIV. Ninety three officers voluntarily participated in this cross sectional study by filling out a self-report questionnaire. The results identified several misconceptions about (1) the disease (i.e. the availability of a medicine to cure the disease); (2) the transmission modes (i.e. sharing a tooth brush can transmit the virus); and (3) the prevention strategies (i.e. an isolation room for inmates with HIV can prevent the spread of the virus to other inmates). Moreover, this study showed that there were significant positive correlations between the three types of HIV-related knowledge and the attitudes. The more knowledgeable the officers are, the less likely that they have negative attitudes towards the inmates. These results suggest the vast need of a regular HIV-related education program for the officers as well as proper support from relevant authorities to ensure the availability of updated materials and to implement proper policies within the prisons.

A public school is a potential place to implement HIV prevention program for young adolescents as it is mandatory for those adolescents to attend basic education (9 years). Therefore, teachers at the schools play an active role in increasing HIV-related knowledge among their students. Chapter $\mathbf{4}$ describes a study aimed to examine socio-cognitive factors that determined the teachers' willingness to facilitate a drug education and sexual reproductive health program for adolescents in schools (Study 3). Focus group discussions with selected teachers were conducted prior to the quantitative data collection. Three hundred and sixty teachers from 25 junior high schools voluntarily participated in this study by filling out a self-report questionnaire. Using the Theory of Planned Behavior as a basic theory, it was argued that the more favorable their attitude toward the behavior and the stronger their perceived subjective norm and perceived behavioral control, the higher their intentions to facilitate the two sensitive topics. The results fully confirmed those hypotheses. The attitude toward the behaviors appeared as the most salient determinant for the intention. This study also identified perceived barriers related to facilitating the program among the teachers. The absence of the two topics from the official curriculum and the lack 
of knowledge and skills emerged as the two main environmental and personal barriers. Thus, it is important to develop a training program for the teachers to: (1) develop positive attitude towards teaching the two subjects; (2) develop the teachers' facilitating skills; and (3) provide updated knowledge about the topics. The formal inclusion of the topics in the curriculum is also needed to ensure the time allocation for the intended program and the final exam to evaluate the impact of the program.

Chapter 5 describes the systematic development of a substance use prevention program for students using the Intervention Mapping Framework (Study 4). Active participation of all related stakeholders in the six steps of program development, as suggested by the framework, did maintain the "in-group" feeling of the people involved in this study context. The intended program aimed to prevent and to eliminate substance use behavior, especially the use of tobacco products, among 8th grade students (personal outcomes), and to provide a drug education program as well as a tobacco-free environment in the public schools (environmental outcomes). Specifically, by applying these teaching strategies, the program aimed to increase: (1) the behavioral, normative, and control beliefs of substance-free behavior; and (2) the substance-free-related knowledge. It was expected that the increase of those determinants will increase the intention to perform the substance-free behavior. The program is called HEBAT! program. This is a paper-based program for the 8th grade students in all public schools in Bandung. Guidance and Counseling teachers as well as virtual peer educators were employed as the main facilitators of the program. The main challenge in this program development was to find a balance between the parameter for use as suggested by behavioral theories to ensure the effectiveness of the program and the actual conditions in this study context to ensure the applicability of the program. It is also suggested to develop a program that can address multiple health-related behaviors to guarantee the efficiency of the future program development.

In Chapter 6, Study 5 is described, which the effectiveness of the substance-use prevention program in achieving its initial goals was investigated. The impact evaluation study was conducted by employing a non-randomized control group pre-test and post-test design for more than six thousand students in comparison and intervention groups. A selfreport questionnaire was collected from the students a week before and a week after the implementation of HEBAT! program. It was hypothesized that the implementation of the program would increase the knowledge and the three types of beliefs of the students that might lead to an increase in their intention to perform substance-free behavior. The results showed that the program effectively influenced perceived behavioral control and knowledge of the students immediately after the implementation. No significant effects were found for the attitudes, perceived subjective norms, and intentions. Several explanations were discussed to explain the results of this study, including ceiling effects and implementation 
failures by the teachers. There is a vast need to improve the current teaching strategies and teacher training to ensure that the future program is easier for the teachers to implement.

Finally, in Chapter 7, the main findings of the five studies are discussed and concluded. Several highlights are presented in this chapter, including (1) the specific personal determinants (i.e. knowledge, beliefs, health symptoms and socio demographic) that underlie HIV-prevention behaviors among the most at risk groups and the related social environments; and (2) the challenges in developing a systematic intervention program aimed to modify the targeted behavioral determinants among the students. Possible recommendations for future studies as well as practical implications are discussed. 


\section{Samenvatting}

A Is resultaat van de HIV epidemie in Indonesië gedurende de periode van 2006 tot 2008, waren HIV preventiestrategieën gericht op het vergroten van het bereik van HIV testen en op het vergroten van HIV-gerelateerde kennis onder de risicogroepen en de algemene populatie. Echter, er waren verschillende gedragsgerelateerde barrières bij doelgroepen (zoals niet of laat testen) en bij uitvoerders van preventie programma's (zoals stigmatisering), die de effectiviteit van voornoemde strategieën zouden kunnen belemmeren.

De reeks studies gepresenteerd in dit proefschrift focussen zich op: (1) identificatie van de HIV-preventie determinanten die ten grondslag liggen aan het ongewenste gedrag; en (2) het ontwikkelen en evalueren van een interventieprogramma gericht op het veranderen van gedragsdeterminanten in één van de meest risicovolle doelgroepen.

In dit proefschrift worden vijf verschillende studies gepresenteerd. Hoofdstuk 1 introduceert de HIV-gerelateerde gedragsproblematiek onderprogramma-uitvoerders in de gezondheidszorg, gevangenissen en educatieve instellingen als mede het belang van gedragstheorieën in de ontwikkeling en evaluatie van een systematische HIV-preventie programma. Dit hoofdstuk eindigt met een overzicht van iedere studie. Alle studies werden uitgevoerd in Bandung, één van de steden in Indonesië met het hoogste aantal HIV-geïnfecteerden. Intraveneus druggebruik werd geïdentificeerd als de voornaamste HIVtransmissieroute in Bandung gedurende die periode.

Om het HIV testen te bevorderen onder de meest risicovolle doelgroep en onder de algehele bevolking moeten zorginstellingen in Indonesië door zorgverleners geïnitieerde testen en counseling (PITC - "provider-initiatedtesting and counselling") promoten. Het is zeer belangrijk voor hulpverleners (HCWs -"health care workers") om kennis te hebben van de meest voorkomende HIV-gerelateerde persoonskarakteristieken, ziekteverschijnselen en risicogedragingen.

Hoofdstuk 2 beschrijft een studie gericht om de specifieke HIV-gerelateerde gezondheidsklachten en sociaal-cognitieve determinanten bij VCT- en PITC-patiënten in 
een ziekenhuisin West-Java te onderzoeken (Studie 1). Het verzamelen van gegevens van deze cross-sectionele studie werd uitgevoerd met behulp van een zelf-rapportagevragenlijst en bloedafname. De resultaten van deze studie gaven aan dat: (1) een combinatie van twee specifieke symptomen (chronische diarree en spruw) en HCV co-infectie een hoge voorspellende waarde voor HIV-infectie heeft; (2) lagere CD4-cellen werden gevonden bij patiënten die gediagnostiseerd werden met behulp van de PITC procedure en bij hen die een extreem gewichtsverlies hadden; en (3) de belangrijkste HIV test gerelateerde barrières voor deze doelgroep gebrek aan kennis waren en afwezigheid van preventie-bewustzijn. De HCWs in deze kunnen deze resultaten gebruiken om proactief patiënten te identificeren die zich in een laat stadium komen laten testen. Een goed educatief programma is nodig voor de algehele bevolking, met name degene met lager opleidingsniveau, die gericht is op het verhogen van: (1) HIV-test gerelateerde kennis; en (2) preventie-bewustzijn.

Hoofdstuk 3 beschrijft een studie onder de gevangenispersoneel in een narcoticagevangenis (Studie 2). De prevalentie van HIV was in Indonesische gevangenissen aanzienlijk hoger dan onder de algemene bevolking. In deze correctionele instelling zijn de bewakers de belangrijkste personen bij het verstrekken van zorg en steun voor gedetineerden met HIV. De doelstellingen van deze studie waren gericht om specifieke misvattingen over de ziekte te identificeren en de relatie tussen enerzijds kennis en anderzijds houding ten opzichte van gedetineerden met HIV te onderzoeken. Drieënnegentig bewakers participeerden vrijwillig in deze studie door een vragenlijst in te vullen. De resultaten toonden verschillende misconcepties over (1) de ziekte (zoals beschikbaarheid van medicijnen om de ziekte te genezen); (2) de transmissiemethoden (zoals dat het delen van een tandenborstel het virus kan overdragen); en (3) de preventie-strategieën (zoals dat een isoleercel voor gedetineerde een goede methode is om verspreiding van HIV naar andere gedetineerden voorkomen). Bovendien liet deze studie zien dat er een significante positieve correlatie was tussen de drie typen van HIV-gerelateerde kennis en houding. Hoe beter de kennis van bewakers is, des te kleiner is de kans dat ze een negatieve houding ten opzichte van gedetineerden hebben. Deze resultaten suggereren dat er grote behoefte is om regelmatig een HIVgerelateerd voorlichtingsprogramma aan gevangenispersoneel aan te bieden evenals steun van autoriteiten om beschikbaarheid van up-to-date materialen te garanderen en dit te ondersteunen met adequaat beleid.

Scholen zijn een goede optie voor het uitvoeren van HIV preventieprogramma gericht op jonge adolescenten aangezien het deze adolescenten verplicht onderwijs hebben. Docenten kunnen daarom een actieve rol spelen om HIV-gerelateerde kennis onder de studenten te vergroten. Hoofdstuk $\mathbf{4}$ beschrijft een studie gericht om de bereidheid te onderzoeken van docenten om drugseducatie en seksuele voorlichting voor adolescenten op scholen te ondersteunen (Studie 3). Er werden focus groep discussies met docenten 
uitgevoerd voorafgaand aan de kwantitatieve dataverzameling. Driehonderdenzestig docenten van 25 middelbare scholen namen vrijwillig deel aan dit onderzoek door het invullen van een vragenlijst. Gebruikmakend van de Theory of PlannedBehaviorals basistheorie, werd verondersteld dat naarmate de houding van docenten positieve was, en des te sterker hun waargenomen subjectieve norm en waargenomen gedragscontrole, hoe hoger hun bereidheid zou zijn om drugseducatie en seksuele voorlichting te ondersteunen. De resultaten bevestigen deze hypotheses volledig. Deze studie identificeerde ook barrières om het programma bij het onderwijzend personeel te introduceren. De afwezigheid van de twee onderwerpen in het officiële leerplan en het gebrek aan kennis en vaardigheden komen naar voren als de twee belangrijkste omgevings- en persoonlijke barrières. Daarom werd het van groot belang geacht om een trainingsprogramma voor de docenten te ontwikkelen om: (1) een positieve houding te bevorderen om deze twee onderwerpen te bespreken; (2) vaardigheden van docenten te vergroten; en (3) recente kennis over de onderwerpen te verstrekken. Het officieel opnemen van de onderwerpen in het curriculum zijn nodig om voldoende tijd voor het bedoelde programma te garanderen en in het eindexamen op te nemen om zodoende voldoende impact te kunnen hebben.

Hoofdstuk 5 beschrijft de systematische ontwikkeling van een drug- preventieprogramma voor leerlingen op basis van hetlnterventionMapping Framework (Studie 4). Actieve deelname van alle belanghebbenden in de zes stappen van programma- ontwikkeling, zoals voorgesteld in dit kader, heeft de betrokkenheid van de deelnemers als groep in stand gehouden in deze studie context. Het beoogde programma was gericht op het voorkomen en het gebruik van verdovende middelen, in het bijzonder van tabaksproducten, onder groep 8 leerlingen (individuele resultaten), en het aanbieden van een voorlichtingsprogramma, evenals een rookvrije omgeving in de openbare scholen (omgevingsresultaten). Met name door toepassing van deze leerstrategieën, richtte het programma zich op het verbeteren van: (1) de attitude, en normatieve en controle-overtuigingen ten aan zien van drugsvrij gedrag; en (2) de drugs-gerelateerde kennis. Het programma heet "HEBAT!". De verwachting was dat de verbetering van deze determinanten zou leiden tot een toename van de intentie tot drugsvrij gedrag. Dit programma is bestemd voor groep 8 studenten van publieke scholen in Bandung. Begeleiding en adviseringsdocenten zowel als virtuele peeronderwijzers zijn als de belangrijkste uitvoerders van het programma gehanteerd. De belangrijkste uitdaging in de ontwikkeling van dit programma was om een evenwicht te vinden tussen de parameters voor gebruik zoals voorgesteld door gedragsmatige theorieën om de effectiviteit van het programma te garanderen en de werkelijke omstandigheden in deze studiecontext om de toepasbaarheid van het programma te verzekeren. Er wordt voorgesteld om een programma te ontwerpen dat meerdere gezondheidsgerelateerde gedragingen kan behandelen om de efficiëntie van de ontwikkeling van het toekomstige programma ontwikkelingen te garanderen. 
In Hoofdstuk 6, wordt Studie 5 beschreven, die de effectiviteit onderzoekt van een drugspreventieprogramma. Aan deze evaluatiestudie namen meer dan zesduizend studenten deel. Een zelfrapportage vragenlijst werd door scholieren een week voor en een week na de implementatie van HEBAT! programma ingevuld.De hypothese was dat de uitvoering van het programma zou leiden tot positievere kennis en gedragsdeterminanten met betrekking tot de intentie om geen drugs te gebruiken. De resultaten toonden dat het programma direct na de uitvoering leidde tot een significante verbetering van gedragscontrole en kennis van de studenten. Er werden geen significante effecten gevonden voor de houding, waargenomen subjectieve normen en intenties.

$\mathrm{Er}$ is grote behoefte aan het verbeteren van de huidige lerarenopleidingen om ervoor te zorgen dat docenten een dergelijk programma gemakkelijker kunnen uitvoeren.

Tenslotte worden in hoofdstuk 7 de belangrijkste bevindingen van de vijf studies samengevat en bediscussieerd. Verschillende aspecten worden in dit hoofdstuk gepresenteerd, inclusief (1) de specifieke persoonlijke determinanten (zoals kennis, overtuigingen, gezondheidssymptomen en sociaal demografische factoren) die ten grondslag liggen aan HIVpreventie gedrag onder de meest risicovolle groepen en de gerelateerde sociale omgeving; en (2) de uitdagingen bij het ontwikkelen van een systematisch interventieprogramma gericht om gedragsdeterminanten onder scholieren te veranderen. Mogelijke aanbevelingen voor toekomstige studies en praktische implicaties worden besproken. 


\section{Acknowledgements}

n completing this dissertation, I have received support from many people and institutions, to whom I would like to express my sincere gratitude. First and foremost, to the most glorified Allah for blessing, protecting and guiding me throughout this period. I could never have accomplished this without the faith I have in the Almighty.

I express my profound sense of reverence to my promotor Prof. dr. Harm J. Hospers, for his constant guidance, support, motivation and untiring help during my PhD. Although he has given me a lot of freedom during my field research in Indonesia, he has also always given me very challenging comments, questions and suggestions in the manuscripts. Harm, thank you for trusting me to become one of your students. Good luck in your future career.

I express my deepest appreciation to my co-promotor Prof. dr. Gerjo Kok, for boosting my energy in writing my articles and dissertation. I will always remember his calm nature. However, he was also always quick to provide relevant literature and a lot of constructive feedback for my draft. Gerjo is definitely a very reliable supervisor. Bedankt!

To the manuscript committee: Prof. dr. R. A. C. Ruiter, Prof. dr. H. W. van den Borne, Dr. J. N. Leerlooijer, Dr. L. E. Rijsdijk and Prof. dr. N. K. de Vries. Thank you for reading, providing constructive feedback and approving this doctoral dissertation.

A very special thank-you is extended to all respondents as well as participant institutions of these studies, especially the Mayor of the city of Bandung, Bandung local educational office, Bandung AIDS commission, participant schools, Hasan Sadikin Hospital, the narcotics prison, teachers and students, for the opportunities in collecting data, the invaluable access to information and the participation in the development of the HEBAT! program.

During this long PhD journey, I have received continual support from three different deans of the Faculty of Psychology, Padjadjaran University, Bandung. Therefore, I would like to thank the former deans, Prof. dr. Zulrizka Iskandar and Prof. dr. Juke R. Siregar, as well as the current dean, Dr. Hendriati Agustiani. I would also like to acknowledge the former 
and current vice deans for their support, particularly Dr. Ahmad Gimmy Prathama, who has taken care of my students during my work-stay in Maastricht and Dra. Nurul Yanuarti, M. Si., who has assisted me by making administrative documents available when needed. For all my colleagues in the Faculty of Psychology, thank you very much for your support during my study. I hope I can share this wonderful research experiences with our students in Jatinangor.

I have also received enormous support from the Faculty of Medicine, Padjadjaran University, Bandung. I would like to express my gratitude to Prof. dr. Tri Hanggono Achmad and his vice deans for their valuable support to ensure the sustainability of the HEBAT! program among the $8^{\text {th }}$ grade students in all public schools in Bandung. I hope this excellent collaboration between our faculties will last longer and become bigger in the future.

I would like to remember and thank the late Dr. Harry Suherman, for his dedication to HIV/ AIDS patients in Bandung. He was always there when his patients needed him. He was also the one who "introduced" me to the world of HIV/AIDS for the first time by asking me to join IMPACT at the end of 2006. May your soul rest in peace, Mas Harry...

It is my pleasure to acknowledge all my colleagues in the Department of Industrial and Organizational Psychology, Faculty of Psychology, Padjadjaran University, Bandung, especially Prof. dr. Suryana Sumantri, Drs. Andi Rizaldi, M.Psi, Prof. dr. Diana Harding, Dr. Yus Nugraha, Dr. Maya Ardiwinata, Dr. Marina Sulastiana, and Dr. Anissa Lestari, for their huge support and providing a good atmosphere in the department. Hatur nuhun akang, mas, mbak dan ade...

I would like to thank my friendly "boss" in the Health Research Unit, Faculty of Medicine, Padjadjaran University, Bandung, Dr. Bachti Alisjahbana. I know it is not easy to manage a multidisciplinary team but you have managed us very well, dok! I am looking forward to another big collaboration in the future. Thank you Dr. Rovina Ruslami. I always admire your enthusiasm in doing scientific projects. Also, Dr. Rudi Wisaksana, our new captain in the HIV working group. Thank you for your support, dok! Thank you to Dr. Nirmala Kesumah, my dear co-author. Working with you has been a pleasure. I have learnt a lot about HIV/AIDS-related issues from you. Thank you to Dr. Teddy Hidayat as one of the advisory boards of the HEBAT! program. Dr. Ahmad Rizal Ganiem, many thanks for your guidance in preparing my public defense.

My dearest ibu-ibu HEBAT! at Health Promotion sub working group: Ibu Dr. Elmira N. Sumintardja, Eka Riyanti, Mawar Pohan, Tejarukmi Mutiara, Yayu Mukarommah, Miasari Handayani, Meita Nisa, Anindya Prasetyani and Ibu Dr. Sri Rahayu Astuti. You ladies are my second family. We have gone through a very amazing journey together since 2008. Thank you very much for that. It has not finished, though. Let's continue our journey... 
For the Pinxtens: Pak Lucas, Ibu Imelda and Juul. It was Pak Lucas who persuaded me to ask one of the professors for the opportunity to pursue my $\mathrm{PhD}$ in the Netherlands during the first IMPACT workshop at Bumi Sangkuriang in 2007. He had not even known me for more than half a day at that time! Thank you very much for all your support and trust. I do hope that we can still work together in the future. I thank Ibu Imelda for your kindness and for allowing me to stay at your beautiful house during my stay in 2009 and 2014.

For Dr. Reinout van Crevel, my first supervisor in IMPACT. I learnt a lot from him. It was not an easy journey, but I thank God for the opportunity to work with him. I also wish to extend my gratitude to the former IMPACT team in the Netherlands, Prof. dr. Andre van der Ven as well as the team in Bandung, Irma Anintya, Irvan Afriandi, Sri Yusnita, Nisaa Nur Alam, Lika Pamoso, Diba Basar, Adiatma Siregar, Erni Nelwan, Hartiah Haroen, Kusman Ibrahim, Agnes Indrati, Shelly Iskandar, Rozar Prawiranegara, Yanni Meilandari, Dini Noviartin and Tita Sri Puspitasari. It was fun to work with you guys. Thank you. To all IMPACT staff and secretaries, particularly Yusni Widya, Rostini, Ria Widyani, Endah Sriwulandari, and Pak Aang. Thank you for your help.

I would like to express my gratitude to the staff at the Department of Work and Social Psychology, Faculty of Psychology and Neuroscience and University College Maastricht. Thank you for allowing me to work in your place during my stay in Maastricht. To the secretaries in these two institutions, Mariella Muermans and Marie-Lou Mestrini, I thank you for your willingness to help me with all those administrative things. To Fraukje Mevissen and Henna Toppenberg, thank you for the good chats during our lunch time and after office hours.

I want to thank Jo Reinders for technically assisting our working group at the beginning of the HEBAT! journey. I also had a pleasant stay in Utrecht, thanks to you. Thank you also to former and current colleagues of Rutgers WPF in Jakarta: Ibu Kus, Mbak Wati, Mbak Sari, Andre; and in Utrecht: Henk and Nathalie. I hope both DAKU and HEBAT! can be implemented among students in Indonesia.

I would also like to acknowledge the guidance given to me for my statistical analyses during the first study in the prison until the last study in the schools by Heri Susanto, Mbak Ratna Jatnika and Nopi Susilawati. Thank you Alice Revell, Galina Stoyanov and Matthew for proof reading my manuscript. I would also thank Ammara Meijerink for translating my summary into Dutch in such a short time. Muhammad Roniyadi is thanked for designing this fresh green cover as well as for doing the lay out of this manuscript. Thank you to all the enumerators who helped me in collecting data.

For my dearest friends, Esti \& Ira, thank you for being there when I need you during my happy and rough days. You know laa. Azhar and Zeta, thank you guys for our good chats, 
good laughs, fun selfies, fun adventures, and of course for all the good food and movies that we have enjoyed. Hail hydra!

To my fellow PhD students in the Netherlands, Mbak Marisa, Mbak Efi, Olin, Aster and Aulia, thank you for the fruitful discussions, good Indonesian food and fun times travelling during our stay abroad. To my colleagues in the Faculty of Psychology: Bang Peter, Mas Darmo, Maharani and Whisnu, thank you for replacing my teaching responsibility during my work-stay in Maastricht.

To one of my BFFs, Jeannie Grace and her family, including Tante Utje, thanks so much for our friendship, your hospitality and the warm Indonesian food during my stay in your lovely home during winter 2012 and 2013. Arianto, Andina and little Danika, thank you very much for allowing me to stay in your apartment. May God always bless your little family. Vava, Vania and other PPI students in Maastricht, thank you for being my companions in Maastricht.

To my family, I offer genuine gratefulness for your patience, love and unwavering belief in me. I would like to particularly thank my dearest parents Achmad A. Hinduan and Moedijati for their gift of determination. Terimakasih Bapak dan Ibu. My sisters: Zulfa, Nuri and Lulu as well as my brothers-in-law: Danni Sidik and Reza Pribadi, you are great friends of mine. Thank you for your support mates. For Aisha, Ameera and Akmal, thank you botjah-botjah for cheering up my life.

To all Andrya family: dad, mom, sisters, brothers, and their beautiful kids, thank you very much for welcoming me into your big family. Thank you for helping me and Aditya in many situations. Finally, I would like to express my profound gratitude for Aditya Dharma Andrya for his encouragement and challenges during my study.

I dedicate this work to my late son Ghifary "Toughy" Aditya. I love you, dear... 


\section{Fundings}

The studies in this dissertation have been financially supported by: (1) IMPACT (Integrated
Management of Prevention and Control and Treatment of HIV/AIDS), a five-year program
funded by a European Commission grant (Prevention Control and Treatment of HIV/AIDS
of IDU in West Java Indonesia, contract number SANTE/2005/105-033). The content of
this document is the sole responsibility of the authors and can under no circumstances
be regarded as reflecting the position of the European Union; and (2) NFP (Netherlands
Fellowship Programmes (NFP) for PhD Programme 2011, Ministry of Development
Cooperation/Netherlands organization for international cooperation in higher education. 


\section{About the Author}

Z ahrotur Rusyda Hinduan or Rosie was born in Bandung, West Java, Indonesia on November 20, 1975. She obtained her bachelor degree on psychology from Faculty of Psychology, Padjadjaran University, Bandung in 1998. She continued her studies at the same university and graduated as a psychologist in 2002. Then, she completed her master degree in Organizational Psychology at Monash University, Australia in 2005.

In 1998, she started her career in higher education as a lecturer in Department of Industrial and Organizational Psychology at Faculty of Psychology, Padjadjaran University. She has appointed as secretary for the department since 2011.

She joined IMPACT (Integrated Management of Prevention and Control and Treatment of HIV) program in 2007 and mainly worked in the prevention part of the program. During 2007 - 2011, she had valuable opportunities to conduct HIV prevention-related studies in several public services in Bandung such as in (1) HIV clinic in Hasan Sadikin Hospital - a referral hospital; (2) Banceuy Prison - a narcotics prison; and (3) several junior high schools. After the program had finished in 2011, she continued her work as a behavioral-related researcher in Health Research Unit at Faculty of Medicine, Padjadjaran University.

In 2010, she received a fellowship from the Netherland Fellowship Program (NFP) to pursue her doctoral degree in Maastricht University, Maastricht, The Netherlands.

Currently, she lives in Bandung and is longing to learn how to cook a proper Indonesian cuisine. 


\section{Publication List}

\section{Peer reviewed and submitted articles}

Hinduan, Z. R., Sumintardja, E. N., Kok, G., \& Hospers, H. J. Factors associated with teachers' intention to teach HIV/AIDS-related topics: An application of the theory of planned behavior. Under review.

Hinduan, Z. R., Kok, G., Fitriana, E., \& Hospers, H. J. Effectiveness of substance use prevention program for students in Indonesia: A pre- and post-test impact evaluation. Under review.

Hinduan, Z. R., Riyanti, E., Reinders, J., Kok, G., \& Hospers, H. J. Development of a school based drug education program for students in Bandung, Indonesia using the Intervention Mapping framework. Under review.

Hinduan, Z. R., Suherman, R. A., Pinxten, L. W. J., Alisjahbana, B., \& Hospers, H. J. (2013). HIVrelated knowledge and attitudes among Indonesian prison officers, International Journal of Prisoner Health, 9, 92-102.

Yusnita, S., Ibrahim, K., Haroen, H., Afriandi, I., Sunjaya, D., Hinduan, Z. R., Antono, ..., \& Meheus, A. (2011). Knowledge, attitude and perceived with adherence to universal precaution among health care workers in the Obstetrics and Gynaecology Department of an Indonesian teaching hospital, International Journal of Infection Control, 4, 1-7.

Hinduan, Z. R., Riyanti, E., Tasya, I., Pohan, M. N., Sumintardja, E. N., Asturi, S. R., Jabar, B. A., ..., \& Hospers, H. J. (2009). HIV prevention through drugs and sex education in junior high schools in Bandung West Java: The teachers' perspective. Acta Medica Indonesiana, 1 (Suppl 1), 6-11.

Hinduan, Z. R., Kesumah, N., Iskandar, Z., van Crevel, R., Alisjahbana, B., \& Hospers, H. J. (2009). Characteristics of subjects counseled and tesed for HIV in an Indonesian Hospital: Factors associated with HIV-status and CD4 cell-count. Acta Medica Indonesiana, 1 (Suppl 1),12-17;

Alisjahbana, B., Susanto, H., Roesly, R., Yusuf, H., Hinduan, Z. R., Mose, J. C., Surahman, E., \& van der Ven, A. (2009). Prevention, control and treatment of HIV/AIDS among intravenous drug use in Bandung, Indonesia. Acta Medica Indonesiana, 1 (Suppl 1), 65-69.

Sumintardja, E., Pinxten, L., Siregar, J., Suherman, R. A., Wisaksana, R., Tasya, I., Hinduan, Z. R., ..., \& Hospers, H. J. (2009). Behavioral aspects of HIV prevention and care in Indonesia: A Plea for a multi-disciplinary, theory- and evidence-based approach. Acta Medica Indonesiana, 1 (Suppl 1), 79-86. 
Hinduan, Z. R., Wilson-Evered, E., Moss, S., \& Scannel, E. (2009). Leadership, work outcomes and openness to change following an Indonesian bank merger. Asia Pasific Journal of Human Resources, 47, 58-78.

\section{Oral Presentations:}

Pohan, M. N., Hinduan, Z. R., Riyanti, E., Mukaromah, Y., Mutiara, T., Tasya, I. A., Sumintardja, E. N., ..., \& Hospers, H. J. HIV-AIDS prevention through a life-skills school based program in Bandung, West Java, Indonesia: Evidence of empowerment and partnership in education. Oral presentation at the 3rd World Conference of Educational Sciences 2011, Istanbul, Turkey.

Hinduan, Z. R., Sumintardja, E. N., Kok, G., \& Hospers, H. J. The application of the theory of planned behavior to teaching HIVIAIDS-related issues effectively among junior high school teachers in Indonesia. Oral presentation at the International Congress of Applied Psychology (ICAP) 2010, Melbourne, Australia.

Hinduan, Z. R., Kesumah, N., Iskandar, Z., van Crevel, R., Alisjahbana, B., \& Hospers, H. J. Characteristics of subjects counseled and tested for HIV in an Indonesian Hospital: Seroprevalence. Oral presentation at the 9th International Congress on AIDS in Asia and the Pacific (ICAAP) 2009, Bali, Indonesia.

Hinduan, Z. R., Suherman, R. A., Pinxten, L. W. J., Alisjahbana, B., \& Hospers, H. J. HIV-related knowledge and perceived risk of HIV infection: An examination of their relation to attitude toward inmates with HIV among prison officers. Oral presentation at Open Science Meeting 2007, Bali, November.

Hinduan, Z. R., Hami, A. E., \& Sulastiana, M. The Influence of Positive and Negative Affect on Individual's Commitment to Change Following Organisational Restructurisation. Oral presentation at Simposium Kebudayaan Indonesia-Malaysia (SKIM) X UNPAD-UKM 2007, Kuala Lumpur, Malaysia.

Hinduan, Z. R., Wilson-Evered, E., Moss, S., \& Scannel, E. The Moderating Effects of Openness to Change on the Relationship between Transformational Leadership Style and Work-related Outcomes Following Organizational Merger. Oral presentation at the 19th Australian - New Zealand Academy of Management Conference 2005, Canberra, Australia. 



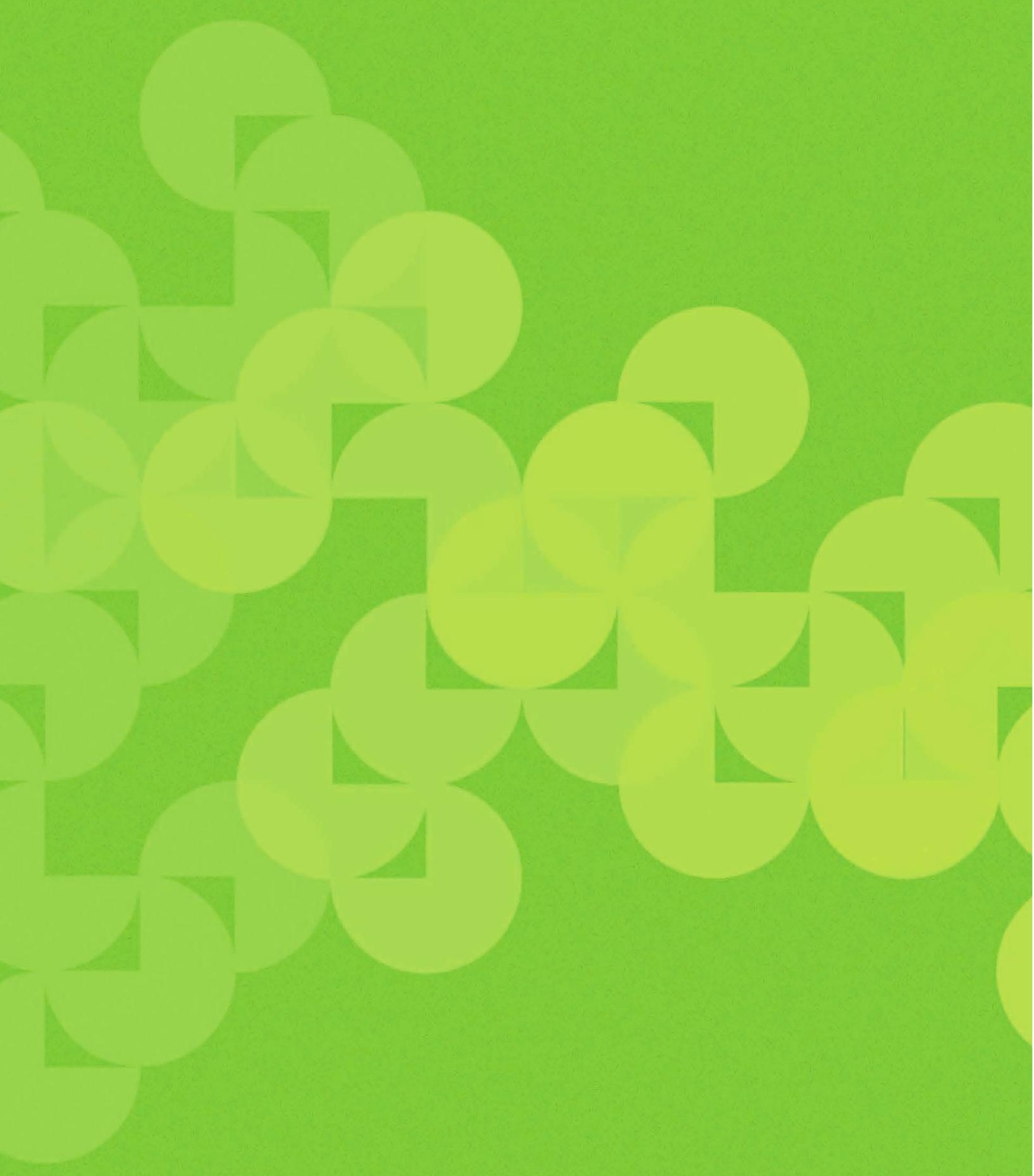

